\title{
Apresentação: Perspectivas antropológicas sobre deficiência no Brasil
}

Anthropological perspectives on disability in Brazil

Clarice Rios, Éverton Luís Pereira e Nádia Meinerz

\section{(2) OpenEdition \\ 12 Journals}

Edição electrónica

URL: http://journals.openedition.org/aa/3475

DOI: $10.4000 /$ aa. 3475

ISSN: 2357-738X

Editora

Programa de Pós-Graduação em Antropologia Social (UnB)

\section{Edição impressa}

Data de publição: 1 junho 2019

Paginação: 29-42

ISSN: 0102-4302

\section{Refêrencia eletrónica}

Clarice Rios, Éverton Luís Pereira e Nádia Meinerz, «Apresentação: Perspectivas antropológicas sobre deficiência no Brasil», Anuário Antropológico [Online], v.44 n.1 | 2019, posto online no dia 06 julho 2019, consultado o 28 abril 2021. URL: http://journals.openedition.org/aa/3475 ; DOI: https://doi.org/ 10.4000/aa.3475

\section{(c) (i) $\ominus$}

Anuário Antropológico is licensed under a Creative Commons Atribuição-Uso Não-Comercial-Proibição de realização de Obras Derivadas 4.0 International. 
$\$ 27$

(a)

$$
\begin{gathered}
n \\
0 \\
0 \\
0
\end{gathered}
$$


28 


\section{Apresentação \\ Perspectivas antropológicas sobre deficiência no Brasil}

Clarice Rios

Antropóloga independente - Brasil

Éverton Luís Pereira

Universidade de Brasília - Brasil

Nádia Meinerz

Universidade Federal de Alagoas - Brasil

As disputas em torno do conceito de deficiência mobilizam diferentes campos do conhecimento e movimentam a arena política nacional e internacionalmente. Teorias oriundas de diferentes saberes científicos, discursos de movimentos sociais, formas locais de definir e categorizar pessoas com deficiência e leis e regulamentações compõem algumas das grandes narrativas em uso no cenário social e político.

Sem dúvida, a disputa mais conhecida e candente é aquela entre o modelo biomédico e o modelo social da deficiência. A tensão provocada entre os impedimentos corporais como determinantes na classificação da deficiência - apresentando o conhecimento biológico e médico como preponderante em suas definições - ou os contextos socioculturais como produtores das deficiências é a força motriz de um conjunto de estudos, desde as ciências da saúde até a antropologia.

Além dos embates conceituais entre os modelos biomédico e social, os tratados internacionais e as leis nacionais auxiliam na configuração das rotas pelas quais os estudiosos da deficiência nos diferentes campos têm caminhado. A Convenção sobre os Direitos das Pessoas com Deficiência (BRASIL, 2009), a Lei Brasileira de Inclusão (BRASIL, 2015), apenas para citar algumas das mais importantes no Brasil, alteram o tom do debate e inserem a voz legal e normativa nas definições de deficiência. Se o embate entre o modelo biomédico e o social ganha contornos particulares na academia, as normativas atravessam o debate e definem categoricamente o que é deficiência.

Colin Barnes e Michel Oliver (1993) são enfáticos em afirmar que a deficiência é um fenômeno sociológico e que foi historicamente negligenciado pelos sociólogos. Os autores argumentam nesse sentido por acreditarem que são os contextos 
socioculturais que irão impossibilitar que determinados indivíduos com impedimento vivam suas vidas em igualdade de condições. São eles, também, que auxiliam na consolidação do modelo social da deficiência e que impulsionam um conjunto de estudos sociológicos na temática. A mirada dos autores é um processo avaliativo sobre a construção de uma agenda de pesquisas na sociologia, mas também uma reflexão sobre a necessidade de ampliar o debate da deficiência para além dos conhecimentos que historicamente detiveram a hegemonia na temática.

$\mathrm{Na}$ antropologia, a deficiência também não foi um objeto clássico de reflexão. Reid-Cunningham (2009) argumenta que as pesquisas antropológicas constantemente se referiram à deficiência. Para esta afirmação, realiza uma imersão em estudos consolidados para demonstrar como a temática apareceu inclusive em estudos de antropólogos renomados (o estudo de 1934 de Ruth Benedict sobre epilepsia e de Margaret Mead sobre natureza humana de 1953). Entretanto, a autora ressalta que as mudanças significativas ocorreram apenas após a década de $1970 \mathrm{com}$ o nascimento do campo dos estudos da deficiência.

Uma contribuição decisiva para emergência da deficiência como temática de pesquisa antropológica pode ser localizada nas publicações de Débora Diniz (2003; 2007), que divulgam em língua portuguesa uma leitura sociocultural para um fenômeno até então apreendido exclusivamente em termos biomédicos. Além disso, ela demonstra, através da discussão sobre autonomia reprodutiva entre casais surdos, o modo enigmático e ao mesmo tempo ordinário que a experiência da deficiência se oferece ao pensamento antropológico. Não por acaso, os primeiros investimentos em profundidade vão abordar e tensionar justamente a noção de uma "cultura surda” (SILVA, 2010/2012; GEDIEL, 2010; PEREIRA, 2013) e os desdobramentos desse tipo de leitura para discussões mais gerais sobre corpo, gênero e sexualidade (MEINERZ, 2010; MELLO; NUREMBERG, 2012). Mais do que iniciativas pontuais, esses trabalhos apontam para o florescimento de novos questionamentos no interior e nas circulações de estudantes por entre linhas de pesquisa mais consolidadas no cenário nacional, como a antropologia do corpo e/ou da saúde, a antropologia urbana e/ ou pesquisas sobre as cidades, e os estudos de gênero e sexualidade. Nesse sentido, além de identificar estudos pioneiros, é importante apontar o ambiente acadêmico no qual eles se desenvolveram. A pesquisa de Correa (2008), que apresenta narrativa de homens sobre a "perda da visão”, é emblemática por percorrer um caminho à margem da penetração dos disability studies no país, partindo das questões articuladas na sociologia das emoções, passando pela problematização 
sobre o visual na antropologia, chegando até a cidade como cenário do seu encontro intersubjetivo com a cegueira.

Outro marco importante é a organização de atividades sobre deficiência nas principais reuniões científicas da área. O grupo de trabalho intitulado "Etnografias da Deficiência”, sob a organização de Adriana Dias e Débora Diniz (ABA, 2014), inaugura em 2014 uma série de iniciativas de aproximação entre os pesquisadores (especialmente antropólogos em formação, mas também pesquisadores de outras áreas) de diferentes regiões do país para composição de um debate coletivo. A continuidade dessa atividade nas edições subsequentes do evento, a sua expansão para outras reuniões ${ }^{1}$ assim como a proliferação de mesas redondas, oficinas, minicursos revelam um crescente fluxo de pesquisas que já transborda as fronteiras da antropologia através do diálogo interdisciplinar com áreas como a saúde coletiva, a linguística, a educação, o direito e o serviço social.

O dossiê Antropologias e Deficiências foi construído por meio de uma chamada pública amplamente divulgada entre a comunidade antropológica. Os dezenove artigos recebidos estabeleceram diálogos entre a deficiência e campos consolidados da antropologia. Desses, foram selecionados seis para compor o conjunto de trabalhos apresentados. A intensidade dos debates promovidos e a grande demanda nos mostram a efervescência do campo e a importância de se estimular a discussão sobre deficiência na antropologia, seja por meio de eventos, grupos de trabalhos, mesas redondas, disciplinas na graduação e pós-graduação, livros ou ainda, a produção de outros dossiês.

Além de elaborações inéditas, resultados de pesquisas recentemente concluídas ou ainda em andamento, os artigos que compõem este dossiê são parte de uma intensa e absorvente movimentação na antropologia brasileira em relação à problemática da deficiência. Não devem, portanto, ser pensadas como contribuições isoladas e sim como amostras de um engajamento mais amplo de jovens antropólogos na construção de uma agenda autônoma de pesquisa. Além disso, é importante destacar que esse interesse articula um engajamento com o desenvolvimento e a implementação de políticas públicas e com a proposição de demandas e ações de acessibilidade no interior das associações profissionais e das suas instituições de ensino. É o caso, por exemplo, de uma série de pesquisas que acompanharam os desdobramentos da aprovação da chamada Lei Berenice Piana, ou Lei no 12.764/2012, que reconhece os autistas como pessoas com deficiência para todos os efeitos legais (NUNES, 2014; RIOS; COSTA ANDRADA, 2015; COSTA ANDRADA, 2017). 
A articulação dos debates teóricos sobre deficiência e os embates políticos do tema são constantemente reiterados neste campo de estudos. A interlocução entre a produção na antropologia e em outras ciências aponta a tônica dos trabalhos que versam sobre a temática. No presente dossiê, os artigos estabelecem pelo menos três eixos de reflexão importantes: deficiência como categoria relacional; deficiência como categoria diagnóstica e jurídica; e a contribuição da antropologia para a superação do paradigma clássico da normalização.

\section{Deficiência como uma categoria relacional}

Em seu artigo de revisão sobre o campo da deficiência na tradicional revista norte-americana Annual Review of Anthropology, Ginsburg e Rapp (2013) afirmam que a “deficiência é uma categoria profundamente relacional” (p. 4.2). Além de sugerir a contraposição de uma abordagem relacional acerca da deficiência a um modelo classificatório fixo e engessado produzido pelo saber biomédico, o chamado "modelo médico da deficiência", as autoras afirmam também que "o que conta como lesão em contextos socioculturais diferentes é altamente variável” (id., p. 4.2). Ainda que proponham pensar a deficiência como uma "categoria relacional”, as autoras parecem atribuir sua variabilidade à diversidade de contextos socioculturais e ao modo como a lesão é definida em diferentes contextos culturais. A perspectiva é bastante conhecida e articula, em certo sentido, a lógica do chamado "modelo social da deficiência”. Entretanto, mais do que descrever um modo de pensar a deficiência, há o perigo de aqui acabarmos por subsumir sob categorias abstratas e gerais como "contexto sociocultural”, o complexo jogo de forças capaz de fazer a deficiência existir, seja como categoria teórica, experiência individual e coletiva, seja como categoria política.

Assim, se é verdade que contextos socioculturais diversos fazem variar as interações entre "pessoas com uma lesão e seu meio social" (loc. cit.), não é menos verdade que os modos como as pessoas com uma lesão se apropriam dos recursos e limitações colocados por seu meio social também produzem interações diversas, podendo inclusive afetar e transformar o próprio meio social. Mais que isso, não são apenas os contextos socioculturais que determinam o que "conta como lesão", mas, acima de tudo, os contextos políticos.

É levando em conta esse complexo jogo de forças, e não apenas variações de “contextos socioculturais", que se justifica a iniciativa de produzir, desde o ponto de vista sócio-historicamente situado, um dossiê como este. Partindo de uma reflexão 
antropológica acerca do campo dos estudos sobre a deficiência no Brasil, os dois primeiros artigos que compõem este dossiê consolidam uma perspectiva relacional da deficiência ao descrever os jogos de forças que dão contornos específicos à deficiência em diferentes contextos socioculturais.

No artigo de Mello e Gavério - "Facts of Cripness to the Brazilian: dialogues with Avatar, the film"-, os autores apresentam a teoria crip, usando-a como ponto de partida para abordar questões importantes do campo da deficiência. A instabilidade conceitual e fenomenológica da deficiência é abordada a partir da crítica à tradicional lógica binária da capacidade/deficiência (ability/disability) e de uma reflexão acerca do potencial analítico e interseccional de uma epistemologia aleijada. O material etnográfico apresentado inclui a análise crítica de um filme de James Cameron (Avatar) e a experiência dos dois autores, não só pessoal como também acadêmica. Fica claro, a partir do material apresentado, que uma epistemologia aleijada não pode prescindir de uma reflexão acerca das relações de poder que atravessam o campo da deficiência - seja em função da heterogeneidade das lesões/impedimentos corporais, das experiências interseccionais e relacionais de cada um, ou mesmo das instituições acadêmicas a partir das quais os autores pesquisam e pensam a deficiência. Neste sentido, não é por acaso que a teoria crip segue uma lógica semelhante à teoria queer - apropriar-se de um termo derrogatório para designar a deficiência (crippled, traduzido pelos autores como “aleijado") com o propósito de subverter a relação de forças que nele se inscreve.

O artigo de Lopes - "Deficiência como categoria analítica: trânsitos entre ser, estar e se tornar"- também revisita o conceito de deficiência, propondo uma discussão acerca de seu potencial analítico para a antropologia. Para tal, Lopes destaca a importância de ir além de uma lógica identitária engessada e restritiva na compreensão da deficiência, em favor de uma abordagem mais processual e corporificada, onde a deficiência se coloca como "uma experiência humana universal e não somente uma particularidade de um grupo minoritário” (p. 16). Do ponto de vista antropológico, algumas implicações interessantes decorrem desse argumento. A categoria deficiência deixa de ser restrita aos corpos das pessoas com deficiência, passando a designar um "sistema de nomeação da diferença como um todo" e não somente o polo negativo de um sistema hierarquizado de classificação. Questiona-setambém a cisão natureza/cultura implícita no binômio lesão/deficiência (impairment/disability) que, na formulação original do modelo social da deficiência,pretende subsumir a experiência corporificada da deficiência ao fenômeno de 
exclusão social das pessoas com configurações corporais e funcionais diversas. Tal cisão coloca o risco de uma "culturalização da diferença corporal” (p. 14), que se manifesta claramente na retórica e política da identidade. Mas se por um lado, as identidades pós-modernassão tidas como complexas, situadas, interseccionais e socialmente construídas, também é verdade que as identidades associadas a algum tipo de traço corporal são muito menos maleáveis e contingentes (DAVIS, 2013). Assim, reduzir a experiência da deficiência meramente ao registro identitário, à condição de "agregador político" (p. 20), é também desprovê-la de sua radicalidade e universalidade. Trata-se, nos termos utilizados por Lopes, de pensar a deficiência não apenas como um marcador social que incide sobre corpos “desviantes" e "disfuncionais", mas como uma

categoria analítica que interpela também os corpos que não nomeia (...) que pode nos ajudar a nomear a desigual variedade de formas, funcionalidades e experiências corporais que vivemos, ou, ainda, a desigual variedade das relações sociais que atribuímos a formas, funcionalidades e experiências corporais - sejam elas marcadas ou não pela categoria pessoa com deficiência (p. 22).

No argumento desenvolvido por Lopes, e também por Mello e Gavério, o corpo nunca é tomado simplesmente como objeto, mas a partir da experiência corporificadade ser e estar no mundo. Os argumentos desenvolvidos por esses autores caminham no sentido de deslocar a deficiência da condição de experiência corporal substantiva pautada exclusivamente pela negatividade e ausência, para uma corporeidade experimentadaem toda sua transitividade - seja na forma de acoplamentos materiais como cadeiras de rodas e implantes coclearesmencionados no artigo de Mello e Gavério, seja nas relações intersubjetivas descritas por Lopes, ou nos processos de transformação ou devir corporais descritos em ambos os artigos.

\section{Deficiência como uma categoria diagnóstica e jurídica}

Para além das discussões conceituais apresentadas no artigo de Mello e Gavério e no de Lopes, observamos nos artigos de Aydos e Simões a relação entre políticas públicas calcadas em classificações biomédicas da deficiência e os dilemas colocados por políticas de cunho identitário. O artigo de Aydos- "A (des)construção social do diagnóstico de autismo no contexto das políticas de cotas para pessoas com deficiência no mercado de trabalho" - trata da construção social do diagnóstico 
do autismo ao etnografar um projeto de implementação da política de cotas para pessoas com deficiência no Rio Grande do Sul. Em sua etnografia, acompanhou dois rapazes com um diagnóstico de autismo que ingressaram em empresas através desse projeto. Embora o artigo faça menção a profissionais da área de saúde e ao processo diagnóstico, sua etnografia deixa claro que se por um lado cabe a esses profissionais o poder de conferir diagnósticos e garantir o acesso a direitos, os contornos do autismo extrapolam, em muito, a esfera da saúde. Entretanto, como a entrada nas empresas se faz a partir de políticas de cunho identitário, é nesse momento que as ambivalências inerentes ao autismo enquanto identidade diagnóstica se tornam mais evidentes. Antes de tudo, porque um dos jovens que Aydos acompanha, recusa esse diagnóstico, ainda que se veja imbricado em uma rede de relações composta por especialistas e colegas de trabalho que o acolhe a partir do diagnóstico. Afinal, seo autismo é mais do que um simples diagnóstico psiquiátrico e passou a ser, cada vez mais, uma marca identitária, é preciso considerar também a possibilidade do sujeito não se deixar interpelar por essa identidade (a esse respeito, ver VALTELLINA, 2018).Além disso, segundo Aydos, o autismo é "visto pelos especialistas como um diagnóstico obscuro, fluido e dinâmico" (p. 3). A falta de um "biomarcador" ou uma "marca corporal”tornaria o autismo uma categoria especialmente perigosa para a lógica identitária que subjaz às políticas de cota no mercado de trabalho.Parece-nos, entretanto, que a questão se coloca para além da existência ou não de biomarcadores. Se a positividade de um diagnóstico de autismo se constrói a partir de ausências e déficits na sociabilidade e comunicação (sejam eles atribuídos a biomarcadores ou não), como colocar de fato em prática uma política de inclusão sem negar sua premissa básica, qual seja, que o sujeito em questão não tem suficiente capacidade para se comunicar e se socializar no meio laboral? Assim, na política de inclusão no mercado de trabalho não parece haver horizonte possível para uma visada relacional do autismo como deficiência situar o autismo no campo da deficiência é impossibilitar o processo de inclusão na prática, e retirar o autismo do campo da deficiência é impossibilitar sequer a oportunidade de inclusão. A solução para tal impasse aparece numa equação simples, enunciada por seus informantes "[as empresas] não contratam pessoas, elas contratam deficiências".

O artigo de Simões- "Sobre gramáticas emocionais e violência sexual. Notas a partir de dois casos de interrupção legal de gestação realizados por mulheres com deficiência intelectual" -, por sua vez, envereda de modo mais explícito pelo aspecto interseccional da produção da deficiência, trazendo para a discussão a agenda dos 
direitos sexuais e reprodutivos. Em sua pesquisa, a experiência da deficiência intelectual é narrada a partir da participação do etnógrafo nas discussões de uma equipe multidisciplinar em saúde que responde pela assistência à interrupção legal da gravidez. Ao descrever as apreensões sobre a violência sexual, ele destaca a articulação de uma gramática emocional como organizadora da relação dos profissionais de saúde e as famílias afetadas tanto pela situação da gravidez não planejada quanto pela legitimidade da interrupção. Além disso, o texto evidencia a relevância do cruzamento entre marcadores de diferença como idade/fase de vida, classe e gênero para pensar as experiências afetivo-sexuais de pessoas com deficiência intelectual.

É importante destacar o comprometimento do autor em apresentar a complexidade dos casos, assim como a ambivalência dos encaminhamentos em termos do reconhecimento das mulheres com deficiência intelectual como titulares de direitos sexuais e reprodutivos. Além disso, o entrecruzamento entre a prática médica e a prática jurídica, na qual esse idioma moral que articula dor, sofrimento e vitimização opera garantindo um direito reprodutivo, descortina uma série de outras discussões relativas á interrupção legal da gravidez como a objeção de consciência dos profissionais, a violência de gênero que perpassa a assistência de saúde e principalmente, a gestão dos corpos em situação de abortamento.

Em suma, tanto o artigo de Aydos como o de Simões deixam claro que as normativas jurídicas não podem prescindir de uma lógica identitária, em que a deficiência emerge desde sempre adjetivada por categorias tais como "incapacidade" e "vulnerável”, como aponta Simões. Além disso, esses dois artigos também problematizam, cada um a seu modo, uma ambiguidade fundamental na inclusão da deficiência no âmbito político e normativo - afirmar juridicamente uma identidade adjetivada pela deficiência implica negar a possibilidade de ampliação de horizontes existenciais para além da normativa jurídica. O que está em jogo em cada caso pode variar, mas os processos de exclusão persistem - no caso dos autistas, a possibilidade de inserção plena no mundo laboral e nas redes de sociabilidade ali engendradas; no caso das deficientes intelectuais, a possibilidade de uma gestão mais independente de sua vida sexual e reprodutiva.

\section{Para além da normalização}

O artigo de Gediel, Miranda e Mourão-nos “A inclusão e suas práticas: aspectos socioantropológicos da produção de materiais pedagógicos inclusivos para Surdos” - apresenta as disputas na construção de material didático para inclusão de uma 
pessoa Surda no ensino superior. O artigo está em diálogo com o conjunto de políticas públicas que versam sobre a deficiência e, especialmente, sobre o uso da Língua Brasileira de Sinais (LIBRAS) no contexto nacional. Os autores assumem uma posição ao longo do artigo: as políticas públicas elaboradas e implantadas nas últimas décadas são importantes para a inclusão das pessoas com deficiência, inclusive nos meios universitários. Porém, também demonstram como as disputas que ocorrem na execução dessas políticas: as melhores formas de “apresentar" o material didático transcenderam o legal (ou o prescrito) e necessitam de arranjos locais para que seja efetivo.

Ao longo do artigo, os autores vão demonstrando como a complexa trama na construção da inclusão dos surdos no meio universitário é entrecruzada por discursos de várias ordens: desde as advindas das normativas até aquelas concretizadas pelos "estudos surdos". Os autores fazem uso do linguajar desse campo do conhecimento para argumentar em função da diferença "linguística e cultural" dos Surdos e a necessidade de o material didático traduzir essa particularidade.

O artigo de Gediel, Miranda e Mourão traz uma marca importante do campo de estudos sobre deficiência: a interdisciplinaridade. Por um lado, o artigo apresenta um conjunto de reflexões que estão ancoradas em campos distintos do antropológico, como a linguística e a educação. Por outro, a problemática central do artigo a produção de material didático para surdos em uma universidade - leva os leitores a refletirem sobre a forma como as respostas públicas para deficiência necessitam de diferentes olhares. Além disso, insere na narrativa termos comumente utilizados pelos movimentos sociais como, por exemplo, cultura Surda.

O texto “A 'janela da expressão': reflexões sobre corpo, movimento e gesto nas relações entre visão e cegueira” também dialoga com a complexidade das práticas de inclusão colocada em curso pelas políticas públicas. Através de vivências de reabilitação de pessoas cegas, discute os efeitos excludentes de um aprendizado focado na comunicação verbal e na funcionalidade dos gestos. A pista perseguida por Olívia von der Weid vem da percepção sobre a expressividade corporal na sua interação com pessoas cegas. Nos olhos parados de Dora [interlocutora], ela vê refletida a linguagem do seu próprio corpo e a importância dos gestos para expressar o que sente. Ao articular a fala, ela sente a responsabilidade e ao mesmo tempo a impossibilidade da linguagem verbal condensar tudo o que pode ser comunicado.

Através dessa interlocução privilegiada, a autora explora o modo como códigos visuais organizam a interação entre as pessoas, de tal modo que mesmo o exercício 
da oralidade (que aparentemente não seria uma desvantagem) se apresenta como um recurso limitado para o cego. A interrupção na comunicação disparada pelo silêncio, a impossibilidade de modulação da fala a partir da reação do outro e a ocorrência de conversas paralelas demonstram que a comunicação sempre excede a troca verbal. Frente a isso, a autora apresenta estratégias corporais desenvolvidas pelos cegos para potencializar a comunicação com os não cegos, como por exemplo, a tentativa de fixar o olhar para o rosto do interlocutor a partir da localização corporal.

$\mathrm{O}$ artigo aprofunda uma crítica ao capacitismo que orienta o modo como as pessoas com cegueira são reabilitadas e ao caráter profundamente visuocêntrico dessa oferta de acesso à participação social. Segundo a autora, a problematização da relação entre cegueira e visão desenvolvida nos programas "para a vida independente", aponta para a necessidade de uma reinvenção das possibilidades de interação entre cegos e não cegos. Nesse sentido, de modo similar ao observado por Gediel, Miranda e Mourão, o que se apresenta como desafio é deslocar a referência das formas de "compensação" (que supõe que a tradução para LIBRAS no caso das pessoas surdas é suficiente) na direção de iniciativas que ampliem as possibilidades de interação entre cegos e não cegos, reabilitando também os corpos das pessoas não cegas para o aprendizado de códigos não visuais. Nessa direção, uma aposta seria o investimento em programas de desenvolvimento da linguagem corporal, do potencial expressivo dos movimentos, bem como atividades que promovam a expansão da consciência corporal, como a prática artística por exemplo.

De forma geral, esses dois últimos artigos colocam em evidência, cada um a seu jeito, os modos como as normatividades hegemônicas estruturam, ainda que de maneira implícita, as práticas de habilitação/reabilitação e as políticas de inclusão no campo da deficiência. No primeiro caso, se debruça sobre a elaboração de materiais pedagógicos inclusivos para Surdos, e no segundo, explicita a ênfase na comunicação centrada na linguagem verbal na educação de cegos. Em ambos os casos, nota-se que a reflexão de cunho antropológico acerca desses temas caminha no sentido de desafiar uma compreensão das práticas de educação e inclusão como meros processos de tradução entre dois universos estanques e monolíticos - o da deficiência e o da normalidade - acenando com a possibilidade de expandir e aprofundar o sentido da inclusão para além de normativas capacitistas e padronizadoras. 
Os debates apresentados no dossiê descortinam as mais recentes produções sobre deficiência na antropologia brasileira. Os artigos estão em diálogo com as problemáticas internacionais que compõem o campo e que estão dando respostas particulares para questões clássicas da antropologia. As discussões sobre deficiência apresentam possibilidade de "fazer pensar" o campo e suas produções.

Da mesma forma, os artigos trazem contribuições sobre as especificidades da antropologia na reflexão sobre políticas públicas. Fazendo emergir vozes, produzindo respostas locais e ampliando o espectro das potencialidades dos sujeitos imersos em um meio social, os autores demonstram como é possível que a antropologia produza respostas - teóricas, políticas e epistemológicas - para a ampliação de direitos e para a melhoria das ações públicas.

Clarice Rios acabou de encerrar um período atuando como professora substituta no Departamento de Psicologia Social da Universidade Federal do Rio de Janeiro, tendo lecionado disciplinas na área de saúde pública e saúde coletiva para alunos da graduação em psicologia. Tem doutorado em Antropologia Sociocultural, com especialização em antropologia psicológica e antropologia médica, pela University of California, Los Angeles; e mestrado em Ciências Sociais pela University of Chicago. Sua pesquisa atual explora a biopolítica dos tratamentos para autismo no contexto do Sistema Único de Saúde Brasileiro (SUS). Ela também se interessa pela questão do conhecimento tácito e corporificado no contexto da expertise leiga acerca do autismo. ORCID: 0000-0002-4246-962X. Email: clarice.r@gmail.com

Éverton Luís Pereira é graduado em Ciências Sociais pela Universidade Federal de Santa Maria (UFSM). Mestre e doutor em Antropologia Social pela Universidade Federal de Santa Catarina (UFSC). É professor do Departamento de Saúde Coletiva (DSC), do Programa de Pós-Graduação em Saúde Coletiva (PPGSC) e do Programa de Pós-Graduação em Ciências Sociais - Estudos Comparados sobre as Américas (PPG-ECsA) da Universidade de Brasília (UnB). Atualmente pesquisa políticas públicas para pessoas com deficiência. ORCID: 0000-0002-7771-1594. E-mail: everton.epereira@gmail.com 
Nádia Meinerz é graduada em Ciências Sociais (UFSM), mestre e doutora em Antropologia Social (UFRGS). Professora do Programa de Pós-Graduação em Antropologia Social da Universidade Federal de Alagoas (UFAL) e pesquisadora do Mandacaru - Núcleo de Estudos em Gênero, Saúde e Direitos Humanos. ORCID: 0000-0002-4549-2016.E-mail: nadiameinerz@gmail.com

\section{Referências bibliográficas}

ABA, Caderno de Resumos. 2014. Diálogos Antropológicos: Expandindo Fronteiras. 29a Reunião Brasileira de Antropologia, Natal.

BARNES, Colin; OLIVER, Michel. 1993. Disability: a sociological phenomenon ignored by sociologists. In: _. The disability reader: social science perspectives, Stockport, United Kingdom: Continuum, pp.65-78.

BRASIL. 2015. Lei 13.146, de 6 de julho de 2015. Lei Brasileira de Inclusão. Diário Oficial da União, Brasília, DF.

BRASIL. 2009. Decreto n. 6949, de 25 de agosto de 2009. Promulga a Convenção Internacional sobre os Direitos das Pessoas com Deficiência e seu Protocolo Facultativo, assinados em NovaYork, em 30 de março de 2007. Diário Oficial da União, Brasília, DF.

CORREA, Luiz Gustavo. 2008. A pupila dos cegos é seu corpo inteiro? Compreendendo as sensibilidades de indivíduos cegos através das suas tessituras narrativas. Tese de Doutorado, Programa de Pós-Graduação em Antropologia Social, Universidade Federal do Rio Grande do Sul8.

COSTA ANDRADA, Bárbara. 2017. Sentidos e desafios do autismo para o território: um estudo etnográfico. Tese de Doutorado em Saúde Coletiva, Instituto de Medicina Social, Universidade do Estado do Rio de Janeiro.

DIAS, Adriana. 2013. Por uma genealogia do capacitismo: da eugenia estatal a narrativa capacitista social. Anais do I Simpósio Internacional de Estudos sobre a Deficiência, SEDPcD/Diversitas/USP Legal, São Paulo.

DINIZ, Débora. 2007. O que é deficiência? São Paulo: Brasiliense.

DINIZ, Débora. 2003. Autonomia reprodutiva: um estudo de caso sobre a surdez. Cadernos de Saúde Pública, v. 19, n.1, pp.175-181.

GEDIEL, Ana Luiza. 2010. Falar com as mãos e ouvir com os olhos? A corporificação dos sinais e os significados dos corpos dos Surdos de Porto Alegre. Tese de Doutorado, Programa de Pós-Graduação em Antropologia, Universidade Federal do Rio Grande do Sul.

GINSBURG, Faye; RAPP, Rayna. 2013. Disability Worlds. The Annual Review of Anthropology, v. 42, pp. 4.1-4.16.

MELLO, A.; NUERNBERG, A. 2012. Gênero e Deficiência: interseções e perspectivas. Revista de Estudos Feministas, v. 20, p. 635-655.

MEINERZ, Nádia. 2010. Corpo e outras (de)limitações sexuais. Uma análise antropológica da revista Sexuality and Disability entre os anos de 1996 e 2006. Revista Brasileira de Ciências Sociais, v. 25, n. 72 . 
NUNES, Fernanda. 2014. Atuação política de grupos de pais de autistas no Rio de Janeiro: perspectivas para o campo da saúde. Dissertação de Mestrado em Saúde Coletiva, Instituto de Medicina Social, Universidade do Estado do Rio de Janeiro.

PEREIRA, Everton Luís. 2013. Fazendo cena na cidade dos mudos: surdez, práticas sociais e uso da língua em uma localidade no sertão do Piauí. Tese de Doutorado, Programa de Pós-Graduação em Antropologia, Universidade Federal de Santa Catarina.

REID-CUNNINGHAM, Allison Ruby. 2009. Anthropological theories of disability.Journal of Human Behavior in the Social Environment, n. 19, pp. 99-111.

RIOS, Clarice; COSTA ANDRADA, Bárbara. 2015. The changing face of autism in Brazil.Culture, Medicine and Psychiatry, v. 39, issue 2, pp.213-234.

SILVA, César Augusto de Assis. 2010.Entre a deficiência e a cultura: análise etnográfica de atividades missionárias com surdos. Tese de doutorado, Programa de Pós-Graduação em Antropologia, Universidade de São Paulo

SILVA, C. A. 2012. Cultura Surda. Agentes religiosos e a construção de uma identidade. São Paulo: Terceiro Nome.

VALTELLINA, Enrico. 2018. A. S.: Classification, Interpellation.In: .Autism in translation: an intercultural conversation on autism spectrum conditions. Switzerland: Palgrave Macmillam. pp. 207-229. 
Perspectivas antropológicas sobre deficiência no Brasil

Resumo: Mesmo recentes, as reflexões sobre "deficiência" vêm assumindo contornos específicos e demonstrando vitalidade na antropologia brasileira. Diferentes matrizes teóricas são utilizadas pelos autores brasileiros para discutir a temática e estabelecer relações com campos consolidados, como gênero e sexualidade, saúde, políticas públicas. O presente dossiê é apresentado através da articulação entre três eixos de reflexão: deficiência como categoria relacional; deficiência como categoria diagnóstica e jurídica; e a contribuição da antropologia para a superação do paradigma clássico da normalização.

Palavras-chave: Deficiência; Etnografia; Antropologia
Anthropological perspectives on disability in Brazil

Abstract: Ethnographic research on disability has recently gained visibility in Brazilian anthropology, developing its own specific traits and demonstrating great effervescence. Brazilian authors use different theoretical perspectives to discuss this theme, and establish connections with other consolidated areas of study such as gender and sexuality, health and public policies. This special issue is presented through the articulation of three critical axes: disability as a relational category; disability as diagnostic and judicial category; and anthropological contribution to overcoming the classic normalization paradigm.

Key words: Disability; Ethnography; Anthropology 


\title{
Facts of cripness to the Brazilian: dialogues with Avatar, the film
}

\author{
Anahi Guedes de Mello \\ Universidade Federal de Santa Catarina - Brasil \\ Marco Antonio Gavério \\ Universidade Federal de São Carlos - Brasil
}

\section{Introduction}

Queer theory influenced disability studies, contributing towards the emergence of crip theory, proposed by Robert McRuer (2006), which relates cultural signs of queerness and disability. While the main axiom of queer theory postulates that contemporary society is governed by hetero-cis-normativity, crip theory builds itself upon the postulate of compulsory able-bodiedness of the social structure less sensitive to body diversity. The translation of the term crip, short for cripple, for the category of "aleijado" in Portuguese, is a way of approximating its definition in English. The meaning of the term crip initially was directed against all that does not fit within bodily/functional standards. It reveals the abject zone reserved for persons with disabilities. Similar to the term "queer", crip terminology has an openly aggressive, derogatory and subversive connotation. In order to mark a crip commitment towards developing an analytics of the normalization of the body, inspired by the work of deconstructionist authors like Michel Foucault (1990), Jacques Derrida (1998), Judith Butler (1990, 1993, 2004), among others, developing critiques around systems of oppression marked by patriarchy, by compulsory heterosexuality $^{1}$ (Rich, 1980) and the compulsory able-bodiedness (McRuer, 2002):

I argue that the system of compulsory able-bodiedness that produces disability is thoroughly interwoven with the system of compulsory heterosexuality that produces queerness; that - in fact - compulsory heterosexuality is contingent on compulsory able-bodiedness and vice versa. [...] The idea of imbricated systems is of course not new - Rich's own analysis repeatedly stresses the imbrication of compulsory heterosexuality and patriarchy. I would argue, however, as others have, the feminist and queer theories (and cultural theories generally) are not yet accustomed to figuring ability/disability into the equation, and thus this theory of compulsory able-bodiedness is offered as a preliminary contribution to that much-needed conversation (McRuer, 2002: 89). 
According to McRuer, it's not possible to speak of "persons with disabilities", once crip theory stands in relation to disability, as queer stands towards homosexuality and transsexuality. That is, a radical critique of institutionalized categories by normativity. Meaning, crip theory deconstructs the boundaries between disabled and non-disabled persons, suggesting that we are all, one way or another, in the same situation, enabling us to break down barriers between "us" and "them"

In Anthropology, we learn that social relationships are built on binary categories, so we propose the use of crip theory as another way of thinking about disability in order to deconstruct the binary logic "disability/ability". This is the perspective guiding this study. Since our interest is not in the Goffmanesque social processes that sociologically create people with disabilities as stigmatized or labeled as "deviant" (Goffman, 1963), but focuses on the debate of disability from one queer perspective. It questions the "normalizing processes marked by the simultaneous production of hegemonic and of subaltern"3 (Miskolci, 2009: 171).

The main objective is to problematize the production of "truths" about disability, departing from crip theory. For this deconstruction, we critically analyzed "Avatar", a science fiction movie, and its representation of the disabled body. What we find interesting in using "Avatar's" approach is that it allows us to make some mention of the analytical and intersectional potential of a crip epistemology of disability. To this cultural discussion, we will link some of its aspects to a perspective autoethnographical in which the authors bring their respective personal narratives as disabled, exercising one cripistemological way to analyze both their bodies as their own dichotomy disability/ability. The expression "autoethnographical" refers to autoethnography, a form of "self-writing" (Foucault, 1992) that combines characteristics of autobiography and ethnography, describing and analyzing (graphy) personal (auto) experience in order to understand the cultural experience (ethno) (Ellis, 2004; Holman Jones, 2005) of people with disabilities. In this sense, having the researcher's body as a simultaneous mediator between the observer and the observed, autoethnography implies the exposition of a vulnerable self (Ellis \& Bochner, 2000), precisely because it is "an autobiographical genre of writing and research that displays multiple layers of consciousness, connecting the personal to the cultural" (Idem, ibidem, p. 739).

The fundamental idea is to show that the social production of disability is also "naturalized" by the dominant knowledge, whose meanings attributed to disability are organized in an apparent binary opposition system to the notions of disability 
and ability, in which the presence of disability supposedly is due the clear lack of ability. Therefore, in a queer/crip analytical disability and ability are revealed as interdependent.

\section{Avatar, the film: an anthropological narrative, queer and crip}

Avatar (2009), a film directed by James Cameron, is a fictional film work permeated by hybrid and mythological narratives. The story is set in the year 2156 on Pandora, one of the moons of Polyphemus planet, in a region covered by lush flora, luminescence, and dense with giant plants that shrink. In Pandora's forest there is also a rich, mythologically exotic and monstrous fauna (Oliveira, 2011), and its local inhabitants, the Na'vi people, blue humanoids about three meters high, having long limbs, a tail, a long braid of black hair ${ }^{4}$, ears and nose resemble a feline whose ways of life inspired a profusion of mythologies and religious influences:

[...] The Na'vi culture condensed resonance of mythologies and various religious influences, ranging from pantheism to tecnopaganism also visiting monotheism, African religiousness and shamanism, and even reincarnationism, to the taste of the beliefs of miscegenation that makes part notably the Latin American universe ${ }^{5}$ (Oliveira, 2011: 4).

In the midst of the paradise of Pandora images, the soldier Jake Sully, a former Marine, is the paralyzed twin brother of the scientist dead shortly before completing the scientific experiment called Avatar. Sully, by having identical genome to his brother, is appointed to replace him. Following the team of scientists, the former soldier gets lost during the expedition and ends up contacting Neytiri, daughter of Eytukan, the head of the Omaticaya clan, and Mo'at, shaman and legitimate representative of Eywa ${ }^{6}$. Neytiri, about to kill him, receives a signal of Eywa, the Great Mother, not to do this. Then Jake is conducted by Neytiri and other Na'vi warriors to her village. After a tense moment, the head of the clan says, "This is the first warrior walker we see. We need to learn more about it". The Omaticaya clan decided then to give a chance to Jake to learn the ways of the Na'vi, to speak the native language and to walk like one. From there, Jake spends three months learning the ways of the $\mathrm{Na}$ 'vi and goes through all the rites of initiation to become a Na'vi warrior: he learns to ride, hunt, respect and love. In this deep relationship with the tribe, Sully has been accepted by its members as one of them. This cycle is completed a passion for Neytiri. Gradually Jake is delighted with the natives and 
realizes the emptiness of his life as a paraplegic with no prospect in the human "civilized" world and begins to question Western values and himself. Sit torn between two worlds, the loyalty to Colonel Quaritch, to whom he must transmit all the information about the Na'vi, and the loyalty that keeps him increasingly linked to Omaticaya clan. All this was because Jake understood the culture, the native thought the other under a perspectivistic bias:

We must learn that we have a body [the body of your avatar Na'vi], and this learning in the case of Jake Sully will take you to "see" and "feel" of another way, until it is no longer the "driver" and start to think with his own body. Until your mind and your values are converted into a "point of experience", a perspectivism and radical "point of view" amending our own experience of world and the separation between subject and object. In this sense, Avatar can be read as a conversion of instrumental reason and the body/mind dualism to a "thought of the body", in which the body point of view radically changes our identity and subjectivity ${ }^{7}$ (Bentes, 2010: 73).

Avatar is anthropologically inspired by the indigenous populations, with a cosmology in the mold of Amerindian perspectivism proposed by Eduardo Viveiros de Castro (1996), where lifestyles are totally subject to the holistic laws of nature. For example, they produce, collect and hunt without the intention of generating surplus, still have a social organization divided among the warriors, the chief and spiritual leader of the clan. Amerindian perspectivism as a concept emerges in Levi-Straussian-inspired Indigenous Ethnology from "savage thinking” (Lévi-Strauss, 1989) and has another meaning with the "ontological turn" in Anthropology when Viveiros de Castro defines it as a "way of thinking that rejects dualisms typical of Western-modern thought". (Barcelos Neto et al., 2006: 177). Thus, "it is the conception common to many peoples of the continent, according to which the world is inhabited by different kinds of subjects or persons, human and non-human, who apprehend it from different points of view" (Viveiros de Castro, 1996: 115). Hence, in the perspectivist conception, "[...] the classical distinction between Nature and Culture cannot be used to describe dimensions or domains internal to non-Western cosmologies without first passing through a rigorous ethnological critique" ${ }^{10}$ (Viveiros de Castro, 1996, loc. cit.).

Interestingly, parallel to this body/mind dualism, another background permeates Avatar narrative: the duality disability/ability is the thread of the plot, whose 
"essence" is connected to the artificiality of the machines. It is precisely this binary opposition which serves as a starting point to crip theory, leading us to the debate on bodily perfection that McRuer (2006) calls "full physical capacity".

Jake Sully character lives in crisis between two worlds, human and $\mathrm{Na}$ 'vi. As a human, Sully is despised by his abject condition invalid veteran, impure, depraved and disabled; as Na'vi is chosen by his perfection, purity and courage. At first, the human form of Jake, as being raw and disabled, prevails. But it is slowly being replaced by the "pure essence $\mathrm{Na}$ 'vi". Consequently, the victory occurs at the expense of "brutal and defective essence" having as extreme paradigm Colonel Quaritch. In this sense, the Avatar's narrative incorporates the demands of our Western capitalist ableist society by heroes, being able to transcend the bodily limitations and achieve great deeds.

The metaphor of the colonial context between indigenous peoples of the Americas and Oceania and their European invaders is explicit when the narrative of Avatar introduces a former Marine who, like a Na'vi, dreams of flying over dense forests freely, but upon waking as a human faces his harsh reality as a wheelchair user, disabled. As a human, Jake is on Earth in a futuristic and dystopian moment, but a future that has not yet been able to "eradicate" disability even with all the advances of "science". In a passage from the film, Sully says:

They can fix a spinal, if you got the money, but not on vet benefits, not in this economy. A VA check and 12 bucks will get you a cup of coffee. I'm what they call... waitlisted. The Bengal Tiger, extinct for over a century is making a comeback. These cloned tiger cubs at the Beijing Zoo are the latest of a number of species that have been cloned back into existence in the past five years.

We wonder about the interests behind Pandora and its resources and, throughout the movie, we realize that science, militarization and capitalism are mixed in the exploration of the moon and Earth may no longer have enough energy resources. This is a dystopian future that is in the plot of the science fiction Avatar. However, even this plot could tell us about a "cultural shock", recognizable in a colonial fashion to the anthropological gaze - echoing the distinctions nature $\mathrm{x}$ culture, tradition $\mathrm{x}$ modernity, individual $\mathrm{x}$ society and body $\mathrm{x}$ mind - the film portrays a "sci-fi colonial shock", effectively the assault of one species from one galaxy to another. In this way, the Western colonial process also created its "scientific fictions" by assuming that other peoples were inferior to the inhabitants of Earth. To what extent 
does the concept of human take shape? Could not our idea of "original humanity" come from a colonial mix that has been processing the term through science, deadly weapons, and capital?

Avatar's dystopia lies in this imminent end of the human species and the conditions of existence on planet Earth. Jake Sully has the DNA needed to take over the place of his twin brother scientist, but as an invalid ex-military man he has nothing to lose either. "Have nothing to lose", if we comprehend this phrase through a crip reading of the futuristic disabilities projections, according to Kafer (2013), we have two situations of "fictional space-time". The first posits the utopian promise of a world without disabilities, without diseases, without ills and sufferings; The second projects a dystopia, a future environment in which disability and disease have not yet been eradicated and may even become more pronounced due to the very ambiguous nature of technoscience, that is, at the same time that it is the great paradox which has effectively extended human life expectancy, few people access these resources satisfactorily. In the case of the movie Avatar, the dystopia that Sully literally embodies is not only individual and techno-medical, it is economic also, as when Jake comments that genetics can reproduce an extinct tiger, but his spine has not been repaired because he cannot pay for the procedure with his pension as a war veteran. Jake Sully then rejects his body and decides that, like Na'vi, he has nothing to lose by walking back into another body. However, the character Jake Sully is not a symbol of the disabled activist, nor proud of his wheelchair and thin legs. Nor would it be just a disability studies scholar who sees Sully's disability as a social, political and theoretical experience. Sully understands that he has a hole in his life and that his disability is synonymous with a disintegrated body, flawed and marked by absences. Hence, Jake allows himself to be seduced by the Colonel's promise that if he reported the information about Pandora to his military superiors, he would have "his legs back." However, Sully is also seduced by the body of his Na'vi avatar.

This Avatar movie review aims to make a didactic and brief introduction to crip theory, to make a point to the abjection processes of disabled bodies. In this case, the subversive power of the abject body of crip theory is linked to processes of subjection of disability to able-bodied hegemonic patterns because disability is the materiality of abjection in its most radical sense:

Yet there is a strange and really unaccountable silence when the issue of disability is raised (or, more to the point never raised); the silence is stranger, too, since 
so much of left criticism has devoted itself to the issue of the body, of the social construction of sexuality and gender. Alternative bodies people this discourse: gay, lesbian, hermaphrodite [sic], criminal, medical, and so on. But lurking behind these images of transgression and deviance is a much more transgressive and deviant figure: the disabled body (Davis, 1995: 5).

In this sense, the disabled body refers to the idea of crippled as disturbing, degenerated, disposable, morbid, revolting, disgusting, in short, disability is the totalizing synthesis of the aberration of the monster figure (Gil, 1994; Silva, 2000). However, for the crip project, the distinction between disability and ability, registered only in the so disgusting figure of the disabled body, can't be effectively achieved due to the impossibility of achieving the full physical capacity, or "disability is a natural part of life. Everyone will be disabled someday” (Pfeiffer, 1999:106). Furthermore, it is not enough to make positive this universal and virtual projection of disability. As Robert McRuer (2006) points out, not all people who can be considered disabled voluntarily fit in this politically resignified category, especially people who are already considered "not disabled" and who tend to understand, ultimately, that the disabled body is itself the proper example, the great metaphor of the flawed condition of vulnerable, finite and unwanted humanity. Here prefigures the critical and crip conceptualization of a severely disabled position. According to McRuer (2006),

[...] everyone is virtually disabled, both in the sense that able-bodied norms are "intrinsically impossible to embody" fully and in the sense that able-bodied status is always temporary, disability being the one identity category that all people will embody if they live long enough. What we might call a critically disabled position, however, would differ from such a virtually disabled position; it would call attention to the ways in which the disability rights movement and disability studies have resisted the demands of compulsory able-bodiedness and have demanded access to a newly imagined and newly configured public sphere where full participation is not contingent on an able body (McRuer, 2006: 30-31).

This severely disabled position does not seem to get the same weight when we think of abject materiality of the deaf body inhabited by Anahi. To give an example, we illustrate Anahi's remarkable ethnographic experience with a person with Down syndrome, which occurred at Galeão International Airport, Rio de Janeiro, coming from Recife, where she participated from 11 to 13 October 2012 at the invitation of the Ministry of Education (MEC) of Brazil, to the VI Brazilian Congress on Down Syndrome: 
I was sitting waiting for the flight to Florianopolis when suddenly I saw two faces. The first was a face of a person who I had just met at this event, but there was no time for greetings. Soon after, I see the second person's face. An unknown face that instantly disturbed my eyes in time and space, revealing the power of fascination for me: a woman with Down syndrome walked alone and in high heeled shoes, with astonishing ease. She walked by, disappearing from sight in a few seconds. I was staring at the body with Down syndrome walking in high heels, an ability that I do not own, and suddenly I thought about my own prejudice, simply because the owner of the high-heeled shoes is a woman with Down syndrome "independent" and "alone" because she wasn't accompanied. (Anahi's field diary, October 2012).

Thinking of a hierarchy of extraordinary bodies (Garland-Thomson, 1997), I, Anahi, a deaf body, I experienced an extraordinary moment that Rosemarie Garland-Thomson (2009) calls staring, a persistent fascination for the disabled body, feeling the threshold between the sacred and the profane (Douglas, 1966), because at first glance the deaf body is configured in an "ideal body", i.e. a kind of disabled body that approaches the ideas of ordinary bodies. In this unexpected episode, I was the ordinary body; woman with Down syndrome, the extraordinary body:

Extraordinary-looking bodies demand attention. The sight of an unexpected body - that is to say, a body that does not conform to our expectations for an ordinary body - is compelling because it disorders expectations. Such disorder is at once novel and disturbing. This interruption of expectations, of the visual status quo, attracts interest but can also lead to disgust, according to William Ian Miller (1997). Unusual bodies are "unsettling because they are disordering; they undo the complacency that comes with disattendability; they force us to look and notice, or to suffer self-consciousness about looking or not looking. They introduce alarm and anxiety by virtue of their power to horrify and disgust." Such bodies fascinate; they demand that we "sneak a second look" [...] (Garland-Thomson, 2009: 37).

In this sense, although the deaf body provokes fascination through social markers that identify (sign language, the "deaf voice", cochlear implants etc.), it seems to cause less disgust than a Down syndrome body or an amputated or quadriplegic body. Also, my brief stay in Recife, when I closely witnessed desires, flirtations and expressions of public affection among many couples with Down syndrome, this led me to compare the Down syndrome bodies to gay and lesbian bodies when they are not in repressive environments where they feel more comfortable publicly express- 
ing their affections. In fact, beyond the "compulsory heterosexuality" (Rich, 1980), we also have the "compulsory able-bodiedness" (McRuer, 2002).

Marco tells of an experience in which he realized that his "pride" of his "wheelchair body" - half human, half machine - could not be easily understood in certain contexts:

I, as a wheelchair user for 18 years, feel part wheelchair, a cyborg. The symbiosis that I make with her makes me realize the world and reach it with my body-chair. A body that runs, that disassembles, that disengages and engages again in other positions, in other places and contexts. How can I deny that my chair and I are part of each other, thus deny that my being has wheels and engine? A few months ago I got a ride with a friend to a party. Upon arriving at the public parking, we had difficulties opening the car trunk, which only opened from the inside, to withdraw my wheelchair. Maybe our internal movements in the car looked suspicious at that hour of night and some security guards approached us. I was in the car, dismantled in the passenger's seat while listening to my friend arguing with one of them: "I am trying to open the trunk to take out my friend's chair, he is a wheelchair user." ${ }^{11}$ One of the guards immediately shot back: "Wheelchair user?! What is a wheelchair user doing here? This is no place for him!" (Marco's field diary, September 10, 2015).

The "severely disabled" critique of the second author confronts the anxieties that the figure of a disabled person provokes. Why can't they be there? Because of the parking lot is at a Brazilian public university? Because it was at a party? Because the wheelchair testifies the frailty of human beings? The point is that no one wants to take a politically disabled experience as telos of their identity. Yet as much as "[...] if we live long enough, we will all become disabled (Garland-Thomson, 2009: 46)", the wheelchair, as well as crutches, walkers and oxygen atoms pipes are not commonly designated as "dreams of consumption" or totally stripped of its medical and hospital symbology.

This ambiguous figure of the wheel-chair-body - between the healthy and the sick; between life and death; between imprisonment and the freedom of technology; between human and non-human - is the one that brings the idea of "inadequacy" and "transgression". Transgression that creates anxieties, like the figure of cyborg analyzed by Donna Haraway (1987: 5) ${ }^{12}$, because of the breakup with the image of Western ontological distinction between body and machine. In the words of Haraway, 
a cyborg is a cybernetic organism, a hybrid of machine and organism, a creature of social reality as well as a creature of fiction. Social reality is lived social relations, our most important political construction, a world-changing fiction. [...] Contemporary science fiction is full of cyborgs — creatures simultaneously animal and machine, who populate worlds ambiguously natural and crafted. Modern medicine is also full of cyborgs, of couplings between organism and machine, each conceived as coded devices, in an intimacy and with a power that was not generated in the history of sexuality (Haraway, 1987: 1-2).

\section{Disability as stigma and experience queer/crip}

For many people with disabilities, especially those born with a disability or who acquired disability at an early age, disability is often the first queer experience, long before the gender and sexuality ${ }^{13}$. The disabled body is queer. It's a dissident corporeality. The metaphor of "the crippled" shows the proximity of the "monster" of queer theory with the "monster" of crip theory. There is a "crip hierarchy" of queer bodies. Therefore, we must crip queer theory to include subaltern voices of disabled persons, deconstructing the hegemonic assumption that only LGBT bodies are likely to "queering".

In The Body Silent, Robert Murphy (1987) discusses the deviance models of disability in Talcott Parsons and Erving Goffman. According to this author, especially Parsons did not consider what happens when the patient neither does not dies nor gets better, theorizing the fact that people who acquire a disability enter into a permanent liminal state between health and illness. In other words, the discussion of disability is relegated to the background of discussions on rational and deviant models the health and sickness. About the interactionist theory of Goffman, Murphy argues that

Erving Goffman's stigma had great influence on the sociological study of disability by providing a common framework within which the handicapped, criminals, and certain minority groups could be seen as sharing a common lot: They are all outsiders, deviants from social norms. There are, however, problems with this framework. First of all, it throws into one pot people who are deliberate violators of legal or moral standards and persons who are in no way to blame for their stigmatized state. A person chooses to follow a life of crime, but nobody asks to be born a black, and certainly nobody wants to become a quadriplegic. These stations in life are visited upon people by inheritance or bad luck, not through choice. This, of course, does not prevent others from blaming the victim, and all too 
many benighted whites look on blacks as lazy and unintelligent people who prefer welfare and crime to working for a living. Even the disabled are often vaguely blamed for their condition, or at least for not achieving maximum recovery. And as sure proof that they bear stigmatized identities, physical impairment is looked upon as something that does not happen to respectable people. The blind are folks who make brooms in sheltered workshops, or who sit on street corners with cups. They certainly do not belong among the upwardly mobile (Murphy, 1987: 129).

In fact, the concept of stigma strongly influenced sociological studies on disability by providing a framework in which "disabled", "criminals" and other minority groups would present "common destiny": all are outsiders and deviant social norms. However, to Murphy (1987), this frame also presents problems by putting together and classifying as "stigmatized" people who deliberately violate legal or moral norms with those who have no blame for their condition. A person can choose to follow a life of crime, but no one asks to be born black, much less choose to become quadriplegic. These are events that occur through inheritance or "bad luck". If to be disabled is less of a "choice" and more about "bad luck", or vice versa, it expands the scope of the stigma concept, to exchange their conventional content by another sense of its meaning, especially in the context of "politics of appearance" as proposed by Rosemarie Garland-Thomson (2009) to refer to the "abominations of the body" described by Goffman as "stigmata hierarchy" that begins with disabilities:

[...] Human variation, in other words, is seldom neutral. "Abominations of the body" are in the eye of the well-acculturated beholder. Modern culture's erasure of mortality and its harbinger, bodily vulnerability, make disabled bodies seem extraordinary rather than ordinary, abnormal instead of mundane - even though in fact the changes in our function and form that we think of as disabilities are the common effects of living and are fundamental to the human condition. What Goffman describes as "abominations" come to most ordinary lives eventually. If we live long enough, we will all become disabled (Garland-Thomson, 2009: 44-46).

Here there is a relationship between Goffman's concept of stigma (stigmatized bodies) and the idea of abjection (abject bodies) of queer theory. The hierarchy of corporealities, including the "abominations of the body" and all the contrasts between ordinary and extraordinary bodies (Garland-Thomson, 1997), organizes the able-bodiedness of our social structure little sensitive to body diversity.

For queer thought, all "difference than [if] want to be assimilated or tolerated, 
and therefore its form of action is much more transgressive and disturbing"14 (Louro, 2001: 546), may also be considered queer. From this perspective, disabled bodies are also queer. The "invention of disability" also produces an "exclusionary matrix" that "requires the simultaneous production of a domain of abject beings" (Butler, 1993: 3). By abject we understand the subjects whose bodies do not fit the prevailing social standards. For Butler (1990), the "abnormal" is seen as the "constitutive outside" of the subject "normal" and just designates the "uninhabitable" areas of social life. These zones of abjection are densely populated by those who do not enjoy of a subject hierarchy, there is a need to constitute a "foreign" composed of "not subject" in order to prove as less human for such a matrix can remain hegemonic.

However, as with the queer/crip bodies of the "global south", disability also needs "to be understood in the context of the violence of colonization and neocolonial power" (Connell, 2011: 1369). From this "southern perspective," we should think of Jake Sully as a "settler of the north" seduced by the "colonized from the south". How to access "southern bodies" if Sully is from the "north" and, above all, by his position of geopolitically localized subject, let himself be seduced by the other when he assumed the body of his Na'vi avatar. How do the bodies of the authors of this paper enter the "moral economy" of southern bodies to think of the "global north"? Are we necessarily from the south because we are Brazilian or are in Brazil? For Viveiros de Castro (2002), the other can be understood as possibility of relating to something beyond the self. In this sense, the other is the structure in which the self imagines the existence of other. For this reason, we recognize our position as "southern bodies" in constant tension between being in the "global south" and being in the "Brazilian academic north": in the first case we are post colonized Brazilians, in analogy to the metaphor of being Na'vi in a context of global binary division of the world; in the second case we are in good federal universities of the "center" (represented by the states that compose the southeastern, south and central-west regions of Brazil), enjoying relative academic autonomy and material resources for the research and production of knowledge about disability, so that we are often interpreted by the "academic periphery" (represented by the states that make up the northern and northeastern regions of the country) as "settlers" of certain social thoughts about disability.

In the next section, we will focus on "cripness" of our autobiographical narratives that permeate the crip politicization of our disabled body to Avatar fiction: Marco as a body attached to a wheelchair and being carrier of a genetic disease; and Anahi's 
deaf body connected to a cochlear implant. In the perspective of prosthetic narrative, the connection of Avatar with our disabled bodies is supported by the notion of the hybrid. The hybridization of Sully human and Sully Na'vi helps us to speak of our hybrid condition physically-disabled-wheelchair-body and deaf-cochlear-implanted-body respectively.

\section{My body, my wheelchair}

The fact that I'm a motorized-wheelchair-body, goes beyond the fact that I was a "user of a motorized wheelchair" or a "person on a wheelchair". The first memory I have about wheelchair comes with my refusal and fear, as a child, to not become 'it's' "prisoner". I grew up hearing that one of the effects of "my genetic condition" would be the progressive loss of all muscle tone. One of the major medical concerns, that served as a rehabilitative motto for my incurable clinical prognostics, was to keep my degenerating body as "active and independent" as possible. Be "active and independent" meant keeping up my ability to walk, and my standing position, with a lot of physiotherapy and psychology.

Amid these discourses, the inevitable feeling of weakness consumed me all the more: I could no longer hold my eight-year-old body standing for long; my arms were trying in vain to sustain me under the crutches that had, up until that time, accompanied me. With every failed, flawed step, every time I lost muscle control in my legs, leading to an inevitable fall to the ground, it became less painful to see myself as a "wheelchair bound". I tried hard not to use 'it'. I saw the wheelchair as a "prison" that would not allow me to do anything; but, at the same time, I did not see with the same "critical concern" the heavy iron structure that embraced my legs and hip and that was the last "prosthetic therapy" to save my bipedalism (seen as an index of greater independence).

As my muscle degeneration is inevitable, as well as the loss of my ability to walk, the heavy paraphernalia that helped me to keep standing up. The "dreaded" wheelchair was the only way for me to continue playing around and going to school. Gradually the process by which I stopped seeing "it" involves me in a simultaneous metaphorical and literal process as I felt that "she" embraced me with "her" arms and metal supports and foam, which held me up and off the ground. I perceived it as another way to move around, to communicate with others. To find a way of living "stuck" in an apparatus seen as culturally malevolent, allowed me, over time, to create a symbiosis with this machine. 
My wheelchair is not exactly a possession, it, she became the fundamental means of my own condition of social existence, including as a "disabled person". As she, it and I we were inappropriate for many spaces; she and I were, and are, a cybernetic hybrid configuration, as Haraway (1987) defines cyborgs. There is no presence of one without the other. The apparent simple act of dismounting "my" wheelchair starts at the exact moment that we are tortuously uncoupled for it to be folded, defragmented in parts to fit in a car's trunk. This disassemblage consumes me in the anxiety of our distance. I feel inert to be outside of her and I wonder what my "real" legs are paired with the momentary stillness of the chair's wheels. In this mixture of flesh, bone, metal, plastic, and electricity, I feel a motorized-wheelchair-body, a rolling-body, a mechanical organism disfigured of its supposed essences.

What makes me disabled? The wheelchair? The perception of others about my body? My degenerative disease that leaves me "cock high in the world" (Mairs, 2001: 54). The world that does not include bodies extremely out of social, cultural, and biological norms and expectations? What comes first? Donna Haraway's cyborg refers to a noise in the cultural and scientific certainties of human ontology, and allows us to think as ambiguous beings, indeterminate or multiple sources. To prefer the idea of being a cyborg instead of a goddess (Haraway, 1987; Meekosha, 1999; Puar, 2012) the author tenses a critical idea of embodied consciousness by devices and power techniques historically locatable. The possibility of (un)learning the body emerges not only as a means of meeting a pre-existing world, but also to create new bodies-worlds contingent to each other.

\section{My cochlear implant, my crip sex toy}

My deaf body, my cochlear implant. My cochlear implant, my crip sex toy. My crip sex toy, my subjectivity. I do not have the primacy of "deaf knowledge" because I do not intend to be recognized first as deaf. Deafness is part of my identifications, but it is not something with which I have a main identification. However, if my deafness is the "stigma" in evidence, people tend to take it as my "primary identity". This intrinsic characteristic of my body obscured my other political subjectivities: being a woman and lesbian. The ableist and hetero-cis-normative social structure generally tends to contribute to this disappearance, to the extent that society only sees me as deaf. Deafness is my first queer experience, but it was the consciencia mestiza (Anzaldúa, 1987), not "Deaf consciousness", that allowed me to go beyond the deafness so I can move "constantly out of crystallized formations" (Anzaldúa, 2005: 706). 
My deaf body is mediated by a machine, the so-called cochlear implant, a highly sophisticated technology to enhance hearing ability in a more effective way than an ordinary hearing aid. In a human-machine interface, in the terms of Haraway (1987), the cochlear implant deaf-hybridization could be thought of as a counter power to the "Deaf Pride", with the motto inscribed "Bionic Ear Pride". Considering cybernetics as "the art of ensuring the effectiveness of an action" (Couffignal, 1968: 23), I propose to think the cochlear implant-deaf relationship under these cyber effects when the cochlear implant as a "foreign agent" ensures the deaf body's effectiveness of mechanical ability to listen. Here the cyborgization process is configured in construction be deaf in connection with a cochlear implant, performing social measures, since both are involved in the same ratios.

In 1998 I had the first contact with the theoretical assumptions of the Deaf Studies from reading academic texts in Portuguese on "Deaf identities". In my view, these texts are filled with "accusatory categories", the sorting of deaf people into various categories of deaf identities being counterproductive because it split us into "good deaf" and "bad deaf". Good deaf would the Deaf with letter "d" uppercase, those who communicate and have sign language as their first language, being fans of "Pride Deaf". The "bad deaf" would be the "oral deaf" and users of the Portuguese language as a first language in Brazil, those who speak, do lip-reading and use "hearing technologies".

The talking, lip reading and "hearing technologies" of cochlear implants are considered by the "good deaf" as "things of hearing people" and therefore should be rejected. Although I don't subscribe to these ideas "in these terms", it is true that the hearing-deaf relationship does not cease to be a relationship majority-minority, where inequality is also evident through communication and the ability to hear. In this sense, just as the "white privilege" or racism against blacks and the "male privilege" or sexism against women can be, respectively, systems of oppression based on race/ethnicity and gender, the "hearing privilege" or audism against deaf people can be understood as a system of oppression based on hearing ability (Eckert \& Rowley, 2013; Ha'am, 2017). However, regarding the cochlear implant, as cybernetic prosthesis it is treated by many Brazilians Deaf with some disgust, a "bad thing", almost automatically a "negative experience" to be avoided, often without considering subjective aspects involved in each particular situation and that demand in a continuous exercise of relativity.

If sexuality in human life is a subjective meaning variable in different cultures, so 
I can say the subjectivity of cochlear implant-deaf experience. One of the powerful dimensions of the cyborg and queer/crip experience with cochlear implants are the sounds of sex we produce and heard during the sexual relations. There are reports of physical disabled people that show how some erotic-sexual nuances and seduction mechanisms are designed from their wheelchairs, sometimes in a sensual dance or as extension of their disabled bodies in sexual and/or erotic games practices (Oliveira, 2016). But reports of the sexual practices of deaf people are scarce, especially when they involve the use of cochlear implants. This difficulty is due to the fact that deafness be, at first sight, an "invisible disability", i.e. the "surface" the deaf body does not present "deformed" to be considered worthy of reflexivity in the field of the dissident sexualities. There is a gradation of disability, or "crip hierarchies" of disabled bodies, with the deaf body very close to the first level of the hierarchy.

In fact, for many cochlear implant users this technology has become an ingredient to more sexual satisfaction. They like to make love with cochlear implant, because they love to hear the sounds of sex. Thus, listening may come to represent a very particular positive dimension of subjective experience of deaf people with cochlear implants. In my case, it is not different. Making love with cochlear implant affects my libido, greatly changing the sexual scripts, once I stop to discover and actively participate in the sounds present in seduction games in bed. So my cochlear implant is a fetish, affectionately treated as sex toy. My cochlear implant, my crip sex toy. This is one of the reasons why those Deaf who have never experienced a cochlear implant can't and should not refer to it as a "bad thing". Sex with cochlear implant is also a powerful experience because of the subjectivity of each subject. However, as in any experience of the subject, the subjectification of the cochlear implant should not do without the subjective position of the subject, i.e. the experience with a cochlear implant is tributary of the subjective position of the deaf person.

\section{Final considerations}

Sully has dreams in which their freedom is to fly over heavy trees canopies. Dream of freedom in his narrative are contrasted by his image among the people of a planet Earth with no future. Sully does not see his disabled body as a creative power. The former paraplegic Marine believes that in his life there is a hole and what it lacks is in his life before the accident. This fetish returns to a previous alleged bodily life, in a way, is the same fetish encouraged by rehabilitative historic speech that Henri-Jacques Stiker (1999: 122) comments hold its reference to a "[...] 
assumed prior, the normal state." Stiker continues to state that

this iterative term to designate the rehabilitation initiative, especially from the 1920s onward, is remarkable in its own right. It is applied to congenital cases as well as the adventitious. It implies returning to a point, to a prior situation, the situation that existed for the able, but one only postulated for the others (Stiker, 1999, loc. cit.).

It is this will to walk again that animates Jake Sully for much of the film narrative and his plotting against the Na'vi. It is for this same freedom that walking again is symbolic and seduces Sully to use as avatar the powerful Na'vi body created "in vitro". A disabled, paraplegic, Jake Sully works as the foundation of other forms of knowledge and access to inhuman information at the same time he needs to be both dismissive and overprotected. This is precisely one of the points that makes us think in an analytical queer/crip of disability.

We all know that Jake Sully, when using the Na'vi body remains with his human body in a broadcasting room. If his human body suffers any damage, the experience of using the body as Na'vi Avatar fails. However, only we realize such fragility of the human body condition when in a deadly struggle, while immersed in Avatar, the cabin in which lies the body of Sully is broken. The former soldier is vulnerable to the toxic gas moon Pandora and its Avatar goes off when the human lungs can't breathe. One of the most beautiful scenes of the film, we see the warrior Neytiri, with its slender, blue-bulk, holding in her lap, in comparison, the small body of her beloved, almost dead. This is where we have our "able-bodied epiphany" when the end of the movie to recognize that Jake Sully survived and become the Omaticaya clan hero, his dying body to be left out, "discarded".

The crip theory critique to the notion of a "complete physical capability" seems to cross an analysis of normalization that results, for instance, from the misunderstanding of what constitutes a queer analysis about the relation between homophobia and compulsory heterosexuality. One might see that as a result from the fact that the problematizing towards physically able bodies did not strongly benefit from the intersection among categories such as sexuality, race, ethnicity, and disability - in the sense of a "sexualization/racialization of disability" or a "disabling of sexuality and race" whereas queer theory itself relies on an intersectional approach to discuss the sexualization of race and the racialization of sexuality. 
Crip theory questions the normalization of bodies. It questions the exclusion of ableism as intersectional discrimination matrix in the feminist and queer theories. It questions the "compulsory able-bodiedness" because it is socially and culturally marked by a "hierarchy of corporealities" in which to "dwell in the world" (Butler, 1990) certain bodies seem to be "more acceptable", "selected" or "privileged" that others. By questioning a hierarchy of bodies, the crip theory necessarily covers the size of non-hegemonic sexualities. Thus, queer theorists must or should know about crip theory, since queer theory relates to a "crip hierarchy" of queer bodies.

We also have a doubly tensioned, divided experience: we are seen by the "northerners" as the "global south", the "third world," "subalternized localities in global political economy," and it seems that in many ways we have to recognize ourselves in these terms. At the same time, we are often seen by other compatriots as the "academic north"15: "very theoretical," "with research resources," and "with full academically activism conditions." Paradoxically, it is precisely because of this our hybrid condition that we are generalized as from the south (global) and from the north (national) that our critical power resides to produce a southern crip thinking.

Recebido: 14/02/2019

Aprovado: 09/04/2019

Acknowledgments The authors express their thanks to Pamela Block for reviewing the manuscript's English. Anahi expresses her thanks to Capes for granting her doctoral scholarship, and to $\mathrm{CNPq}$ for funding of the project Feminist Theory, Queer Theory or Contemporary Social Theories?: the field of Gender Studies and Sexuality in Brazil (Process No. 402545/2010-9). Marco wants to say thanks to the CAPES and $\mathrm{CNPq}$ for his doctoral fundings.

Anahi Guedes de Mello is PhD in Social Anthropology from Federal University of Santa Catarina (UFSC), in Florianópolis, Brazil. Researcher of the Núcleo de Identidades de Gênero e Subjetividades (NIGS), at the UFSC's Department 
of Anthropology, and of the Núcleo de Estudos sobre Deficiência (NED), at the UFSC's Department of Psychology. She is also an associate researcher at Anis Instituto de Bioética, in Brasília, Brazil. ORCID: 0000-0002-5536-7171. Contact: anahigm75@gmail.com

Marco Antonio Gavério is a PhD student at the Pos-Graduate Program in Sociology, at the Federal University of São Carlos (UFSCar), in São Carlos, Brazil. Researcher of the group Sexualidade, Entretenimento e Corpo (SEXent), at the UFSCar's Department of Sociology. ORCID: 0000-0002-0744-3520. Contact: marcaosemacento@gmail.com

\section{Notas}

1. This term lies critically on to the obligation of women to undergo a heterosexual relationship and maternity.

2. Going further, crip theory aligns with the premises of symmetrical anthropology, since the symmetrical thinking point of departures the construction of a conceptual apparatus that reconfigures anthropology and for it uses concepts that overcome dualistic renderings of the world, such as network, symmetry, multinaturalism, relationship.

3. Free translation.

4. This long braid works as "nerve terminal" for communication, transmission and sharing of feelings, practices and traditional knowledge among the $\mathrm{Na}$ 'vi and their ancestors, the animals, plants, in short, everything that exists in Pandora.

5. Free translation.

6. The Na'vi preserve their beliefs, customs and traditions and are religiously attached to their land, considered the abode of their goddess Eywa. In this sense, in Pandora everything and everyone is connected to Eywa, through a network of energy that connects all living beings.

7. Free translation.

8. Free translation.

9. Free translation.

10. For a good introductory text on perspectivism, see Bruno Latour (2009).

11. Note: in Brazilian Portuguese language, "cadeirante" does not have the same sense of "wheelchair user" in English. "Cadeirante" is a native category widely used in Brazil. "Wheelchair user" may be translated in Portuguese as "usuário de cadeira de rodas" as if the chair were separated from the person. Already "cadeirante" is the embodiment of the chair to the person. Thus, the term "cadeirante" combines and transforms the chair and the person into a single thing, as a cyborg. In this sense, the chair is a person because it's an extension of the user's body.

12. Regarding other ruptures mentioned by Haraway that erupt through the cyborg are: the breaking of the modern western boundaries between 'human and animals' and within the limits of the 
'physical and non-physical'. For a feminist-queer-crip analysis of this work of Haraway and some of its developments in Disability Studies, see Kafer (2013:103-128)

13. See too Eli Clare (2001, p. 361): "Let me begin with my body, my disabled queer body. I use the word queer in both of its meanings: in its general sense, as odd, quirky, not belonging; and in its specific sense, as referring to lesbian, gay, bisexual, and transgender identity. In my life, these two meanings have often merged into one. Queer is not a taunt to me, but an apt descriptive word. My first experience of queerness centered not on sexuality or gender, but on disability. Early on, I understood my body to be irrevocably different from those of my neighbors, playmates, siblings. Shaky: off-balance; speech hard to understand; a body that moved slow, wrists cocked at odd angles, muscles knotted with tremors. [...] Only later came gender and sexuality. Again I found my body to be irrevocably different."

14. Free translation

15. And here the inversion of the north-south poles occurs in the regional geopolitics of Brazil, where the "southern states", represented by the south, are more economically and politically "evolved" than the "northern states," represented by the northern and nor theastern regions

\section{References}

ANZALDÚA, Gloria. 1987. Borderlands/La Frontera: the new mestiza. San Francisco: Aunt Lute Books Press.

ANZALDÚA, Gloria. 2005. "La consciencia de la mestiza/Rumo a uma nova consciência". Revista Estudos Feministas, v. 13, n. 3, p. 704-719.

CAMERON, James. 2009. Avatar. Los Angeles, CA: Twentieth Century-Fox, 2010, DVD.

BARCELOS NETO, Aristóteles; RAMOS, Danilo; BÜHLER, Maíra Santi; SZTUTMAN, Renato; MARRAS, Stelio; MACEDO, Valéria. 2006. “Abaeté, rede de antropologia simétrica: entrevista com Marcio Goldman e EduardoViveiros de Castro”. Cadernos de Campo, 15, n. 14-15, p. 177-190.

BENTES, Ivana. 2010, "Eu vejo você: antropologia reversa em Avatar, ciber-índios, pós-cinema ou como arrancar um pensamento complexo dos clichês”. In: FELINTO, Erick; BENTES, Ivana (eds.). Avatar: o futuro do cinema e a ecologia das imagens digitais. Porto Alegre: Sulina. p. 55-119.

BUTLER, Judith. 1990. Gender trouble: feminism and the subversion of identity. New York: Routledge. BUTLER, Judith. 1993. Bodies that matter: on the discursive limits of "sex". New York: Routledge.

BUTLER, Judith. 2004. Undoing gender. New York: Routledge.

CLARE, Eli. 2001. "Stolen bodies, reclaimed bodies: disability and queerness". Public Culture, v. 3, n. 3, p. 359-365.

CONNELL, Raewyn. 2011. "Southern bodies and disability: re-thinking concepts". Third World Quarterly, v. 32, n. 8, p. 1369-1381.

COUFFIGNAL, Louis. 1968. La Cybernétique. 3. ed. Paris: Presses Universitaires de France.

DAVIS, Lennard J. 1995. Enforcing normalcy: disability, deafness, and the body. London; New York: Verso.

DERRIDA, Jacques. 1998. Of Grammatology. Translated by Gayatri Chakravorty Spivak. Baltimore: 
John Hopkins University Press.

DOUGLAS, Mary. 1966. Purity and Danger: an analysis of the concepts of pollution and taboo. London: Routledge.

ECKERT, Richard C.; ROWLEY, Amy J. 2013. "Audism:A theory and practice of audiocentric privilege”. Humanity \& Society, v. 37, n. 2, p. 101-130.

ELLIS, Carolyn. 2004. The ethnographic I: a methodological novel about autoethnography. Walnut Creek, CA: AltaMira Press.

ELLIS, Carolyn; BOCHNER, Arthur P. 2000. Autoethnography, Personal Narrative, Reflexivity: researcher as subject. In.: DENZIN, Norman K.; LINCOLN, Yvonna S. (Eds.). 2. ed. Handbook of qualitative research. Thousand Oaks: Sage Publications.

FOUCAULT, Michel. 1990. The history of sexuality.V. 1: an introduction. New York: Vintage Books.

FOUCAULT, Michel. 1992. A escrita de si. In.: FOUCAULT, Michel. O que é um autor? Lisboa: Passagens.

GARLAND-THOMSON, Rosemarie. 1997. Extraordinary bodies: figuring physical disability in American culture and literature. New York: Columbia University Press.

GARLAND-THOMSON, Rosemarie. 2009. Staring: how we look. New York: Oxford University Press.

GIL, José. 1994. Monstros. Lisboa: Quetzal Editores.

GOFFMAN, Erving. 1963. Stigma: notes on the management of spoiled identity. New York: Simon and Schuster.

HA'AM, Boaz A. 2017. "Deafness as disability: countering aspects of the medical view". Public Reason, v. 9, n. 1-2, p. 79-98.

HARAWAY, Donna Jeanne. 1987. "A manifesto for cyborgs: science, technology, and socialist feminism in the 1980". Australian Feminist Studies, v. 2, n. 4, p. 1-42.

HOLMAN JONES, Stacy. 2005. Autoethnography: making the personal political. In.: DENZIN, Norman K.; LINCOLN, Yvonna S. (eds.). 3rd ed. Handbook of qualitative research. Thousand Oaks: Sage Publications.

KAFER, Alison. 2013. Feminist, Queer, Crip. Bloomington: Indiana University Press.

LATOUR, Bruno. 2009. “Perspectivism: 'type' or 'bomb”?". Anthropology Today, v. 25, n. 2, p. 25.

LÉVI-STRAUSS, Claude. 1989. O pensamento selvagem. Campinas: Papirus.

LOURO, Guacira Lopes. 2001. "Teoria Queer: uma política pós-identitária para a Educação”. Revista Estudos Feministas, v. 9, n. 2, p. 541-553.

MAIRS, Nancy. 2001. Waist-high in the world: a life among the nondisabled. Boston: Beacon Press.

MCRUER, Robert. 2002. "Compulsory able-bodiedness and queer/disabled existence". In: SNYDER, Sharon L.; BRUEGGEMANN, BRENDA J.; GARLAND-THOMSON, Rosemarie (Eds.), Disability studies: enabling the humanities. New York: Modern Language Association of America.

MCRUER, Robert. 2006. Crip Theory: cultural signs of queerness and disability. New York: New York University Press.

MEEKOSHA, Helen. 1999. "Superchicks, clones, cyborgs, and cripples: cinema and messages of bodily trans- 
formations”. Social Alternatives, v. 18, n. 1, p. 24-28.

MISKOLCI, Richard. 2009. "A teoria Queer e a sociologia: o desafio de uma analítica da normalização”. Sociologias, n. 21, p. 150-182.

MURPHY, Robert F. 1987. The body silent: the different world of the disabled. New York: Henry Holt and Company.

OlIVEIRA, Adriano Messias de. 2011. "De Avatar à Centaura Mexicana: o monstro e o monstruoso na produção de sentidos da América quinhentista”. Paper presented at the $1^{\circ}$ Congresso Mundial de Comunicação Íbero-Americana, São Paulo, SP. p. 1-6.

OLIVEIRA, Everton Luiz de. 2016. "Pô, tô vivo véio!": história de vida e sexualidade de pessoas com deficiências físicas. Tese [Doutorado em Educação Física]. São Carlos: Universidade Federal de São Carlos.

PFEIFFER, David. 1999. "The categorization and control of people with disabilities". Disability and Rehabilitation, v. 21, n. 3, p. 106-107.

PUAR, Jasbir K. 2012. "I would rather be a cyborg than a goddess”: becoming-intersectional in assemblage theory”. PhiloSOPHIA: A Journal of Continental Feminism, v. 2, n. 1, p. 49-66.

RICH, Adrienne. 1980. "Compulsory heterosexuality and lesbian existence”. Signs: Journal of Women in Culture and Society, v. 5, n. 4, p. 631-660.

SILVA, Tomaz Tadeu (org.). 2000. Pedagogia dos Monstros - os prazeres e os perigos da confusão de fronteiras. Belo Horizonte: Autêntica.

STIKER, Henri-Jacques. 1999. A history of disability. Ann Arbor: University of Michigan Press.

VIVEIROS DE CASTRO, Eduardo. 1996. “Os pronomes cosmológicos e o perspectivismo ameríndio”. Mana, v. 2, n. 2, p. 114-144.

VIVEIROS DE CASTRO, Eduardo. 2002. “O nativo relativo”. Mana, v. 8, n. 1, p. 113-148. 
Facts of cripness to the Brazilian: dialogues with Avatar, the film

Abstract: The influence of queer theory on the humanities is also reflected in disability studies, contributing to the emergence of crip theory. While the main axiom of queer theory postulates that contemporary society is governed by hetero-cis-normativity, crip theory is supported by the socially constructed postulate of compulsory able-bodiedness that is not very sensitive to the body's diversity. The translation of the term crip into the category of crippled in Portuguese (i.e. aleijado) is a way of giving the same sense of the word in English, indicating an area reserved for people with disabilities. Considering that gay and lesbian studies initially focused their investigations on the question of homosexuality being a "natural" or "unnatural" behavior, remaining within a binary logic, queer theory expands the investigative focus by encompassing any kind of sexual practice or identity that circumscribes normative or deviant categories. From this perspective, disabled bodies are also queer. The objective of this work is to discuss the analytical and intersectional potential of a queer/crip epistemology in the constitution of disability experience from the "global south", based on autoethnographic accounts and analysis of the Avatar movie.

Key Words: disability, crip theory, queer theory,epistemologies of the south.
Fatos da aleijadice à brasileira: diálogos com Avatar, o filme

Resumo: A influência da teoria queer nas humanidades também se refletiu nos estudos sobre deficiência, contribuindo para a emergência da teoria crip. A teoria queer postula que a sociedade contemporânea é regida pela hetero-cis-normatividade, enquanto na teoria crip a crítica está no postulado da corponormatividade de nossa estrutura social pouco sensível à diversidade corporal. A tradução do termo crip para aleijado em português é uma forma de dar o mesmo sentido da palavra em inglês, desvelando a zona de abjeção reservada às pessoas com deficiência. Considerando que os estudos gays e lésbicos inicialmente focaram suas investigações na questão da homossexualidade ser um comportamento "natural" ou "antinatural", permanecendo dentro de uma lógica binária, a teoria queer expande o foco investigativo ao abarcar qualquer tipo de prática sexual ou identidade que estejam na fronteira de categorias normativas ou desviantes. Desde essa perspectiva, os corpos deficientes também são queer. O objetivo deste trabalho é discutir, a partir de relatos autoetnográficos e da análise do filme Avatar, o potencial analítico e intersecional de uma epistemologia queer/crip na constituição da experiência da deficiência desde o "sul global".

Palavras-chave: deficiência, teoria crip, teoria queer, epistemologias do sul. 
66 


\title{
Deficiência como categoria analítica: Trânsitos entre ser, estar e se tornar
}

\author{
Pedro Lopes \\ Universidade de São Paulo - Brasil
}

Neste texto percorro questões levantadas pelo uso da noção de deficiência em pesquisas sociológicas e antropológicas, com vistas a apresentar argumentos pelo seu emprego como categoria analítica. Parto da descrição de uma cena que vivi, realizando trabalho de campo em uma empresa de lazer voltada a "pessoas especiais” sediada em São Paulo, e lanço mão de alguns debates clássicos e atuais sobre deficiência no cenário brasileiro e estadunidense para discutir traduções e trânsitos nacionais e internacionais na compreensão desse fenômeno. ${ }^{1}$

$* \quad * \quad *$

Entre 2008 e 2013, realizei trabalho de campo em uma empresa que organizava passeios aos finais de semana a diversos destinos culturais e de lazer em São Paulo, para um público “especial”, e viagens de férias a destinos próximos nos meses de julho e janeiro. De modo esquemático, participavam das atividades homens e mulheres entre 20 e 65 anos - com uma concentração entre 35 e 45 anos -, em sua maioria pessoas brancas, de classe média a alta e que dispunham de razoável autonomia no deslocamento físico - apenas uma frequentadora da empresa contava com o apoio de braços de colegas ao andar. Em torno desse padrão, o público era muito variado em suas trajetórias pessoais e familiares, suas capacidades ou habilidades, cotidianos, anseios e desejos. Outra linha importante na descrição desse contexto é a ausência de uma articulação militante no discurso da empresa e na voz da imensa maioria de participantes. A categoria utilizada de modo mais geral para nomear a especificidade de seu público era "especial”, e quase nunca ouvi ou li menção ao termo deficiência intelectual em campo. ${ }^{2}$

Como se pode notar, opto aqui por grafar uma diferença textual entre a noção de deficiência intelectual, sem marcações, e "especial” ou "pessoa especial”, entre aspas. Trata-se de uma escolha baseada na assunção de um posicionamento não só como autor e antropólogo, mas também sujeito político implicado no debate sobre deficiência $^{3}$. Deficiência intelectual foi o termo acordado internacionalmente a partir da 
Declaração de Montreal, de 2004, que objetivava especialmente diferenciar configurações corporais que diriam respeito ao intelecto (ou seja, relacionadas a alguma forma de aprendizagem de habilidades cotidianas) de questões de ordem mental (que se entende relacionadas a configurações mais amplas da mente e psique) ${ }^{4}$. Enquanto se tende por descrever, a partir de uma mirada biomédica, a noção de "transtorno mental" como "anormalidade" ou "desvio", a deficiência intelectual é imaginada em termos de "falta" ou "insuficiência". Não subscrevo tais definições na medida em que me parece que não compete à nossa disciplina uma compreensão tão cindida entre corpo, mente e relações sociais. No entanto, a noção de deficiência intelectual é utilizada nacional e internacionalmente como categoria de nomeação para coletividades que trabalham pela defesa dos direitos desses sujeitos. Destaco, portanto, que, na minha perspectiva, a melhor pergunta que podemos fazer não é ir atrás de uma definição a priori dessas categorias, mas uma compreensão etnográfica: acompanhar como elas são empregadas nas relações sociais.

"Especial" é uma categoria com outra historicidade. Trata-se de um termo que prolifera junto às Apaes no Brasil, as Associações de Pais e Amigos dos Excepcionais, originalmente nomeando pessoas com corporalidades variadas do ponto de vista das definições acima apresentadas. Esse era o sentido de "especial” no caso da empresa junto à qual trabalhei: lá conheci tanto pessoas com síndrome de Down, o diagnóstico mais emblemático associado à deficiência intelectual, quanto esquizofrenia ou autismo, categorias chave da saúde mental. Já há tempo que os termos “especial” ou "excepcional” são rejeitados pelos movimentos sociais e organizações de defesa de direitos.

Além das disputas pelo termo adequado, estamos também tratando de categorias que derrapam rapidamente entre os registros do que chamamos de êmico e analítico: as pessoas junto a quem eu trabalhava na empresa, seriam elas pessoas com deficiência ou "pessoas especiais" e a quem cabe escolher qual é o termo de nomeação adequado? Certamente a antropologia nos convida a pensar que é dos contextos que emerge a resposta. Na verdade, não exatamente dos contextos, mas da etnografia, que é outra coisa: dizia-se que "não viramos nativos". Se etnografia traz consigo categorias analíticas, além daquelas êmicas que encontra nos contextos de pesquisa, sugiro que deficiência pode ser experimentada como uma categoria analítica, um termo do qual podemos e até devemos lançar mão nas nossas descrições das paisagens sociais que pesquisamos. Por isso, opto aqui por seguir grafando entre aspas aquelas categorias que entendo emergirem dos contextos de pesquisa - sejam 
eles chamados etnográficos ou bibliográficos -, que não são os termos a partir dos quais eu descreveria os universos que encontrei. Com esse procedimento, opero um deslizamento cruzado: não se trata de usar aspas para diferenciar categorias êmicas de analíticas, mas, tomando-as todas em suas dimensões êmicas (seja na voz da militância, seja na voz da academia, por exemplo), marcar com aspas aquelas que, deste meu ponto de vista analítico e político, não se prestam à melhor descrição ou reflexão sobre os contextos de pesquisa.

Feitos esses apontamentos, vamos à cena. Apresento a relação que estabeleci com uma das pessoas que frequentavam a empresa, que chamo aqui e em outros textos de Henrique. Eu nunca soube sua idade exata, mas Henrique me parecia ter entre 30 e 40 anos. Ele era uma das pessoas mais assíduas nos passeios da empresa, e sua forma de interagir com colegas havia me chamado atenção desde meu primeiro encontro com o grupo, pois, apesar de sua frequência nas atividades, Henrique praticamente não se engajava em conversas. Ele tinha um vocabulário extremamente reduzido, articulando pouquíssimas palavras - seu bordão era "gordo" ou "gorda", que utiliza como provocação jocosa constante e como modo de propor breves interações com colegas, em geral quase sem pronunciar o som de R. Mesmo assim, ele compreendia as perguntas que lhe eram feitas e escutava bem os comentários e conversas durante os passeios e refeições.

A restrição de linguagem de Henrique, ou melhor, a restrição de vocalização, articulava-se de modo peculiar à sua assiduidade nos encontros, permitindo-lhe ocupar um espaço de carinho e reconhecimento por todas e todos, que, com alguma condescendência, gostavam de lhe fazer elogios ou retrucar suas provocações e brincadeiras. Era frequente que, após alguma refeição coletiva, Henrique levantasse de seu lugar e passasse a circular pelas mesas fazendo suas habituais provocações, dando risada, ou ouvindo conversas mesmo sem verbalizar sua participação nelas.

Desde minha entrada nesse campo, eu havia tentado interagir com Henrique mais demoradamente em diversas ocasiões e era em geral respondido com um sorriso aberto ou uma risada, seguidos por uma virada de cabeça ou seu afastamento de perto de mim, como se minhas tentativas de uma interlocução mais demorada o incomodassem - também, às vezes, eu era simplesmente ignorado.

Em 2010, acompanhei o grupo em uma viagem de uma semana a um hotel-fazenda no interior de Minas Gerais. Muitas das atividades que realizamos lá requeriam o deslocamento de carro, e os traslados eram momentos de conversa mais prolongada. Conforme fui me dando conta, nesses momentos, havia pequenas disputas 
por ocupar o lugar da frente nos carros, ao lado do ou da motorista, por razões diversas - preferência pessoal, possibilidade de manejar o rádio e escolher CDs, conversar mais detidamente com quem dirigia, ocupar uma posição espacial de destaque etc. Decidi, então, convidar Henrique a me acompanhar na fila de frente e ele aceitou alegre. No carro, fiz algumas tentativas de conversar especificamente com ele, dirigindo-lhe algumas perguntas sobre o que ele estava pensando da viagem, ao que ele respondeu bem, mas percebi sua ansiedade em terminar logo com aquele tipo de interação. Com mais cautela, segui convidando-o para me acompanhar no banco da frente e pude notar que o próprio convite bem como a proximidade espacial durante os trajetos de carro já mudavam a forma como ele respondia a mim. Algumas vezes, alguém no carro proferia algum comentário engraçado, todas e todos compartilhávamos a risada, e eu fazia alguma pequena observação reiterativa a Henrique, como "essa foi boa", e notava maior tranquilidade em me olhar nos olhos e concordar.

Voltamos de Minas Gerais com Henrique me acompanhando no assento da frente. A partir dessa viagem, ele começou inclusive a me procurar para interagir. Várias vezes - repetidamente -, Henrique me mostrou sua carteira do Corinthians, e pude estabelecer com ele algumas conversas, a partir de perguntas minhas e respostas negativas ou afirmativas suas, geralmente sobre futebol - tema que, por sinal, eu absolutamente não domino. Em um passeio, já em março de 2012, fui designado a buscá-lo em casa. Marcos (pseudônimo que atribuí ao dono da empresa) era quem bolava os itinerários de monitoras e monitores nos passeios e estabelecia os horários de chegada em cada casa para buscar participantes. Geralmente, Henrique era buscado pelo próprio Marcos - e acredito que sua confiança e tranquilidade na relação com Marcos pesavam nessa decisão, além da localização de sua casa. O caso é que, na volta do passeio, aconteceu algo que marcou muito minha relação com Henrique e minha percepção da temática da deficiência - o que abre espaço para uma discussão sobre essa categoria.

Estávamos no carro eu, Henrique e Maurício. A conversa com Maurício também tinha uma temporalidade específica: sua articulação oral me deixava confuso e eu tinha de perguntar muitas vezes pelo que ele falava, ao que ele respondia com bastante gentileza. Maurício verbalizava um repertório restrito de palavras, embora mais farto que o do colega: com vagar, ele chegava a contar histórias bem completas, ao passo que Henrique em geral verbalizava somente seus bordões provocativos "gordo" e "gorda" e respostas rápidas a perguntas: "sim”, "não”, "suco", "guaraná”. 
Assim, quando nos aproximávamos da casa de Henrique - por um caminho que eu tivera de consultar um mapa para traçar, e com o qual não estava familiarizado Maurício falou uma palavra que demorei muito a entender: "Diadema" (município que faz fronteira com São Paulo). Comecei a perguntar-lhes informações sobre a região e ambos foram me contando que estávamos perto do município vizinho e que alguns dos ônibus que passavam por nós iam para lá. Comentei com Henrique que o caminho para sua casa tinha me deixado um pouco confuso quando o fora buscar. Em nossa conversa, mais uma vez prioritariamente conduzida por minhas perguntas e breves respostas dele, Henrique me contou que sabia um caminho mais simples que aquele que eu planejara. Segui suas instruções e rapidamente chegamos à sua casa.

Naquele momento, o desfecho desse caso surpreendeu-me especialmente por me dar conta das informações, memórias e habilidades que Henrique manifestou dominar, ao contrário do que eu supunha - eu, de meu corpo sem deficiência, apesar de marcado pela convivência desde meu nascimento com familiares com deficiência. Passado um tempo, conclui que esse dar-se conta dependia do estabelecimento da relação de interlocução e abertura que fomos construindo - sem confiar que ele pudesse saber o caminho de casa, eu jamais verificaria que ele de fato o sabia, sem confiar na minha escuta, ele jamais teria oferecido guiar-me. Partindo de um encontro marcado por muita resistência e evitação, pudemos ir abrindo espaços de reciprocidade e acabei percebendo que muito do que eu não notara na forma como Henrique habitava o mundo tinha mais a ver com pressupostos capacitistas ${ }^{5}$ acerca do que eu supunha serem "restrições de linguagem" que com suas possíveis habilidades, recursos ou competências. ${ }^{6}$

Entre a antropologia e os estudos sobre deficiência, ou Disability Studies, a cena exposta pode ser analisada de muitos modos. Acredito que os atuais horizontes de debate sobre deficiência oferecem ferramentas e levantam problemáticas interessantes, que percorro a seguir. Para começar, faço mais algumas pontuações sobre a distinção entre tomar deficiência como categoria êmica e categoria analítica.

De saída, sublinho que, no contexto em caso, deficiência não emerge como categoria êmica. Alguns termos como "ter problema" ou "dificuldade" eventualmente eram acionados por outros sujeitos para fazer referência a Henrique e suas "limi- 
tações de fala". Suas possibilidades de interação eram pautadas por uma linguagem de afeto e condescendência que ora o marcavam como extremamente querido no grupo, ora o colocavam em posição infantilizada ou cômica ${ }^{7}$. Desse modo, pensar deficiência como chave de análise e atentar para as categorias êmicas relacionadas pode nos levar a uma reflexão acerca dos modos de relação e do posicionamento que Henrique ocupava em função de suas "capacidades” e "limitações” específicas, seus "problemas" e seu perfil "engraçado".

Nessa linha, recordo falas de colegas dos passeios, que comentavam, por exemplo, que "cada um tem a sua dificuldade, não podemos julgar o Henrique", ou “o Henrique não fala nada, mas é muito engraçado”. Lançando mão dos recursos vocais e de linguagem corporal de que dispunha, Henrique negociava um reconhecimento ambíguo de seu pertencimento a esse coletivo. Era constante flagrá-lo, em suas perambulações pelo grupo, tirando sarro de pessoas que, diferente dele - que comia pouco e tinha um porte magro -, repetiam pratos mesmo estando sempre em dietas para reduzir a gordura corporal.

Esse posicionamento de Henrique em um grupo no qual ele se destacava por apresentar uma das mais "severas restrições verbais e de vocabulário" chama atenção quando comparado com outros sujeitos que, apresentando corporalidades e habilidades marcadas por "menos restrições”, tinham muita dificuldade de se engajar em interações e desfrutar do tempo de sociabilidade aos finais de semana. Desse modo, o caso de Henrique parecia-me operar uma inversão de expectativas (expectativas minhas que derivavam "naturalmente" de sua corporalidade uma experiência de restrição): ao ser uma das pessoas com maiores "dificuldades", ele se apresentava também como um dos sujeitos mais "queridos" e, de fato, inserido nas interações e cenas de sociabilidade.

Investigar as noções de "problema" ou "dificuldade" como categorias êmicas talvez levasse a um debate sobre antropologia dos corpos e corporalidades, de modo semelhante à investigação que Peter Torres Fremlin (2011) realizou entre "chumbados”. Esse caminho pode significar abrir mão de deficiência como categoria organizativa do campo, ou como categoria analítica. Vale observar o percurso de Fremlin nesse sentido. Trago a este texto uma citação mais longa de trechos que descrevem o enquadramento do trabalho do autor pela sua eloquência em explicitar o ponto:

Neste trabalho, afastar-me-ei da categoria "deficiência física", mas a pesquisa fica necessariamente marcada pela forma com que foi concebida e o ambiente em que 
foi realizada. Minha entrada no campo foi determinada pelas visões de "deficiência física"; algumas delas visões minhas, outras fora do meu controle. Concebia "deficiência física" como uma chave legítima para comparar situações diversas. Queria ter em mãos uma etnografia que buscasse pessoas ligadas e não ligadas a redes relacionadas com "deficiência física”: e esse pressuposto, sem eu estar totalmente consciente disso, definia pessoas, redes e minhas interpretações delas em termos desta categoria (Fremlin, 2011, p. 1-2).

E agora, depois de viajar tão longe com ela, vou aposentar a categoria "deficiência física". [...] Não se trata da "deficiência" de uma pessoa, ou como essa "deficiência" é construída, mas de desenvolver uma visão para entender corpos e seus movimentos que não se limite à noção de "deficiência”. Chamo essa visão mais ampla de “corporalidades”. Corporalidades são o assunto desta dissertação, e a percepção a seu respeito é a maneira através da qual eu apresento meu campo. Definirei corporalidades como conjunções entre corpos, objetos e palavras (idem, p. 4-5).

"Deficiência física" traz com ela pressupostos de como corporalidades se manifestam, o que, para meus fins, seria responder à pergunta ao formulá-la. [...] a noção de corporalidades não pretende ser universal, mas sim extensível para pensar corpos diferentes em situações diferentes. [...] Desenvolverei o texto fazendo mais referência a antropologias do corpo do que a trabalhos acadêmicos específicos sobre "deficiência" (idem, p. 7).

Em seu trabalho, portanto, embora "deficiência física” tenha sido a categoria operativa que o levou a um recorte do campo, ela não funciona como categoria analítica na discussão sobre corporalidades. A categoria êmica que organiza a reflexão de Fremlin, então, é "chumbado", enquanto a noção de corporalidades é tomada como categoria analítica.

$\mathrm{Na}$ minha leitura, Fremlin abandona deficiência como categoria analítica e a relega ao campo êmico por entender que corporalidades podem ser mais variadas ou diversas que a situação de deficiência, ou que o termo deficiência nos pode nomear. Concordo com o autor em certa medida, mas creio que está em jogo aí uma disputa justamente por definirmos o que nomeamos pelo termo deficiência. Meu esforço, e aqui reitero o diálogo com muitas e muitos colegas de pesquisa (Mello \& Nuernberg, 2012; Mello, 2016; Mello, Nuernberg \& Block, 2014; Gavério, 2015, 2017; Simões, 2014, 2017; Fietz, 2017; Aydos, 2016; Dias, 2013; von der Weid, 2017; além do próprio Fremlin, 2011) é por pensar justamente deficiência como uma categoria que também possa nomear o que Fremlin chama de 
corporalidades, ou organizar nossos campos de pesquisa e reflexão.

No trabalho com marcadores sociais da diferença, Anne McClintock (2010) nos alerta que eles não se encaixam como Lego. Racismo, machismo, homofobia e capacitismo, para citar algumas noções desse universo, são fenômenos articulados, mas não homólogos. Por outro lado, e exatamente em função de sua articulação constitutiva, as comparações - ora por aproximação, ora distanciamento, ora complementaridade etc. - entre raça, gênero, sexualidade e deficiência são produtivas. A que sugiro reter aqui é justamente esta: nesses outros sistemas classificatórios temos um termo abrangente que nomeia o sistema e categorias hierarquizadas que o descrevem, de modo mais ou menos binário, por exemplo: raça nomeia um sistema classificatório, as classificações negra e branca distribuem-se hierarquicamente, eventualmente incorporando-se no Brasil indígena ou asiática. No caso de deficiência, sugiro que o termo marcado, o polo hierarquicamente desprivilegiado, pode ser usado - ou mesmo tem sido - para nomear o sistema classificatório ${ }^{8}$.

Isso significa operar uma certa torção na percepção do que é corpo. Não se trata exatamente de pensar que o corpo é algo com plasticidade, socialmente moldado (Mauss, 2003), mesmo quando se leva em conta que essa modelagem social é de saída hierárquica (Hertz, 1980), ou algo eminentemente sociológico e político (Douglas, 1991). Em alguma medida, a sugestão é por abandonar o corpo, ou pensá-lo, de saída, no registro da diferença - na minha leitura, o que Marco Antonio Gavério chama de "complicar provocativamente os nossos próprios 'locais de nascimento"” (2017, p. 113). Movendo-se nessa direção, Adrienne Rich escreve, em 1984, um texto chamado "Notas por uma Política de Localização", e defende:

Talvez precisemos de uma moratória para a expressão "o corpo". [...] Quando eu escrevo "o corpo", eu não vejo nada em particular. Ao escrever "meu corpo", eu mergulho em experiências vividas, particularidade: eu vejo cicatrizes, desfigurações, descolorações, danos, perdas, assim como vejo o que me dá prazer. [...] Pele branca, marcada e com cicatrizes de três gravidezes, uma esterilização eletiva, artrite progressiva, operações em quatro juntas, depósitos de cálcio, nenhum estupro, nenhum aborto, longas horas em uma máquina de escrever [...] e assim por diante (1986, p. 215).

O fragmento acima assinala que o debate sobre corporalidades pode sinalizar uma experiência em um registro da diferença. Contudo, a vocação universalista da noção de corpo, em relação à qual Fremlin registrava um incômodo (que compar- 
tilho), de fato não é gratuita: "o corpo" parece ser aquilo que emerge da norma biopolítica, um efeito dos trabalhos de disciplinamento, medição e condicionamento sobre os quais tanto escreveu Michel Foucault - ou seja, a norma, que se insiste em se apresentar como universal ou natural ${ }^{9}$. Os sinais que Rich escolhe para narrar seu corpo nitidamente aludem a sua trajetória como mulher feminista, branca, acadêmica e que enfrenta a passagem do tempo e as marcas que ela traz a seu corpo - eu diria, sinais de deficiência. Nesse caso, corpo é o substrato social no qual se constituem as articulações entre raça, gênero, sexualidade e deficiência ${ }^{10}$.

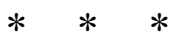

$\mathrm{Na}$ direção de compor o argumento por tomar deficiência como categoria analítica, traço a seguir um percurso exploratório por algumas questões que inspiram e oferecem recursos para tanto.

Um mito de origem já tornado clássico do campo internacional dos Disability Studies parte do que ficou conhecido como modelo social da deficiência, elaborado nesses termos por Michael Oliver em 1983, na esteira dos debates realizados pela Union of Physically Impaired Against Segregation (UPIAS) na Inglaterra. A proposta de um modelo social opunha-se originalmente a um modelo individual, que mais tarde veio a ganhar maior notoriedade como modelo médico ${ }^{11}$. Esses modelos são esquemas de trabalho elaborados por Oliver para dar consequência à distinção elaborada pela UPIAS entre disability e impairment, que têm sido traduzidos para o português como deficiência e lesão ou impedimento (ver, por exemplo, Diniz, 2007, ou Mello \& Nuernberg, 2012). O primeiro termo faria referência ao fenômeno social de exclusão e opressão de pessoas com corpos com formatos e funcionalidades diversas, ao passo que o segundo expressaria o fenômeno da variação (ou "dano") corporal.

Os debates a partir do modelo social da deficiência caminham em muitas direções e transitam entre diversos países. De certo modo, é possível destacar o modelo social como um nó de linguagem que agrega e organiza movimentos sociais e a elaboração de políticas, mas também alinha interpretações sociológicas da deficiência (Blume \& Hiddinga, 2010). Ao ser chamado de “modelo", essa compreensão da deficiência passou a ser incorporada como um referencial teórico, ultrapassando o caráter pragmático de sua formulação inicial, conforme argumenta Tom Shakespeare: 
[...] ao identificar as barreiras sociais a ser removidas, o modelo social tem sido instrumentalmente efetivo na luta das pessoas deficientes [no original, disabled people]. Michael Oliver argumenta que o modelo social é uma "ferramenta prática, não uma teoria, uma ideia ou um conceito" $(2004, \text { p. 30) })^{12}$. A simplicidade que marca o modelo social também é sua maior falha. Os seus benefícios como slogan e ideologia política também são suas desvantagens para uma reflexão acadêmica sobre deficiência. [...] Certamente, se a UPIAS incluísse pessoas com deficiência intelectual [no original aparece a terminologia britânica, people with learning disabilities], problemas de saúde mental ou com impedimentos físicos mais complexas [no original, physical impairments], ou seja, experiências mais diversas ou mais representativas, ela não poderia ter produzido uma compreensão tão estreita da deficiência (ênfase original. Shakespeare, 2010, p. 269) ${ }^{13}$.

Um dos problemas mais imediatos que será notado nos trabalhos subsequentes, que fazem uma revisão crítica da fórmula do modelo social é a oposição discreta e definitiva entre natureza e cultura, corpo e sociedade. Inspiradas pelos debates sobre a distinção entre sexo e gênero, muitas pesquisadoras e pesquisadores vêm revendo o uso político da distinção entre deficiência ou disability e lesão ou impairment. Argumento semelhante encontra-se nos estudos de gênero, que de fato inspiram a elaboração do modelo social. Nesse sentido, por exemplo, Judith Butler argumenta:

Não se pode, de forma alguma, conceber o gênero como um constructo cultural que é simplesmente imposto sobre a superfície da matéria - quer se entenda essa como o "corpo", quer como um suposto sexo. Ao invés disso, uma vez que o próprio "sexo" seja compreendido em sua normatividade, a materialidade do corpo não pode ser pensada separadamente da materialização daquela norma regulatória. O "sexo" é, pois, não simplesmente aquilo que alguém tem ou uma descrição estática daquilo que alguém é: ele é uma das normas pelas quais o "alguém” simplesmente se torna viável, é aquilo que qualifica um corpo para a vida no interior do domínio da inteligibilidade cultural (2001, p. 152).

Na esteira dessa compreensão, por exemplo, Rosemarie Garland-Thomson (2010) argumenta que a distinção entre deficiência e lesão é frágil. A lesão, o impedimento, o corpo lido como "em falta" é assim compreendido de saída por uma sociedade que recusa determinados formatos e funcionalidades corporais, não emanaria da configuração corporal "em si” (ver também McRuer, 2006). 
Na mesma direção de crítica à distinção ente corpo e sociedade no modelo social, Débora Diniz (2003) sintetiza discussões feministas que percebem o corpo não apenas em termos de eficiência, mas também sofrimento. Se, como diz Veena Das, o olho não é apenas o órgão que vê, mas também o órgão que chora (2011, p. 15), o corpo também pode ser pensado como o lugar das experiências de dor, fadiga, perda de memória, degeneração muscular - o espaço próprio da dor ou também do prazer, e não apenas da funcionalidade, eficiência, trabalho. Salientar essas experiências corporificadas para além de uma compreensão do corpo como um instrumento para a participação social, produz ruído no modelo social. Como descreve Diniz,

o argumento do modelo social era o de que a eliminação das barreiras mostraria a capacidade e a potencialidade produtiva dos deficientes, uma ideia duramente criticada pelas feministas. A sobrevalorização da independência poderia ser um ideal perverso para inúmeros deficientes incapazes de alcançá-la. [...] Foram as feministas que mostraram o quanto o modelo social era uma teoria desencarnada da lesão, uma fronteira impossível de ser sustentada em qualquer caso, mas especialmente quando se incluíam lesões provocadas por doenças crônicas ou por lesões intelectuais (2003, p. 4-5).

Esse conjunto de críticas vem sendo incorporado de diferentes maneiras entre aqueles que lançam mão de deficiência ou disability como categorias que organizam seus campos. Sinalizo duas tendências.

Em primeiro lugar, as antropólogas Faye Ginsburg e Rayna Rapp (2013) sugerem um uso intercambiável entre disability e impairment. Essa sugestão está presente em um artigo de revisão dos trabalhos antropológicos sobre deficiência, publicado na prestigiada Annual Review of Anthropology (n. 42) - que apresentou pela primeira vez, em 2013, uma revisão organizada a partir do termo deficiência e não outras categorias mais ou menos aparentadas, como surdez ou autismo. O argumento das autoras é sucinto, mas faz referência a um debate que se acumula: "[...] a relação entre limitações corporificadas [no original, embodied limitations] e discriminação social segue complexa e duradoura" (Ginsburg \& Rapp, 2013, p. 54).

A segunda tendência que identifico é uma certa substituição da noção de lesão ou impedimento por diversidade ou variação - no limite, uma culturalização da diferença corporal.

De certo modo, isso é o que fundamenta a defesa da cultura surda, que se sus- 
tenta pelo argumento da diversidade linguística e cultural, especialmente pelo uso de línguas de sinais (Silva, 2010). De modo semelhante, vemos surgir o movimento de neurodiversidade defendendo que formas de autismo são variações humanas não patológicas, tais como cor/raça/etnia, orientação sexual ou identidade de gênero - ou, para manter o paralelo, cultura e língua (Ortega, 2009). A crítica ao caráter desencarnado do modelo social poderia ser replicada aqui, na medida em que os sujeitos que reivindicam pensar atributos originalmente entendidos como lesões em termos de diversidade são significativamente "funcionais". No entanto, vê-se esse discurso se proliferar até mesmo no campo da deficiência intelectual, seja na militância (Lopes, 2013), seja em instituições como as Apaes (Simões, 2014). Nesses casos, sugiro que a tensão se desloca da oposição entre lesão e deficiência para uma ambivalência entre identidade e diagnóstico.

No próprio modelo social da deficiência, a questão da identidade já estava posta. Uma das forças que caracterizaram o momento de sua criação era salientar a importância de organizações políticas de pessoas com deficiência, e não para pessoas com deficiência. Ao enfatizar essa distinção, a compreensão do que seja a deficiência aproxima-se dos debates sobre gênero, raça e sexualidade, pela política e retórica da identidade. Deficiência, portanto, não seria algo pertinente ao campo biomédico, ou ainda uma tragédia pessoal ou familiar. Assim como no caso das reivindicações de black power, ou gay pride, a deficiência abriria um espaço de encontro e engajamento no qual é possível um sentimento de pertencimento: deficiência articula-se em orgulho e identidade.

Nesse caminho também se encontram ambivalências, expressas em diferentes formas e por diferentes vozes. Em primeiro lugar, destaco uma questão levantada por Tom Shakespeare, que marca o que ele entende por uma diferença entre deficiência e outras identidades:

Embora as pessoas deficientes [no original, disabled people] tenham de encarar a discriminação e o preconceito, tal como as mulheres, as pessoas gays e lésbicas e as minorias étnicas, e embora o movimento pelos direitos da pessoa com deficiência [no original, disability rights movement] se assemelhe em sua forma e atividades a muitos desses outros movimentos, há uma diferença importante e central. Não há nada intrinsecamente problemático em ser uma mulher, ou ter uma orientação sexual, cor de pele ou formato corporal diferente. [...] Remova-se a discriminação social e mulheres, pessoas de cor [no original, people of color] e pessoas gays e lésbicas serão capazes de florescer e participar. Mas pessoas deficientes encaram tanto 
discriminação quanto limitações intrínsecas. [...] Mesmo que barreiras sociais sejam removidas tanto quanto possível, continuará a ser desvantajoso viver com muitas formas de impedimento [no original, have many forms of impairment]. [...] “Orgulho deficiente” [no original, "Disability pride”] é problemático, pois é difícil elaborar a deficiência como um conceito, na medida em que ela se refere a uma limitação ou incapacidade [no original, limitation and incapacity], ou então à opressão e à exclusão, ou ainda a ambas as dimensões (Shakespeare, 2010, p. 272).

As ponderações de Shakespeare ressoam a ambiguidade entre identidade e diagnóstico, defendendo que deficiência se definiria por alguma forma de ausência intrínseca. De fato, por exemplo, a Convenção sobre os direitos das pessoas com deficiência de 2006 pela ONU, que goza de amplo reconhecimento e aceitação tanto pelos movimentos sociais quanto por acadêmicos, define deficiência por certa ausência: "Pessoas com deficiência são aquelas que têm impedimentos de natureza física, intelectual ou sensorial, os quais, em interação com diversas barreiras, podem obstruir sua participação plena e efetiva na sociedade com as demais pessoas" (Brasil, 2008, p. 27).Além da saída desse imbróglio pela chave da "diversidade", ou identidade afirmativa, que tem o perigo de chapar as diferenças, sugiro que podemos notar em anos recentes uma tendência por estabelecer um contrapeso à lógica identitária na compreensão da deficiência, declarando-a como uma experiência humana universal e não somente uma particularidade de um grupo minoritário. Essa tendência também circula entre documentos de ordem normativa - tanto do campo do direito quanto da saúde - e discursos acadêmicos.

Assim, a partir dos anos 2000, organismos internacionais voltaram-se com maior atenção para a temática da deficiência, o que se manifesta tanto com a Convenção da ONU, ratificada também pelo Brasil (Brasil, 2008), quanto com a publicação do Relatório Mundial sobre a Deficiência (OMS, 2012).

Ao longo dos anos 1990, a OMS houvera organizado uma revisão do manual Classificação Internacional de Lesão, Deficiência e Handicap (ICIDH), publicado em 1980 - cujo objetivo era incluir impairments adquiridos em função de doenças já mapeadas na Classificação Internacional de Doenças (CID). A revisão contou com a participação intensa de diferentes movimentos sociais e entidades acadêmicas de diversos países, levando ao lançamento, no início dos anos 2000, da Classificação Internacional de Funcionalidade, Incapacidade e Saúde (CIF) ${ }^{14}$. Segundo a apresentação da própria Organização Mundial da Saúde, 
a CIF lança uma nova luz sobre as noções de "saúde" e "deficiência". Ela reconhece que todo ser humano pode passar por uma diminuição de sua saúde e, portanto, experimentar algum grau de deficiência. Deficiência não é algo que acontece apenas com uma pequena parcela da humanidade. A CIF, desse modo, "generaliza” [no original, "mainstreams"] a experiência da deficiência e a reconhece como uma experiência humana universal. Mudando o foco da causa para o impacto, ela posiciona em pé de igualdade todas as condições de saúde, permitindo-as ser comparadas por uma mesma métrica - a régua da saúde e deficiência (aspas originais. OMS, 2002, p. 3).

Assim, a OMS passou, com o marco da CIF, a incorporar oficialmente considerações de caráter social ou sociológico na definição da deficiência - tornam-se fartos, portanto, os deslizamentos entre o saber biomédico, que usualmente tomamos como campo êmico na antropologia, e a perspectiva sociológica, que tomamos como analítica. Esse processo se manifesta na definição do conceito apresentada no documento, especialmente pela incorporação de "atividades cotidianas" - tarefas realizadas no dia-a-dia de um indivíduo - e "participação social” - envolvimento em situações e eventos da vida social - na consideração do que seja a experiência de deficiência.

De certo modo unindo as preocupações de Shakespeare e a perspectiva da OMS, Ginsburg e Rapp declaram:

Diferente de categorias de raça e gênero das quais alguém só pode sair ou entrar muito raramente e com um esforço enorme e consciente - por "passing" ou "transexualização" [no original, "passing” or "transgendering"], por exemplo - a deficiência tem uma qualidade distintiva: é uma categoria na qual qualquer pessoa pode ingressar pelo envelhecimento ou num piscar de olhos, desafiando pressupostos de vida sobre identidades estáveis e normatividade. É claro, algumas pessoas serão mais vulneráveis que outras, devido a pobreza, guerra, desastres e as contingências da saúde e da atenção à saúde. No entanto, nenhuma categoria social está imune à experiência da deficiência [...] (2013, p. 55).

E seguem:

Dada a centralidade da diversidade para nossa epistemologia [antropológica], por que o tema da deficiência não tem sido um assunto chave para nossa disciplina? [...] A antropologia é conhecida por sua hábil e sempre em expansão compreensão 
da "natureza humana" [...]. Uma ampla quantidade de achados convida a pesquisa antropológica a pensar sobre como a deficiência é enquadrada por meio da organização social da vida cotidiana, noções de pessoa e governamentalidade. Certamente, esta forma de diferença é um aspecto universal da vida humana. Argumentamos que esse insight é tão fundamental e, ao mesmo tempo, tão negligenciado que antropólogos e antropólogas deveriam ser encorajados(as) a integrar deficiência em praticamente todos os tópicos que estudam e pesquisam (2013, p. 55).

O tom programático do texto das antropólogas se justifica por dois fatores. Por um lado, esses excertos também pertencem ao artigo de revisão e organização do campo que foi publicado em 2013, ou seja, trata-se de um amplo esforço de mapeamento. Por outro lado, Guinsburg e Rapp advogam por uma área em ascensão na antropologia estadunidense, declarando em alto e bom tom sua defesa da deficiência não somente como uma categoria êmica, mas também analítica. A postura das autoras é seguida por outros teóricos, especialmente no campo dos Disability Studies, como Lennard Davis, que escreve a máxima: "O que há de universal na vida, se existem universais, é a experiência de limite do corpo" (2010, p. 314).

Encerro este debate sobre uma universalização da noção de deficiência com algumas pontuações sobre o contexto brasileiro. Em primeiro lugar, acredito que uma diferença de linguagem pese na tradução e operacionalização dessa ideia. Um elemento importante na CIF é a articulação entre deficiência e envelhecimento. Em inglês, expressa-se esse processo dizendo que o envelhecimento disables uma pessoa, mas ela não necessariamente se torna uma pessoa com deficiência em termos mais literais ou de enquadramento político ou institucional.

Em alguma medida, penso que a possibilidade de utilizar de um equivalente verbal para o substantivo disability abre a imaginação para associações e formulações textuais com as quais não contamos no português - ou ao menos não contamos com a mesma agilidade. To disable e be disabled são expressões em si intraduzíveis: não se diz deficientizar ou ser deficientizado; termos alternativos não partem do mesmo substantivo, deficiência.

Essas observações me parecem apontar diferenças importantes no uso da noção de deficiência. Sempre em sua forma nominal (deficiência ou deficiente), não temos como intuitivamente flexionar o termo para transformá-lo em uma expressão que sugira um processo ou uma ação; ser deficiente, estar deficiente ou mesmo se tornar deficiente são distinções temporais, que, contudo, sinalizam estados definitivos em suas durações, e não exatamente processos de transformação ou devir. 
Uma saída aparentemente possível para a rigidez nominal e temporal da expressão deficiência seria o termo, inspirado na versão dos países de língua espanhola, descapacitar ${ }^{15}$. No entanto, aqui, as expressões incapaz ou incapacidade têm conotação pejorativa e dificilmente comporiam o léxico legítimo da deficiência - e são mobilizadas por variadas pesquisadoras e pesquisadores justamente para nomear o efeito do capacitismo (Mello, 2017; Dias, 2013). Além disso, como alertam Diniz, Medeiros e Squinca (2007), a escolha do termo deficiência é fruto de um acúmulo político de longa data, e faz frente ao poder dos saberes biomédicos por disputar o mesmo termo que circula na saúde.

De todo modo, para além dos jogos de tradução, uma diferença importante na forma como o Brasil vem trabalhando a noção de deficiência diz respeito às quatro categorias funcionais clássicas, que definem deficiência física ou motora, visual, auditiva e intelectual - uma questão que se articula com essa compreensão universalista da deficiência, diferente da identitária. No discurso da OMS, que encontra muita receptividade na produção acadêmica estadunidense, há uma crescente recusa ao uso dessas categorias. Segue um trecho da tradução para o português do Relatório Mundial sobre a Deficiência:

Os dados sobre deficiência [no original, impairment] não são um substituto adequado para as informações sobre deficiência [no original, disability; apenas destacarei aqui os casos em que o termo em inglês era impairment]. Amplos "agrupamentos" de diferentes "tipos de deficiência" se tornaram parte da linguagem sobre a deficiência, com algumas pesquisas procurando determinar a prevalência dos diferentes "tipos de deficiência" direta ou indiretamente baseada em avaliações e classificações. Geralmente, os "tipos de deficiência" são definidos utilizando-se apenas um aspecto da deficiência, como as alterações [impairments] - sensoriais, físicas, mentais, intelectuais - e outras vezes se confundem problemas de saúde com deficiência. As pessoas com problemas crônicos de saúde, dificuldades de comunicação, e outras deficiências [impairment] talvez não sejam incluídas naquelas estimativas, apesar de encontrarem dificuldades na sua vida cotidiana.

[...] As deficiências podem ser conceituadas num contínuo de dificuldades menores de funcionalidade a grandes impactos sobre a vida de uma pessoa. Os países estão cada vez mais adotando uma abordagem continuada [contínua, e não discreta] para a mensuração, onde as estimativas de prevalência de deficiência - e funcionalidade - são derivadas da avaliação dos níveis de deficiência em múltiplas áreas (OMS, 2012, p. 22). 
O Censo brasileiro de 2010 lançou mão das propostas do Grupo de Washington sobre Estatísticas da Deficiência, por sua vez respaldado pela Convenção sobre os direitos da pessoa com deficiência (Brasil, 2008) e pelo corpo de documentos que percorro aqui. No entanto, o resultado produzido pelo Censo apresenta os "tipos” acima mencionados, produzindo dados sobre a população de pessoas com deficiência "visual”, "auditiva", "motora” e "mental ou intelectual” (Secretaria Nacional de Promoção dos Direitos da Pessoa com Deficiência, 2012). Originalmente, a recomendação do Grupo de Washington seria por utilizar, além das percepções sobre dificuldades na "visão", "audição” e "mobilidade”, as categorias "comunicação”, "cognição” e "memória”, "uso da parte superior do corpo" e "aprendizado e entendimento".

Essa persistência no uso das categorias funcionais está presente também na publicação da História do Movimento Político das Pessoas com Deficiência no Brasil (Lanna Júnior, 2010). No livro, registra-se a trajetória dos movimentos de pessoas cegas, surdas e com deficiência física - o movimento que representa pessoas com deficiência intelectual é encabeçado por instituições para pessoas com deficiência, e não por, portanto, não foi contemplado do mesmo modo -, chegando-se à sua organização em nível nacional a partir dos anos 1980, e perspectivas futuras. Compreendo que esse recorte segue o uso êmico da noção de deficiência na história política nacional. No entanto, o resultado é que, textual e conceitualmente, a noção de deficiência opera mais na chave da identidade como um agregador político que como um fenômeno de cunho universalista como se vem desenhando em outros espaços.

Essa elaboração que venho chamando de universalista, no entanto, não se justifica apenas pelo fato de que todos os corpos estão por definição sujeitos à deficiência em função do envelhecimento ou de eventos associados a doenças e acidentes. Há uma outra dimensão, dos serviços e instituições, que influi nessa dinâmica, já presente no excerto acima citado do Relatório Mundial e que ganha maior nitidez nas palavras das antropólogas Benedicte Ingstad e Susan Reynolds Whyte:

Em um nível elementar, programas posicionam pessoas em diferentes categorias - como pessoas deficientes, idosas, inférteis, soropositivas - apesar de todas poderem ser consideradas pessoas com deficiência. Na Noruega e na Dinamarca, assim como em muitos países nórdicos, há uma enorme diferença entre o apoio dado pelo governo a jovens adultos com deficiência intelectual severa e pessoas idosas com demência. Os "deficientes" têm direito a sua própria residência e cuidadores, enquanto os "idosos senis" precisam esperar por vagas em casa de repouso que frequentemente carecem de funcionários [...]. Que pessoas com necessidades 
funcionais semelhantes sejam percebidas e tratadas de maneira tão diferente pode ser em parte devido a experiência de vida e geração, mas também é resultado da forma como estruturas institucionais fazem com que identidade (e compatibilidade) pareçam naturais (2007, p. 14-15) .

Com a atenção que as autoras chamam às experiências das pessoas e suas trajetórias na relação com o Estado ou instituições que nomeiam - identificam, classificam, mensuram - deficiência em corpos, concluo este percurso com ressalvas. $\mathrm{Na}$ antropologia, sugerir qualquer universalismo é algo a ser tomado com cuidado - o caráter universal aqui refere-se à compreensão de que a categoria deficiência nos informa não só sobre os corpos das pessoas com deficiência, mas ao sistema de nomeação dessa diferença como um todo. Por exemplo, podemos levantar questionamentos: como fazer uma comparação intercultural ou um levantamento histórico de longa data de uma categoria que emerge, enquanto tal, apenas com a modernidade? Para fazer uma análise comparativa, eventualmente sugere-se tomar como ponto comum determinadas disposições corporais, como não mexer certos membros do corpo, não enxergar, não ouvir etc. Contudo, resgatando o modelo social, não seria a deficiência um efeito do (des)encontro entre essas corporalidades e uma configuração política e histórica que as trata segundo um repertório cultural específico - e capacitista? Nesse sentido, uma história da deficiência seria também uma história da modernidade, da medicina ou da política, em vez de uma história "do corpo"?

$* \quad * \quad *$

Realizado o percurso acima, retomo brevemente a cena etnográfica. O modo como narrei o caso de Henrique partiu da referência às minhas expectativas de que seu modo de falar indicaria "restrições" na articulação de linguagem, em suas capacidades intelectivas e comunicacionais. Essas "restrições" podem ser compreendidas, face ao percurso anteriormente descrito, como lesões ou impedimentos, que, no caso, não lhe privavam do estabelecimento de relações jocosas com outras pessoas. Ou seja, nessa cena particular, o que temos descrito como lesão ou impedimento não se traduz em limitações de interação, ao contrário do que acontece com outras pessoas que frequentavam os passeios e demonstravam menos impedimentos comunicacionais, mas mais inseguranças nos jogos de sociabilidade.

Incorporando a crítica à distinção entre lesão e deficiência, ou impairment e disability, contudo, como reformular essa descrição? Sugiro seguir a pista de Butler, 
segundo a qual a materialidade do "corpo" é descrita como um processo de materialização da norma social no corpo - a noção de deficiência, em nosso repertório cultural, nos leva a projetar para a natureza determinados corpos (interpretados como “normais”, “capazes”, "perfeitos”) e marcar outros como "desviantes” e “disfuncionais”. Compreendo que uma análise crítica nos conduz a pensar a deficiência em termos de sistema classificatório, como marcador social da diferença, o que experimentei nomear como algo universal. No caso da cena em foco, essa abordagem diz respeito tanto a Henrique quanto a mim. Construímos uma relação de interpelação, tanto por minha insistência em falar com ele, quanto por suas esquivas; tanto pelas provocações jocosas que recebi dele, quanto por meu convite a interagir de modo mais espacial e menos verbal. Se a deficiência é um devir propriamente humanoinevitavelmente histórico - em função da vida em corpos, espaços e tempos, ela pode ser considerada como categoria analítica que interpela também os corpos que não nomeia. Meu corpo não deficiente é agente relacional na marcação da deficiência no corpo de Henrique, por exemplo pela suspeita - e consequente surpresa - de que ele não teria domínio do caminho para casa. A sugestão, portanto, é por tomar deficiência como categoria analítica que pode nos ajudar a nomear a desigual variedade de formas, funcionalidades e experiências corporais que vivemos, ou, ainda, a desigual variedade das relações sociais que atribuímos a formas, funcionalidades e experiências corporais - sejam elas marcadas ou não pela categoria pessoa com deficiência.

Encerro este texto deste modo aberto, experimentando caminhos interpretativos. O trabalho com a noção de deficiência apresenta potencialidades e desafios para a antropologia e a análise do social. Seu desdobramento é um empenho a que temos nos dedicado no Brasil, em interlocução com o que se produz em outros países, bem como com pesquisas dedicadas a outras categorias de diferença que nos ajudam a entender como produzimos hierarquias e desigualdades, mas também encontros e alianças.

Recebido: $14 / 02 / 2019$

Aprovado: 02/05/2019 
Pedro Lopes é mestre e doutorando em Antropologia Social pela Universidade de São Paulo. No mestrado, realizou estágio de pesquisa no exterior na Universidade de Princeton (Estados Unidos) e no doutorado na Universidade de Stellenbosch (África do Sul). É membro do Núcleo de Estudos sobre Marcadores Sociais da Diferença (Numas - USP) e professor da Escola da Cidade - Faculdade de Arquitetura e Urbanismo. ORCID: 0000-0003-0772-4370. Contato: pedro. lopes@usp.br

\section{Notas}

1. Uma primeira versão deste texto foi submetida aos anais da $29^{a}$ Reunião Brasileira de Antropologia, realizada entre os dias 03 e 06 de agosto de 2014, Natal/RN. O artigo reelabora uma reflexão que iniciei em meu mestrado em antropologia social pela Universidade de São Paulo (Lopes, 2014), orientada por Laura Moutinho e financiada pela Fapesp. Nesta oportunidade, apresento um texto revisado e atualizado a partir da continuidade de minha pesquisa sobre o tema no doutorado (financiado pela Capes, também realizado na USP) e, especialmente, de discussões que temos cultivado nas variadas edições do GT Etnografias da Deficiência. O presente trabalho foi realizado com apoio da Coordenação de Aperfeiçoamento de Pessoal de Nível Superior - Brasil (CAPES) Código de Financiamento 001.

2. Não uso neste texto de masculino universal, como “os frequentadores dos passeios", tampouco feminino universal, "as participantes", exceto em caso de erro ou referência a outros textos ou expressões.

3. Em outras oportunidades (Lopes, 2013, 2014), mantive todas as categorias relacionadas a deficiência entre aspas, no intuito de frisar sua contingencialidade e, ao mesmo tempo, a polifonia terminológica que atravessam este campo de atuação política e pesquisa. Meu intuito era por simetrizar essa polifonia entre os campos de pesquisa etnográfica e as produções acadêmicas. $\mathrm{O}$ procedimento inspirava-se no uso de aspas para discutir categorias raciais, por exemplo, por Laura Moutinho (2004).

4. Sobre o tema, ver Lopes (2014), Simões (2014) e Mello (2015).

5. Em linhas talvez demasiado gerais, o termo nomeia o preconceito e violência contra pessoas com deficiência, de modo análogo às noções de racismo ou machismo, por exemplo. Para uma reflexão densa, ver especialmente Mello (2016).

6. Particularmente, neste trecho refiro-me com atenção às sensíveis reflexões de Anahí Guedes de Mello (2016) e Marco Antonio Gavério (2017). Sugiro fortemente a quem lê este texto que triangule meus argumentos aqui com os que Mello e Gavério trazem em seus artigos.

7. A percepção da comicidade nas atitudes de Henrique, interpelando as pessoas com provocações jocosas, de modo geral, não era enunciada com tom de deboche, mas de ternura.

8. Sobre marcadores sociais da diferença ou interseccionalidade - referencial que compreende que a diferença e a desigualdade sociais são produzidas pela articulação de variados sistemas de classificação, hierárquicos e contingentes, que ora abrem ora encerram possibilidades de atuação -, ver as revisões fundamentais produzidas por Adriana Piscitelli (2008), Laura Moutinho (2014) e Natália 
Padovani (2017) bem como a coletânea organizada por Gustavo Saggese et al. (2018).

9. Aqui há um debate de fundo com a chamada Teoria Crip, ou Teoria Aleijada, na tradução de Marco Antonio Gavério. Sobre o tema, ver McRuer (2006), Kafer (2013), Gavério (2015) e Mello (2016).

10. Nesta reflexão, tenho em mente um paralelo com a discussão de Joan Scott, que sugere que a noção de gênero pode ser entendida como uma "uma categoria útil de análise histórica”, expressando-se como uma: "[...] forma primária de dar significado às relações de poder. Seria melhor dizer: o gênero é um campo primário no interior do qual, ou por meio do qual, o poder é articulado. [...] Estabelecidos como um conjunto objetivo de referências, os conceitos de gênero estruturam a percepção e a organização concreta e simbólica de toda a vida social. Na medida em que essas referências estabelecem distribuições de poder (um controle ou um acesso diferencial aos recursos materiais e simbólicos), o gênero torna-se implicado na concepção e na construção do próprio poder" (1995, p. 88).

11. Sobre essa trajetória, ver Oliver (1990).

12. Referência a: OLIVER, Michael. The Social Model in Action: If I Had a Hammer. In: BARNES, C. \& MERCE, G. (Orgs.) Implementing the Social Model of Disability: Theory and Research. Leeds: The Disability Press, 2004.

13. Todas as traduções de originais em inglês neste artigo são de minha autoria.

14. Sobre esse processo, ver Farias \& Buchalla (2005) e Di Nubila (2007). Para uma discussão a respeito da tradução dos termos impairment por deficiência e disability por incapacidade na tradução da CIF para o português, ver Diniz, Medeiros \& Squinca (2007).

15. A tradição de países de língua espanhola utiliza-se do termo discapacidad.

\section{Referências}

AYDOS, Valéria. 2016. Agência e subjetivação na gestão de pessoas com deficiência: a inclusão no mercado de trabalho de um jovem diagnosticado com autismo. Horizontes antropológicos, v. 22, n. 46, pp.329-358. BLUME, S. \& HIDDINGA, A. 2010. Disability studies as an academic field. Medische Antropologie. v. 22, n. 2, p. 225-236.

BRASIL. 2008. Convenção sobre os direitos das pessoas com deficiência. Brasília: Secretaria Especial de Direitos Humanos (SEDH)/Coordenadoria Nacional para a Integração da Pessoa Portadora de Deficiência (Corde).

BUTLER, Judith. 2001. Corpos que pesam: sobre os limites discursivos do sexo. Tradução de Tomaz Tadeu da Silva. In: LOURO, Guacira Lopes (org.). O corpo educado. Belo Horizonte: Autêntica. p. 151 172.

DAS, Veena. 2011. O ato de testemunhar: violência, gênero e subjetividade. Cadernos Pagu, n. 37, pp. 9-41.

DAVIS, Lennard. 2010. The End of Identity Politics: On Disability as an Unstable Category. In:

(org.). The Disability Studies Reader, 3. ed. Nova York; Oxon: Routledge. p. 301-315.

DI NUBILA, Heloisa Brunow Ventura. 2007. Aplicações das classificações CID-10 e CIF nas definições de deficiência e incapacidade. Tese de doutorado. Universidade de São Paulo - Faculdade de Saúde Pública. 
DIAS, Adriana. 2013. Por uma genealogia do capacitismo: da eugenia estatal a narrativa capacitista social. Anais do I Simpósio Internacional de Estudos sobre a Deficiência. SEDPcD/Diversitas/USP Legal, São Paulo.

DINIZ, Débora. 2003. O modelo social da deficiência: a crítica feminista. Série Anis, 28, Brasília: Letras Livres, p. 1-8.

DINIZ, Débora. 2006. O que é deficiência. São Paulo: Brasiliense. (Coleção Primeiros Passos).

DINIZ, Debora; MEDEIROS, Marcelo \& SQUINCA, Flávia. 2007. Reflexões sobre a versão em Português da Classificação Internacional de Funcionalidade, Incapacidade e Saúde. Cadernos de Saúde Pública, v. 23, n. 10 , pp. 2507-2510.

DOUGLAS, Mary. 1991. Pureza e Perigo: ensaio sobre as noções de poluição e tabu. Tradução de Sónia Pereira da Silva. Lisboa: Edições 70.

FARIAS, Norma \& BUCHALLA, Cassia Maria. 2005. A Classificação Internacional de Funcionalidade, Incapacidade e Saúde da Organização Mundial da Saúde: Conceitos, Usos e Perspectivas. Revista Brasileira de Epidemiologia, n. 8, v. 2, pp. 187-193.

FIETZ, Helena Moura. 2017. Deficiência, cuidado e dependência: reflexões sobre redes de cuidado em uma família em contexto de pobreza urbana. Teoria e Cultura. v. 11, n. 3, pp. 101-113.

FREMLIN, Peter Torres. 2011. Corporalidades de Chumbados: uma etnografia de Pessoas com Deficiências Físicas no Rio de Janeiro. Dissertação de mestrado no Museu Nacional da Universidade Federal do Rio de Janeiro.

GARLAND-THOMSON, Rosemarie. 2010. "Integrating Disability, Transforming Feminist Theory". In: DAVIS, Lennard J. (org.). The Disability Studies Reader, 3. ed. Nova York; Oxon: Routledge. p. 353-373.

GAVÉRIO, Marco Antonio. 2015. Medo de um Planeta Aleijado? - Notas para possíveis aleijamentos da sexualidade. Áskesis. v. 4, n. 1.

GAVÉRIO, Marco Antonio. 2017. Nada sobre nós, sem nossos corpos! O local do corpo deficiente nos Disability Studies. Revista Argumentos, Montes Claros, v. 14, n. 1, pp. 95-117.

GINSBURG, Faye \& RAPP, Rayna. 2013. DisabilityWorlds. Annual Review of Anthropology, n. 42, pp. 53-68.

HERTZ, Robert. 1980. A proeminência da mão direita: um estudo sobre a polaridade religiosa. Religião e Sociedade, v. 6.

INGSTAD, Benedicte \& REYNOLDS WHYTE, Susan. 2007. Disability in local and global worlds. Los Angeles: University of California Press.

KAFER, Alison. 2013. Feminist, Queer, Crip. Bloomington: Indiana University Press.

LANNA JÚNIOR, Mário Cléber Martins (Comp.). 2010. História do Movimento Político das Pessoas com Deficiência no Brasil. Brasília: Secretaria de Direitos Humanos/Secretaria Nacional de Promoção dos Direitos da Pessoa com Deficiência.

LOPES, Pedro. 2013. "Normal, normal mesmo, é só deus”: sobre possibilidades e contradições da identidade de "pessoa com deficiência intelectual”. Vivência: Revista de Antropologia, v. 1, n. 41, p. 85-89.

LOPES, Pedro. 2014. Negociando Deficiências: identidades e subjetividades entre pessoas com "deficiência intelectual”. Dissertação de Mestrado, Universidade de São Paulo. 
MAUSS, Marcel. 2003. As técnicas do corpo. In: Sociologia e Antropologia. Trad. de Paulo Neves. São Paulo: Cosac Naify. pp. 399-422.

McCLINTOCK, Anne. 2010. Couro Imperial: raça, gênero e sexualidade no embate colonial. Campinas: Editora da Unicamp.

McRUER, Robert. 2006. Crip theory: cultural signs of queerness and disability. Nova York: New York University.

MELLO, Anahí Guedes de. 2015. “Ou todo mundo é louco ou ninguém é!”: refletindo sobre possibilidades de articulação entre deficiência e loucura. Vivência: Revista de Antropologia, v. 1, n. 44.

MELLO, Anahí Guedes de. 2016. Deficiência, incapacidade e vulnerabilidade: do capacitismo ou a preeminência capacitista e biomédica do Comitê de Ética em Pesquisa da UFSC. Ciência \& Saúde Coletiva, v. 21, n. 10, pp. 3265-3276.

MELLO, Anahi Guedes de; NUERNBERG, Adriano Henrique. 2012. Gênero e deficiência: interseções e perspectivas. Revista de Estudos Feministas, v. 20, n. 3, pp. 635-655.

MELLO, Anahi Guedes de; NUERNBERG, Adriano Henrique e BLOCK, Pamela. 2014. Não é o corpo que discapacita, mas sim a sociedade: a interdisciplinaridade e o surgimento de estudos sobre deficiência no Brasil e no mundo. In: SCHIMANSKI, Edina; CAVALCANTE, Fátima Gonçalves (Orgs.). Pesquisa e Extensão: experiências e perspectivas interdisciplinares. Ponta Grossa: Editora UEPG. p. 91-118. MOL, Annemarie. 2010. The Logic of Care: Health and the Problem of Patient Choice. Abingdon: RoutledgeOUTINHO, Laura. 2004. Razão, “Cor” e Desejo: uma análise comparativa sobre relacionamentos afetivo-sexuais “inter-raciais” no Brasil e na África do Sul. São Paulo: Unesp.

MOUTINHO, Laura. 2014. Diferenças e desigualdades negociadas: raça, sexualidade e gênero em produções acadêmicas recentes. Cadernos Pagu, n. 42, pp. 201-248.

OLIVER, Michael. 1990. The Individual and Social Models of Disability. Paper apresentado no Joint Workshop of the Living Options Group and the Research Unit of the Royal College of Physicians. Disponível em: http: / / disability-studies.leeds.ac.uk/files/ library/Oliver-in-soc-dis.pdf. Acesso em: 14 jun. 2018.

OMS - ORGANIZAÇÃO MUNDIAL DA SAÚDE. 2012. Relatório mundial sobre a deficiência, Trad. de Lexicus Serviços Linguísticos. São Paulo: SEDPcD.

OMS - ORGANIZAÇÃO MUNDIAL DA SAÚDE. 2002. Towards a Common Language for Functioning, Disability and Health - ICF. Genebra. Disponível em: http://www.who.int/classifications/ icf/icfbeginnersguide.pdf?ua=1. Acesso em: 19 jan. 2019.

ORTEGA, Francisco. 2009. Deficiência, autismo e neurodiversidade. Ciência \& saúde coletiva, Rio de Janeiro, v. 14, n. 1, pp. 67-77.

PADOVANI, Natália Corazza. 2017. É possível fazer ciências sociais sem uma análise crítica das categorias de diferenciação? Uma proposição feminista. Cadernos de Estudos Sociais e Políticos, Rio de Janeiro, v. 7, n. 12, pp. 6-30.

PISCITELLI, Adriana. 2008. Interseccionalidades, categorias de articulação e experiências de migrantes brasileiras. Sociedade e Cultura, v. 11, n. 2, pp. 263-274.

RICH, Adrienne. Notes toward a Politics of Location. In: . Blood, Bread and Poetry. Nova York;

Londres: W.W. Norten \& Company, 1986. pp. 210-231. 
SAGGESE, Gustavo Santa Roza; MARINI, Marisol; LORENZO, Rocío Alonso; SIMÕES, Júlio; CANCELA, Cristina Donza (orgs.). 2018. Marcadores sociais da diferença: gênero, sexualidade, raça e classe em perspectiva antropológica. São Paulo: Terceiro Nome; Gramma.

SCOTT, Joan. 1995. Gênero: uma categoria útil de Análise Histórica. Educação \& Realidade, v. 20, n. 2, pp. 71-79.

SECRETARIA NACIONAL DE PROMOÇÃO DOS DIREITOS DA PESSOA COM DEFICIÊNCIA. 2012. Cartilha do Censo 2010 - Pessoas com Deficiência. Texto de Luiza Maria Borges Oliveira. Brasília: Secretaria de Direitos Humanos da Presidência da República (SDH/PR) / Secretaria Nacional de Promoção dos Direitos da Pessoa com Deficiência (SNPD)

SHAKESPEARE, Tom. 2010. The Social Model of Disability. In: DAVIS, Lennard J. (org.). The Disability Studies Reader, 3. ed. Nova York; Oxon: Routledge. pp. 266-273.

SILVA, César Augusto de Assis. 2010. Entre a deficiência e a cultura: Análise etnográfica de atividades missionárias com surdos. Tese de doutorado, Universidade de São Paulo, São Paulo.

SIMÕES, Julian.2014. Assexuados, libidinosos ou um paradoxo sexual? Gênero e sexualidade em pessoas com deficiência intelectual. Dissertação de Mestrado, Universidade Estadual de Campinas, Campinas.

SIMÕES, Julian. 2017. “A gente que está aqui é diferente”: notas etnográficas sobre deficiência intelectual numa Apae do interior de São Paulo-BR. Teoria e Cultura. v. 11, n. 3, pp. 75-88.

VON DER WEID, Olivia. 2017. Provincializar a visão: esboços para uma abordagem metodológica. Teoria e Cultura. v. 11, n. 3, pp. 131-144. 
Deficiência como categoria analítica: trânsitos entre ser, estar e se tornar

Resumo: A partir da década de 2000, a noção de deficiência vem ganhando contornos específicos no contexto global e brasileiro, por meio de acordos, convenções e manuais internacionais, bem como prolifera na produção de ativismos, trabalhos artísticos e formas de sociabilidade e construção de si. Nesses trânsitos, sua definição oscila não somente entre identidade e diagnóstico, uma compreensão social e uma médica, mas também entre um estado e um processo, ser e se tornar. Este texto apresenta uma reflexão sobre traduções e trânsitos nacionais e internacionais acerca da noção de deficiência, com vistas a percorrer questões teóricas e etnográficas que têm atravessado pesquisas e interlocuções sobre o tema. Para tanto, debato uma cena etnográfica no trabalho junto a pessoas com deficiência intelectual. Minha sugestão é que estruturar esta discussão por meio de uma reflexão acerca do estatuto da própria ideia de deficiência pode ser produtivo, advogando pelo potencial analítico da categoria.

Palavras-chave: Deficiência; Antropologia; Deficiência Intelectual; Marcadores Sociais da Diferença.
Disability as an analytical category: negotiations between being and becoming

Abstract: Since the 2000s, the notion of disability has been gaining specific contours in the global and Brazilian context, through agreements, conventions and international manuals, as well as proliferating in the production of activism, artistic pieces and forms of sociability and self-construction. In these negotiations, its definition oscillates not only between identity and diagnosis, social and medical approaches, but also between a state and a process, to be and to become. This text presents a reflection on national and international translations and negotiations about the notion of disability, aiming to explore theoretical and ethnographic questions that can be noted across researches and interlocutions on the subject. To do so, I present an ethnographic scene from my work alongside people with intellectual disabilities. My suggestion is that structuring this discussion by reflecting on the status of the very idea of disability can be productive, advocating for the analytical potential of the category.

Keywords: Disability; Anthropology; Intellectual Disability; Social Markers of Difference. 


\title{
A (des)construção social do diagnóstico de autismo no contexto das políticas de cotas para pessoas com deficiência no mercado de trabalho ${ }^{1}$
}

\author{
Valéria Aydos \\ Universidade Federal do Rio Grande do Sul - Brasil
}

\section{Introdução}

O cenário de uma crescente propagação midiática sobre o autismo tem trazido à tona um debate acadêmico acerca da produção clínica desse diagnóstico e de uma possível "epidemia de autismo". Tal debate pauta uma problematização sobre a flexibilidade e a complexidade da sua produção como um "diagnóstico clínico" e situado em um espectro altamente diversificado, assim como sobre essa condição ser considerada uma deficiência ${ }^{2}$ ou uma neurodiversidade, uma "maneira diversa de ser e estar no mundo".

Segundo especialistas psi e neurologistas, há hoje um certo consenso ${ }^{3}$ de que o autismo seria "um transtorno do desenvolvimento que prejudica a interação social, compromete a comunicação verbal e não verbal e apresenta padrões repetitivos de comportamento" (White, 2013:114 apud Hollin, 2014a). Na literatura das ciências humanas sobre o tema (Hacking, 2006; Eyal et al., 2010; Ochs et al., 2004; Holin, 2014), há indicações de que o autismo está se tornando cada vez mais presente e se manifestaria (colocando em xeque) exatamente naquilo que mais precisaríamos para "conviver bem em sociedade": as habilidades de socialização e comunicação.

É com o intuito de compreender estas questões que proponho aqui uma análise das especificidades do processo diagnóstico do autismo (Silverman, 2008; Grinker, 2010; Hacking, 2006; Campoy, 2015; Valtellina, 2018) e das disputas em torno do seu status nosológico ${ }^{4}$ (Hacking, 2007; 2009; Ortega et al., 2013) em um contexto específico de interação social: o cotidiano laboral de pessoas com esta condição, espaço no qual pouco se discute e se pesquisa sobre esses temas.

Para tanto, trago ao longo do texto cenas de uma etnografia realizada, entre 2013 e 2017, com dois jovens que tiveram suas primeiras experiências de emprego, a partir de um projeto ${ }^{5}$ de implementação da política de cotas para pessoas com deficiência $^{6}$ no Rio Grande do Sul: Tomás, um jovem de 21 anos, de classe popular, que foi contratado como assistente administrativo em uma empresa de serviços, e 
Ricardo, um rapaz de 26 anos, pertencente às camadas médias, que ingressou como tradutor de inglês-português no setor de comunicação em uma empresa multinacional com sede em Porto Alegre. Na construção de meus argumentos, refiro-me também a relatos de experiências laborais de outros jovens ${ }^{7}$ com autismo, ao acompanhamento do trabalho de assessoria de inclusão da psicopedagoga Clara ${ }^{8}$ e a entrevistas com neurologistas e psiquiatras especializados em autismo.

Tal material contribui para a compreensão do que está em jogo não apenas na coprodução ${ }^{9}$ da categoria autismo na prática cotidiana de diversos atores, mas também, para a identificação das barreiras presentes nas interações sociais dessas pessoas, as quais dificultam ou impossibilitam a efetivação das políticas de inclusão social de pessoas com esta condição no mundo do trabalho. $\mathrm{O}$ debate sobre a produção do diagnóstico de autismo na prática se torna fundamental neste contexto por ser este laudo/atestado identificado com um $\mathrm{CID}^{10}$, legalmente reconhecido como "deficiência”, um pré-requisito para o acesso às cotas.

Parafraseando o termo "categorias perigosas" de Rosenberg (2002), cuja definição seria "aquelas que possuem status ontológico disputado", minha proposta analítica é pensarmos o autismo, visto pelos especialistas como um diagnóstico obscuro, fluido e dinâmico (Hacking, 2006; Eyal et al., 2010; Ochs et al., 2004; Holin, 2014), como produtor de "subjetividades perigosas" e de novas realidades e sensibilidades sociais, cujos efeitos atuam na produção dos sujeitos assim classificados e transformam também a própria política.

\section{Uma epidemia de autismo?}

O debate em torno do autismo tem conquistado crescente visibilidade na mídia e na cena pública nos últimos anos. Logo após a promulgação da Lei Berenice Pianna (Lei 12764, de 2012), a qual "reconhece o autismo como deficiência para todos os fins legais", a revista Veja teve o tema estampado como destaque de capa. Já a Rede Globo de Televisão, lançou uma série no programa Fantástico e abordou o tema com destaque na novela Amor à Vida (ambos em 2013).

Também nas redes acadêmicas e na agenda pública, o autismo parece ser o "diagnóstico do momento" (Fitzgerald, 2015; Ortega et al., 2013). Só nos dois primeiros anos da minha pesquisa, 2013 e 2014, participei de mais de 10 palestras (presenciais e on-line) e de dois grandes congressos científicos sobre o tema; além de recentemente o autismo ter se tornado uma "prioridade na agenda global de saúde mental" (Ortega, 2018). 
Esta maior visibilidade do autismo na cena pública é de fato acompanhada do registro de um crescente número de casos nos últimos anos, com um aumento dos índices de diagnósticos de 1 em cada 2.500 pessoas em 1978, para 1:100 pessoas em 2014 (Hollin, 2014; Eyal et al., 2010). Tais dados, como comentei, têm gerado debates internacionais sobre uma provável “epidemia de autismo” (Hacking, 2006; Grinker, 2010; Eyal et al., 2010; Hollin, 2014; Rios et al., 2015), cujas teses não descartam o fato de que quanto mais se sabe sobre uma doença ou deficiência, mais se tem ferramentas para diagnosticá-la, e mais pessoas identificam-se sob aquela classificação.

Como lembra Ian Hacking (2006), as investigações científicas interagem com as classificações e as mudam constantemente, processo de construção social chamado pelo autor de looping effect das categorias. A cada looping effect, não só uma nova categoria é criada, mas também novas pessoas são nelas incluídas e as pessoas classificadas são recriadas, não sendo mais as mesmas que anteriormente. No caso do autismo, o percurso histórico de aquisição de conhecimento sobre a condição conta com o fato de que a crescente amplitude de "sintomas" e "sinais diagnósticos" incluídos no chamado Transtorno do Espectro Autista (TEA) ${ }^{11}$ dá margem a sua abertura a diferentes interpretações e o torna adaptável a um número crescente de pessoas (Grinker, 2015).

Segundo Hacking (2006:4), "em 1973 o autismo era um distúrbio de desenvolvimento raro, com um estereótipo bastante definido e estritamente caracterizado. Hoje nós temos o Espectro do Autismo. Nós temos pessoas com autismo de alta-funcionalidade. Nós temos Aspergers"12. O autor cita exemplos de pessoas adultas que hoje se identificam como autistas ou Aspies, mas que, devido à configuração do autismo ser mais desconhecida e estreita quando eram crianças, cresceram sem um diagnóstico específico sobre sua condição ${ }^{13}$.

Em uma das entrevistas que realizei, comentei com um psiquiatra que achava que alguns conhecidos meus poderiam ser identificados como autistas dentro dos padrões de comportamento que ele relatava. Nesse momento, ele me disse:

Isso é muito comum. Vários adultos cresceram achando que eram estranhos ou não sabendo o porquê das pessoas não gostarem deles e porque nunca se sentiram iguais às outras pessoas. Daí alguém fala pra eles sobre o autismo e eles descobrem que têm o diagnóstico. Isso acontece muito também com os pais de autistas nas consultas dos filhos, quando começo a falar as características do autismo e eles se identificam. 
Segundo especialistas, além dos diagnósticos infantis terem-se multiplicado, cada vez mais adultos estão se identificando e sendo identificados nesta classificação.

Este aumento de diagnósticos conta também com uma positivação do Espectro, impulsionada em parte por um crescente número de séries e autobiografias (Hacking, 2009), mas também pelo crescimento do Movimento da Neurodiversidade (Ortega; Choudhury, 2011) no mundo. No Brasil, e especialmente no Rio Grande do Sul, esse movimento é pouco conhecido, inclusive entre alguns especialistas da área psi com quem conversei. Mas, na internet, Rios e Andrada (2015), pesquisadoras do Rio de Janeiro, encontraram uma crescente rede atuante neste sentido.

Por outro lado, alguns elementos do processo parecem indicar uma certa dificuldade na obtenção do diagnóstico. Como a psicopedagoga Clara e também alguns neurologistas salientaram em nossas conversas, o fato de o autismo não ter um "exame médico" que o identifique, um "biomarcador", e nem uma "marca corporal” visível faz com que médicos relutem em dar certeza deste diagnóstico, considerado por eles como "muito subjetivo". Além disso, segundo eles, pelo menos aos olhos de desconhecedores do transtorno, não há como identificar - diferentemente da Síndrome de Down, por exemplo - “o que a pessoa tem”. Os sinais são sutis, porque comportamentais, e exigem um conhecimento sobre o que é o autismo e um "olhar treinado" para que sejam perceptíveis. Segundo eles, tal fato somado à incipiente formação acadêmica em autismo dificulta o acesso ao diagnóstico.

A dificuldade de "fechar um diagnóstico de autismo" se daria, então, tanto por conta do pouco conhecimento que ainda se tem sobre a condição (Fitzgerald, 2015; Hollin, 2014), mas também por ser um processo diagnóstico considerado demasiado "subjetivo" pela classe médica (Grinker, 2010), ou, nas palavras dos especialistas, um “diagnóstico clínico".

\section{Autismo: um “diagnóstico clínico”}

Ao mesmo tempo em que há um discurso médico bastante calcado em uma concepção positivista de ciência que acusa a pouca "cientificidade" do processo diagnóstico do autismo, as habilidades pessoais "subjetivas" dos experts na sua identificação são frequentemente exaltadas. Ou seja, a especificidade de realização de um diagnóstico a partir de observações do comportamento das pessoas, da forma como interagem e se comunicam contribui para uma disputa em torno da sua classificação, tornando o autismo o que poderíamos chamar, seguindo Rosenberg (2002), de uma "categoria perigosa". 
Gregory Hollin (2014a) analisa as especificidades da construção social do diagnóstico do autismo nas experiências profissionais de especialistas no assunto e comenta que vários de seus interlocutores lhe disseram - assim como eu também ouvi algumas vezes em meu campo - que "são capazes de determinar se um indivíduo é autista segundos após a sua chegada na clínica" (Hollin, 2014a:99). "Eu boto o olho e já sei que é autista”, escutei de mais de um especialista. Tais comentários, no entanto, ponderavam a "intuição" com argumentos de "seriedade" e "cientificidade" da profissão, como: "Claro que depois sigo os protocolos, faço vários testes validados cientificamente”; ou: "mas é necessário muitas consultas e várias avaliações para fechar um diagnóstico sério”.

Tais "testes validados cientificamente" utilizados na produção de diagnósticos têm sido objeto de análise e críticas por parte da Sociologia e da Antropologia Médica e Psicológica ${ }^{14}$ já há algumas décadas. Em uma análise recente sobre a produção diagnóstica específica do autismo, a partir do teste ADOS (Autism Diagnosctic Observation Schedule), Elizabeth Fein (2018) argumenta, por exemplo, que, na verdade, esse teste parte de uma avaliação da habilidade das pessoas de performarem o que Giddens (1993) chama de pure relationship. Segundo Fein (2018: 145), a existência de um "self puro individual" e de agir dentro de normas sociais precisas, mas demonstrando estar agindo "espontaneamente" e "livres de pressões socioculturais", além de serem "imperativos culturais" incompatíveis com a forma autista de engajamento social, são uma forma arbitrária e descontextualizada de avaliar a condição. Jurandir Freire Costa e Roy Richard Grinker (2018) também contribuem para o debate com uma análise à luz da filosofia da linguagem e da fenomenologia, sobre como os autistas constroem suas personalidades e vocabulários interpretativos de forma coerente, chamando a atenção para o fato de que "a cognição não é um processo desincorporado a ser julgado nos termos de um consenso neurotípico" (Costa; Grinker, 2018: 160), evidenciando como os "discursos de autistas são também formas de resistência a discursos hegemônicos de autoridade” (op cit:171).

Nessa disputa de saberes, a reivindicação das mães de autistas ${ }^{15}$ (Rios, 2018; Nunes, 2014; Ferreira, 2015) na validação de seus conhecimentos sobre os filhos é uma das especificidades sobre esta condição. Em meu campo sobre a inclusão de pessoas com deficiência pela política de cotas, algumas foram as vezes em que escutei dessas mães que elas "sabiam que seus filhos tinham autismo", mas que "os médicos não davam o atestado" ${ }^{16}$ para que eles tivessem acesso à vaga de emprego pelas cotas. Na maioria das vezes, essas pessoas tinham "traços leves" que os situa- 
vam no Espectro e não havia outras "comorbidades" (doenças ou deficiências além da preponderante) com um CID de uma deficiência legalmente válida.

Certo dia, na saída do curso de capacitação onde Clara trabalhava, presenciei uma mãe de um jovem com autismo que se lamentava para uma professora que “a empresa não aceitou o CID de seu filho". Segundo ela, "lá dizia só que ele tinha TDAH" 17 , mas que ela "sabia que o filho tinha mais que isso". Segundo a professora, esse atestado realmente não se enquadrava nas regras da política de cotas, mas que ela concordava com a mãe sobre o filho "parecer ter algum grau de autismo" e que "conhecia alguns médicos mais familiarizados com o espectro para tentar uma consulta para o rapaz”.

As disputas em torno do diagnóstico de autismo também estavam presentes, mas de outra forma, no processo de Tomás, um dos jovens com quem convivi durante minha pesquisa e cujo processo de inclusão Clara assessorou. Clara contou-me que Tomás havia chegado no curso com o "F7.5, diagnóstico de retardo mental leve", mas que "já de cara" a Renata, sua colega de trabalho, que "tá com um olho bom", havia lhe dito: "Esse menino é estranho". Daí, quando ela foi avaliar, percebeu que era "óbvio que ele era autista". Ela falou com Joana, a mãe do rapaz, e fez uma avaliação. Segundo Clara, ao verificar outros documentos trazidos pela mãe, verificou que Tomás já tinha o diagnóstico F84.0 - “Autismo Infantil” - feito aos 7 ou 8 anos, quando estava na escola.

Mas para Joana, mãe do rapaz, assim como para Tomás, que se refere a si mesmo como "pessoa que tem dificuldade" - tal papel com letras e números não dizia muito sobre seu filho. Joana percebia Tomás em contraste com o filho mais novo, que tinha ecolalia $^{18}$ e limitações para realizar atividades fisiológicas diárias, cujo diagnóstico, para ela, era sim de autismo. Joana me explicou que Tomás não era como o irmão, tinha "apenas uns por cento de retardo lá". Aquele atestado do médico representava para ela apenas um documento que o filho precisava para ter acesso a uma vaga de emprego.

Trago estas controvérsias não para levantar a questão de quem sabe mais sobre Tomás ou qual diagnóstico está certo ou errado. Dizer que Tomás não habita a categoria autismo ou que sua mãe não o reconhece nesse diagnóstico não deslegitima o saber médico, mas nos fala sobre a especificidade desta categoria e sobre como as pessoas experienciam, agenciam e convivem com os rótulos biomédicos. Parece que ao escolher "retardo" ao invés de "autismo", a mãe de Tomás está indicando mais um elemento que compõe o "perigo" da "subjetividade autista": sua compreensão de 
que o autismo representaria uma "deficiência mais incapacitante" do que a que ela via na condição de seu filho, ou, pelo menos, com menor probabilidade de contratação pelo mercado de trabalho.

Como bem lembra Rosenberg (2002), diagnósticos são meios de comunicação, campos de negociação que configuram e reconfiguram vidas e criam alianças. Evidentemente que toda disputa é situada na História e não se dá em termos de igualdade de condições. No caso do diagnóstico do autismo, cabe ainda pontuar que, nas disputas em torno de sua classificação, o papel dos saberes biomédicos (em detrimento dos psicanalíticos) ocupa um espaço central. Na prática da política, a presença de médicos neurologistas e psiquiatras é marcada não apenas pelo poder da produção da verdade na construção do laudo diagnóstico que dá acesso às cotas, mas também na prática cotidiana das pessoas envolvidas na implementação da política.

\section{Os "experts da subjetividade" em disputa}

O poder das categorias biomédicas como detentoras de um saber legítimo sobre a saúde e a doença, sobre corpos e mentes, é incontestável em nossa sociedade. Especificamente em meu campo de pesquisa, para fins da Lei de Cotas, laudos diagnósticos são emitidos apenas por médicos neurologistas ou psiquiatras (Nubila, 2007). Nesse documento deve constar uma "deficiência" diagnosticada com um número da CID. Tal caracterização encontra-se no Decreto 5.296/04, cujas concepções de deficiência são preponderantemente biomédicas (Nubila, 2007).

Segundo Nikolas Rose $(1997 ; 2008 ; 2013)$ e Ortega $(2008 ; 2010)$, nossas características subjetivas estariam cada vez mais sendo interpretadas como localizadas no cérebro físico, sendo, então, a nossa própria subjetividade entendida como neuroquímica. Evidentemente que essa mudança de "estilo de pensamento" (Rose, 2008) não é vista como um processo evolutivo. Uma forma de pensar não substitui a outra, mas se soma às outras já existentes e torna-se hegemônica em certo tempo histórico. Saberes estão sempre em disputa e o que vemos nos debates em torno do autismo hoje, apesar das disputas com a psicanálise no Brasil serem presentes (Lopez \& Sarti, 2013; Ortega et al., 2013), é uma preponderância dos saberes biomédicos na explicação, e principalmente no "manejo" e no "tratamento", desta condição ${ }^{19}$ (Hacking, 2006; Ortega, 2008; Campoy, 2015).

Segundo Ian Hacking (2006), o autismo, que já foi visto como o comportamento de pacientes esquizofrênicos ou "uma desordem psiquiátrica da infância", hoje é objeto de disputas entre os que o entendem como uma desordem do desen- 
volvimento, uma deficiência ou uma diversidade neurobiológica (Hacking, 2006; Ortega, 2008). Em termos gerais, tais nomenclaturas (desordem, transtorno, deficiência, neurodiversidade) carregam diferentes concepções sobre as possíveis causas do autismo, suas características e manifestações físicas, intelectuais, sensoriais e atitudinais, assim como informam as posturas dos experts frente à melhor abordagem e aos possíveis tratamentos/curas (Solomon, 2013; López \& Sarti, 2013; Campoy, 2015) para esta condição.

A passagem do autismo da lista de "psicoses infantis" para sua incorporação aos "transtornos do desenvolvimento", mencionada por Ian Hacking, se deu na terceira edição do DSM. Esta mudança refletiria a chamada "virada fisicalista”, que exporia, também num nível mais pragmático, as mudanças nos sistemas de pensamento mencionadas por Rose, com o deslocamento das concepções psicanalíticas sobre o autismo para o predomínio de uma concepção biológica e cerebral do transtorno.

A ideia de cunho psicanalítico de que o autismo seria causado por uma "falha dos pais no estabelecimento de relações objetais precoces com o filho" (Ortega, 2010:150) foi, então, superada pela concepção hegemônica de que ele estaria localizado no cérebro. Com isso, as metáforas da "mãe geladeira", "conchas", "tomadas desligadas", que tanto culpabilizavam as mães, foram rechaçadas pela maioria dos especialistas (Eyal \& Hart, 2010; Nunes, 2014) ${ }^{20}$. Não é à toa que todos os especialistas que conheci que trabalhavam com autismo, como Clara e Pedro, ou eram neurologistas e médicos psiquiatras, ou eram da linha behaviorista ou cognitivo-comportamental da psicologia, em geral, críticas à psicanálise freudiana (López \& Sarti, 2013).

Há hoje, como mencionei no início deste texto, um consenso entre os especialistas de que, na prática, o autismo se traduziria em "dificuldades de comunicação e socialização”. Estas dificuldades seriam a não compreensão da obrigatoriedade arbitrária e subjetiva de seguirem regras sociais implícitas em situações cotidianas (muitos dizem que eles não têm "filtro social") e de compreensão de sinais culturais e sociais da comunicação, principalmente a comunicação não verbal (como entrelinhas, metáforas e expressões faciais). Tais “características”, apesar de marcarem uma imprevisibilidade de seus comportamentos em sociedade - mais uma marca de sua "subjetividade perigosa" -, não asseguram um consenso entre os especialistas a respeito de suas subjetividades ou sobre "quem são" essas pessoas. 


\section{Diversidade cerebral ou deficiência?}

No Brasil, Rios e Andrada (2015) apontam que o processo de construção diagnóstica do autismo é constituído por um duplo campo de tensões: teóricas e políticas. Seu status nosológico mais do que ser objeto de disputas teóricas - em torno de sua definição como uma condição orgânica ou psicológica - é palco de disputas políticas quanto à sua definição como uma "deficiência” ou uma "diferença”. Eu diria que estas duas questões se intersectam, e que os julgamentos morais que estas concepções carregam estão informados tanto pela possível causa do autismo quanto pela sua classificação.

Neste debate, os interesses acadêmicos voltam-se para a análise do surgimento de grupos de ativistas que entram no campo de disputas pela expertise na área, com a participação, por um lado, de autistas que reivindicam sua identidade de "neurodiversos" (Ortega, 2008; 2010; Fein, 2011) e, por outro, como já mencionei, de grupos de "mães especialistas" (Nunes, 2014; Eyal \& Hart, 2010; Rios, 2018; Hart, 2014), com crescente presença nas redes sociais (Ortega et al., 2013), que denunciam a condição "discapacitante" do autismo e reivindicam o acesso aos benefícios e políticas sociais para seus filhos.

Na visão desses atores, principais envolvidos nesta questão, o reconhecimento do autismo para todos os fins legais como uma "deficiência" 21 , por um lado, proporcionaria às pessoas diagnosticadas no espectro o acesso aos benefícios e políticas sociais, mas, por outro, acarretaria na incorporação de todos os estigmas de "déficit", "incapacidade" e "não autonomia" que esta categoria carrega em nosso senso comum. Por este motivo, tal nomenclatura é rechaçada por aqueles que advogam ser o autismo uma "neurodiversidade" (Ortega, 2010; Ortega \& Choudhurry, 2011; Fein, 2011), desobrigando as pessoas a vestirem o rótulo da "deficiência".

Apesar de minha pesquisa mostrar as barreiras simbólicas que essas pessoas enfrentam em seu dia a dia, esta "fatia" específica de pessoas com autismo que teria condições de levarem suas vidas sem grandes limitações é apenas uma parte pequena da camada da população situada no Espectro. Daí as reivindicações das cuidadoras para que o autismo seja considerado uma "deficiência".

Tais disputas indicam como os rótulos são complicados e o fato de "habitá-los" (ou não) têm efeitos práticos e simbólicos na vida e na construção de subjetividades das pessoas. Como comentei anteriormente, apesar de Tomás e sua mãe não nomearem a sua condição de "autismo", as categorias diagnósticas aparecem como centrais para compreensão da construção da sua subjetividade. Ao final do período 
de estágio na empresa, ele comentou comigo que "agora era um trabalhador" e que seu chefe havia lhe dito que "agora nem parecia mais que tinha dificuldades". Tal transformação subjetiva só pôde se efetivar, pragmaticamente, por conta de ter um diagnóstico válido para ter acesso às políticas sociais e, simbolicamente, por este “diagnóstico" (seja qual for) ter perdido a sua centralidade frente à nova realidade vivida no mundo do trabalho. Sua experiência mostra que, mais do que saber ou “aceitar" se tem autismo ou não, ou “incorporar" esta nomenclatura à sua identidade ou não, esta categoria é acionada ou ignorada ao longo de sua trajetória em situações diferentes e por diferentes atores e motivações. Suas ações e relações estabelecidas com os diversos atores que participaram de seu processo de inclusão transformaram o que é o "autismo" e "como é uma pessoa com autismo" ao longo de seu percurso, evidenciando o looping effect (Hacking, 2006; 2007) dessa categoria.

Autores como Rosenberg (2002) e Hacking (2006) têm mostrado que o processo de construção diagnóstica é histórico e complexo, e envolve não apenas saberes e poderes médicos, mas o papel ativo das pessoas diagnosticadas na construção destas categorias e das subjetividades envolvidas em sua nomeação. Ian Hacking (2006) analisa o processo de classificação das pessoas (o qual ele chama de making up people), mostrando como e por quem as pessoas são classificadas, como as classificações as afetam e, também, como estes efeitos das classificações nas pessoas modificam as próprias categorias (o que ele nomeia de looping effect das categorias). Tanto Rosenberg quando Hacking entendem que o ato de "diagnosticar" vincula a pessoa ao sistema social e tem, ao mesmo tempo, os efeitos de "rotular" e de "libertar”. Nas palavras de Rosenberg (2002:254-257), no momento da identificação diagnóstica, "uma cortina é retirada, e a incerteza é substituída - para melhor ou para pior - por uma estrutura narrativa”, na qual "ansiedade e mistério podem ser ordenados no sistema social”, fazendo do diagnóstico "uma necessidade emocional e burocrática” que atua na subjetificação das pessoas.

\section{Uma subjetividade autista?}

Em meu campo, a preocupação com a dessubjetificação das pessoas frente ao rótulo do diagnóstico não era apenas minha. Esta questão - reforçada pela especificidade do diagnóstico de autismo levar consigo a não presença de uma subjetividade empática - estava em jogo ao longo de todo meu trabalho de campo e nos diversos espaços por onde circulei.

Uma das queixas mais frequentes que escutei de agentes das políticas públicas 
com relação à inclusão de pessoas com deficiência nas empresas é a de que "elas não contratam pessoas, elas contratam deficiências”. Ao invés de fazerem um processo seletivo com foco nas competências e nas habilidades de cada candidato, elas já abrem as vagas direcionadas para uma deficiência específica ${ }^{22}$. Pessoas cegas são telefonistas, surdas trabalham em espaços de alto impacto de ruídos (como fábricas e pistas de aeroportos) e pessoas com Síndrome de Down são empacotadores de supermercados, comentou em entrevista ao rádio um fiscal da política de cotas. "Eles esquecem que ali tem uma pessoa", salientou Clara na saída de uma de suas visitas de consultoria, "me irrita ver como sempre julgam as capacidades deles pelo diagnóstico".

Ver a pessoa em primeiro lugar e não generalizar e homogeneizar as pessoas com deficiência são reivindicações que perpassam os debates dos Disability Studies e a história do Movimento Político das Pessoas com Deficiência. Desde a sua nomeação, passando pelas concepções do que é deficiência, até as suas lutas por direitos, tais atitudes são combatidas por terem um caráter capacitista ${ }^{23}$ (Campbell, 2009; Mello, 2016). No entanto, apesar dos esforços em ter a pessoa como foco (ou em primeiro plano), parece que o poder do sistema biomédico de pensamento e o encantamento pelo "funcionamento do cérebro", que perpassara toda a formação e a vida profissional dos médicos, são hegemônicas em nossa sociedade. Um fascínio pelas neurociências como base de um sistema de pensamento de explicação de si (Rose, 2008) é evidente entre esses profissionais. Quando falam, então, que "quando tu conheces uma pessoa com autismo, tu conheceu uma pessoa com autismo!"24, indicam não apenas que devemos prestar atenção na pessoa como um indivíduo único, mas que não há como generalizar as características do diagnóstico neurológico em si. E, nesta multiplicidade de sujeitos dentro de uma única nomeação diagnóstica, vemos mais uma especificidade desta "categoria perigosa".

Foram muitas as vezes que senti como se os médicos neurologistas e psiquiatras, e também Clara, estivessem falando do cérebro como uma entidade autônoma e com vida própria. Como no dia em que ouvi este comentário de Pedro, um psiquiatra especializado em autismo, em uma de nossas conversas:

Trabalhar com pessoas com TEA é como sintonizar uma rádio naqueles aparelhos antigos. Tem que girar o botão devagar, com precisão, até pegar bem a frequência (...) às vezes leva meses para que a gente consiga entrar em sintonia e começar uma troca, às vezes pode ser instantâneo. 
Pedro já acompanhou a inclusão de vários pacientes no mercado de trabalho e comenta que "o problema é que as empresas não estão prontas para lidar com pessoas com autismo”. A grande maioria, diz ele,

tem dificuldade de aceitar e até de entender que o autista não vai mudar, ele não vai desenvolver muitos dos comportamentos exigidos no mercado de trabalho (...) Depois de um tempo trabalhando na empresa, tu não vais pedir para um cadeirante levantar, mas as pessoas esperam que o autista possa começar a se entrosar, ou possa mudar de departamento e atender o público, por exemplo.

Essa fala de Pedro expressa a necessidade de adaptação da sociedade para incluir as pessoas com deficiência, mas também reafirma a concepção do autismo como uma condição cerebral, situada no campo do biológico e, portanto, "sem cura", sem possibilidades de mudança. Tal ideia, paradoxalmente (ou não!), é compartilhada pelo Movimento da Neurodiversidade, (Ortega, 2008; 2010), o qual considera o autismo como uma outra forma de ver, viver e estar no mundo.

$\mathrm{Na}$ interpretação dos especialistas e, também, dos Aspies, com quem convivi ou conversei, a própria subjetividade das pessoas com autismo parecia ser entendida, até certo ponto, como constituída biológica ou neurologicamente. "Não somos doentes, não temos déficits ou deficiências, somos neurodiversos". "É a sociedade que não tem a capacidade de nos entender e de se comunicar conosco", dizem os ativistas deste movimento.

Inicialmente, num olhar das ciências humanas, como bem indicam Dias Duarte (2018) e Ortega (2008), esta "biologização dos sujeitos" por parte dos ativistas neurodiversos levaria a uma crítica ao reducionismo presente na compreensão do humano como totalmente "fisicalista" ou "naturalista", típica de uma visão biomédica que acarretaria numa concepção reducionista e desubjetivante de pessoa e numa concepção de subjetividade que não concebe as categorias como relacionais (Campoy, 2015). No entanto, no caso do autismo, essas críticas devem ser problematizadas, pois, neste caso, há uma certa positivação da condição e uma compreensão desta "biologia" na chave interpretativa de uma "diversidade humana", que é, de certa forma, não hierárquica e não patologizante. Por outro lado, se é verdade que há um esvaziamento do sujeito na biologização da compreensão da "subjetividade autista”, há também uma ressubjetivação específica destas pessoas a partir dos próprios "traços" do autismo, como constituidores de um "sujeito moral". 
Luiz Fernando Dias Duarte (1983) desenvolve com densidade a constituição do sujeito moderno como a unidade significativa do valor atribuído ao indivíduo: "sujeito da razão, da história e da moral" (1983: 7). Desenvolver um debate aprofundado sobre as moralidades que envolvem a produção de uma "subjetividade autista" vai além do espaço deste texto, no entanto, cabe indicar que a atribuição de características morais ao "cérebro diverso" poderia indicar uma exacerbação da individuação, própria do sujeito moderno analisado por Duarte. Para os objetivos centrais deste texto, cabe perceber que esta ideia fisicalista sobre quem é o sujeito com autismo, além de não ser consenso nas disputas entre experts, tem efeitos práticos na inclusão destas pessoas no espaço laboral, no sentido de que, apesar de positivada, esta subjetividade pode tornar-se "exótica".

Um dos neurologistas do Hospital de Clínicas de Porto Alegre, em entrevista ao programa de TV Vida e Saúde (2013), afirma que: “os autistas são ingênuos, bons e sinceros. Eles são incapazes de dizer uma mentira. Não porque querem, mas porque eles não podem ser de outra forma", e finaliza sua fala afirmando: "Se você quer uma pessoa honesta, contrate um autista". Em uma de nossas conversas, também o psiquiatra Pedro tenta me explicar esta "especificidade" dos autistas, dizendo que "é como se eles tivessem uma forma infantil de pensar. Não têm filtro social, sabe? Dizem o que querem, quando querem. Parecem crianças na fase dos porquês, já que são desconhecedores da maldade e das regras sociais, então cometem gafes seguidamente" (Pedro, entrevista em abril de 2015).

Na prática cotidiana das empresas, as "gafes" a que se refere Pedro, muitas vezes narradas como engraçadas, nem sempre (ou quase nunca) são compreendidas como sendo "coisas do autismo" e, mesmo quando são, não são bem recebidas. Foram várias as histórias anedóticas que presenciei e escutei ao longo da minha etnografia que ilustram "desentendimentos" entre neurodiversos (autistas) e neurotípicos (não autistas). Foram muitos também os momentos de tensão e as injustiças e violências que presenciei devido à incompreensão desta outra forma de estar no mundo.

\section{O cotidiano nas empresas}

Ao longo de minha etnografia com Tomás, convivi com ele por seis meses na empresa na qual teve sua primeira experiência de trabalho. Durante esse tempo, sua característica de "não solicitar nova tarefa ao ter acabado as atribuições que lhe tinham delegado" e "não se entrosar com as pessoas" foram seguidamente apontadas como possíveis causas de sua não contratação após o período de experiência. 
"Hoje em dia temos que vestir a camiseta, construir boas relações com os colegas. Se ele continuar assim isolado não sei se fica”, comentou um colega de trabalho. "Ele fica ali paradão, não tem iniciativa de procurar o que fazer", além de "não falar com ninguém, almoçar sempre sozinho”, me relatou outra funcionária do setor em que Tomás trabalhava, seguindo com a pergunta: “Mas afinal, o que ele tem, hein?".

Além desses traços, Tomás, aos olhos dos colegas, parecia frágil e representava, de certa forma, um "perigo" no ambiente de trabalho: alguém cujas atitudes eram imprevisíveis e com as quais os colegas poderiam não saber lidar. Seu Luís contou-me que "um dia congelou em frente às prateleiras do depósito, ficando lá imóvel por alguns minutos", chamando a minha atenção para o perigo que era ter um rapaz como ele naquele espaço. "E se vem uma empilhadeira? Eles andam rápido naquelas coisas! E se ele, de uma hora pra outra, tem um troço lá? Perigoso isso”, alertou.

No caso de Tomás, a empresa não havia feito o que no espaço empresarial se chama "sensibilização dos funcionários" para a chegada de uma pessoa com deficiência. Seus gestores e colegas não sabiam do diagnóstico de Tomás, o que fez com que nos primeiros meses, as fofocas sobre "seu autismo" fossem assunto pelos corredores da empresa. Aos poucos os colegas foram "se acostumando" com o jeito do menino e alguns pesquisando na internet os "sintomas" da sua condição, explicavam o porquê de Tomás ser daquele jeito para os demais.

Tomás não falava muito, então, as "gafes" mencionadas por Pedro eram menos frequentes, mas num mercado que exige "pró-atividade" e "inteligência emocional”, tais "qualidades do autismo" colocam barreiras muitas vezes intransponíveis se a contratação das pessoas com este diagnóstico não pressupõe uma concepção de processo inclusivo.

Tais "gafes", geralmente identificadas como "próprias dos autistas", também eram corriqueiras no cotidiano de outro interlocutor de minha pesquisa. Durante os quatro meses em que estive na empresa onde Ricardo trabalhava, escutei várias histórias sobre as "suas gafes". A gerente do setor onde ele trabalhava contou que

o Ricardo é um sarro. Um dia a gente pediu que ele distribuísse os convites da reunião com a diretoria para os colaboradores. Ele perguntou quais funcionários. Daí eu disse para ele distribuir para todos os setores. Ele deu convite pros porteiros, faxineiras pro pessoal da segurança... E todos foram na reunião geral! Sabe que isso fez com que caísse uma ficha na gente, né! Ele nos deu uma aula de horizontalização da gestão ali! (Gerente do Ricardo, agosto de 2014). 
Estes mal-entendidos, no entanto, não geravam apenas situações jocosas ou resultados "positivos". Momentos de tensão também faziam parte do cotidiano das relações de Ricardo com os colegas na empresa. Frequentemente sobrecarregados de atividades extras, eles tentavam, sem sucesso, dividi-las com Ricardo. Ao ser solicitado, ele seguia à risca suas atribuições, dizendo que "aquela tarefa não estava prevista em seu cronograma semanal", ou "Ah, não, essas coisas são muito chatas de fazer".

Tais situações foram entendidas por alguns colegas como "coisas do autismo" e por outros como "resultado do mimo excessivo da mãe de Ricardo" ou "esperteza do guri". Clara disse que é bem comum as pessoas se irritarem ou não entenderem esse jeito de eles se comportarem. "Se tu falas que as tarefas são tais, ele vai seguir aquele protocolo". Em um dia em que fizemos várias visitas às empresas que estavam com "casos de inclusão de autistas", presenciei mais algumas destas situações de tensão, nas quais julgamentos morais estavam presentes:

Um dia, um menino que trabalhava em um supermercado foi "flagrado" com vários pacotes de bolacha na sua mochila, quando a verificaram na saída do turno. $\mathrm{O}$ gerente o acusou de roubo e foi um bafafá... O menino disse que havia guardado as bolachas para os colegas porque nas bolsas deles não tinha espaço. Daí me chamaram pra resolver o problema. Eu disse pro gerente que ele acreditasse no menino. Eles não mentem. Se ele disse que foi assim, é porque foi isso que aconteceu. Eu conheço eles [as pessoas com autismo]. (Clara, agosto de 2014).

Uma outra vez foi parecido. Alguém no super reclamou que tinha esquecido o celular em casa e que ficava perdido sem saber as horas e dar uma olhadinha na internet de vez em quando. Não é que o guri diz o seguinte: "Ah eu te dou um. Tem um monte no meu armarinho!”. Um colega roubava os celulares e pedia pro guri guardar pra ele. (Clara, agosto de 2014).

A Maria tem dado bastante problema lá no hospital. Volta e meia me chamam pra conversar com ela e com as colegas. Ela senta no chão dos corredores quando tá cansada; entra na sala da diretora pra conversar e fica lá de papo, come os iogurtes das refeições dos pacientes... E também as colegas de trabalho não conseguem lidar muito com ela. Quem gosta de escutar, assim na lata, as verdades da vida, né? Porque ela chega e diz: "Olha, tu tá mais gorda. Dá pra ver a barriga” ou "Eu não gosto de ti. Tu é bem chata”. (Clara, setembro de 2014).

Tais situações, apesar de gerarem mal-estar e tensão no cotidiano das empre- 
sas, não tiveram punições severas como resultado. Já outros casos que escutei em conversas com os jovens com autismo que conheci, isso não ocorreu. Fabian, um jovem de 24 anos, diagnosticado com Asperger, por exemplo, contou-me que em um de seus primeiros empregos, elogiou a beleza da sua chefe dizendo que "gostaria de namorar com ela”. Segundo ele, tal situação, somada a outras similares, nas quais "estava apenas falando a verdade de como se sentia”, lhe renderam um processo de danos morais. "Não adiantou eu dizer que era autista. Eles não levaram minha condição em consideração". Fabian me conta que ele nunca diz que é autista antes de entrar em um emprego. Se o fizesse, não seria contratado. Mas, por outro lado, reconhece que se não expõe sua condição, não tem acesso a um tratamento diferenciado.

\section{Sobre deficiência, autismo e políticas de inclusão}

Ao longo de toda a minha pesquisa de campo no Rio Grande do Sul, meus interlocutores pouco mencionaram uma possível “epidemia de autismo”, mas os discursos das mães de autistas na internet e de especialistas nos eventos nacionais e internacionais que participei traziam números alarmantes e salientavam a importância da comunidade médica e acadêmica direcionarem seus olhares para esta condição. $\mathrm{O}$ autismo se tornava, em seus discursos, uma urgência médica a ser conhecida e atendida pelo poder público, ao mesmo tempo em que se transformava em uma nova fatia de mercado ainda não explorada para os profissionais da medicina e psicologia. O discurso da "epidemia” legitimava o autismo como uma questão pública tanto na busca por recursos de pesquisa quanto na obtenção de direitos sociais.

Neste texto, procurei mostrar alguns elementos que estão em jogo nesta questão. O caráter fluido e subjetivo da construção do diagnóstico de autismo e a maior amplitude que a mudança do seu status nosológico para "espectro do autismo", assim como a crescente midiatização do fenômeno, podem ter dado margem a um crescente número de pessoas que se enquadram no espectro, contribuindo para a legibilidade quantitativa da condição, fundamental na conquista de espaço na agenda política.

Trouxe também para o debate o fato de que os efeitos desta legibilidade podem estar na aprovação da lei Berenice Pianna e de novas políticas públicas específicas para esta população, como, aqui no Rio Grande do Sul, na criação do projeto Autismo e Mercado de Trabalho. Por outro lado, também a Lei, ao dar maior visibilidade ao autismo, teve efeitos na crescente onda de diagnósticos, agora legitimados 
frente ao acesso aos direitos sociais dela advindos. Não há "números" para auxiliar na reflexão sobre este assunto. O que posso afirmar é que, se essa questão aponta para possíveis efeitos em um nível "macrossociológico" na minha pesquisa, e aparece apenas superficialmente em meu campo, em um nível mais micro, são as formas de compreensão sobre o que é o autismo em si e sobre como lidar com essas pessoas no cotidiano dos processos de inclusão que ganham maior espaço.

Como mencionei, uma das críticas aos processos de recrutamento e seleção das empresas é o fato de elas "contratarem a deficiência e não a pessoa”. No mercado de trabalho, alguns diagnósticos são mais "bem-vindos" que outros na valoração das vidas (Fassin, 2009) - e nas empresas parece ficar o caráter produtor de "subjetividades perigosas" do autismo. O perigo da incerteza do diagnóstico; o perigo de não ter como tipificar "um perfil comportamental"; o perigo de não poder prever como autistas reagirão em situações de tensão ou não rotineiras colocam barreiras atitudinais bastante distintas das encontradas na inclusão de pessoas com deficiência que necessitam de mudanças nos espaços físicos e/ou de tecnologias assistivas, e, por isso, mais difíceis de serem derrubadas.

Além disso, o pouco conhecimento sobre o espectro do autismo, o caráter "clínico" do seu processo diagnóstico e as disputas em torno desta categoria por parte de especialistas também dificultam a obtenção de um laudo que dá acesso às políticas públicas. E o desconhecimento das chamadas características específicas dos neurodiversos pela população em geral levam a julgamentos morais de responsabilização da mãe e dos próprios autistas por suas atitudes "pouco simpáticas" ou "ingênuas", levando muitas vezes a confrontos e momentos de tensão em seus cotidianos.

Com isso, quero salientar que é nas interações sociais que as diferenças de comunicação e interação entre neurodiversos e neurotípicos aparecem e mostram seus efeitos. Romper a barreira que impede o acesso das pessoas com autismo à participação plena na vida social implicaria, então, no questionamento das normatividades impostas na nossa forma de nos comunicarmos e interagirmos com as pessoas, entendendo-as como mais uma entre tantas outras maneiras de estar no mundo.

Nesta tarefa reflexiva, etnografias mostram-se fundamentais para uma compreensão aprofundada tanto do autismo em si, como mais uma entre tantas diversidades humanas, quanto sobre as relações sociais que envolvem pessoas com esta condição. É quando lançamos um olhar mais atento ao cotidiano e à prática das políticas de inclusão que percebemos o quanto direcionar o foco de nossas pesquisas para as pessoas é fundamental. Se em "casos de sucesso" como os de Tomás e Ricardo já 
encontramos tantas barreiras a serem ainda rompidas, novos estudos sobre os casos que "não deram certo" se fazem urgentes para a análise das políticas direcionadas a esta camada da população.

Recebido: 14/02/2019

Aprovado: 05/04/2019

Valéria Aydos é bacharel em Ciências Sociais, mestre e doutora em Antropologia Social pela Universidade Federal do Rio Grande do Sul (UFRGS), com estágio no King's College London, supervisionado pelo prof. Dr. Nikolas Rose. Seus interesses e áreas de pesquisa são os estudos antropológicos sobre Cidadania, Políticas Públicas, Deficiência e Trabalho, buscando perceber as relações entre os modos de governo, a cultura e as subjetividades que se constituem nas dinâmicas dos processos de produção diagnóstica e na inclusão social das pessoas com autismo no mercado de trabalho. Atualmente é pós-doutoranda no PPGAS-UFRGS, aonde atua como professora e pesquisadora vinculada ao Núcleo de Antropologia da Cidadania (NACI), além de participar de Comitês de Assessoramento em Deficiência, Acessibilidade e Inclusão (ANPOCS, ABA, PPGAS-UFRGS). ORCID: 0000-0002-3298-5727. Contato: valeria.aydos@gmail.com

\section{Notas}

1. A pesquisa de doutorado que deu origem a este texto foi financiada pelo CNPq e, posteriormente, contou com bolsa Capes PNPD, junto ao PPGAS-UFRGS. Agradeço a minha orientadora Dra. Patrice Schuch, à colega Helena Fietz, aos colegas do Núcleo de Antropologia do Corpo e da Saúde da UFRGS, especialmente à professora Dra. Ceres Victora, e aos participantes do GT Etnografias da Deficiência (RBA 2018), pela atenta leitura e ricas sugestões.

2. A deficiência é vista aqui de forma relacional (corpos com lesões ou impedimentos em interação com a sociedade na qual existem) e como uma diversidade humana (Diniz, 2012; Ginsburg; Rapp, 2013; Mello; Nuernmberg, 2012).

3. Segundo Ortega (2018), o consenso seria sobre o autismo ser uma neurobiological disorder. Este conceito não implica, porém, em uma ideia comum sobre suas causas e muito menos sobre seu possível tratamento e/ou cura. 
4. A Nosologia é a área da medicina que se dedica ao estudo, descrição e classificação das diferentes doenças.

5. Refiro-me ao Projeto Piloto de Incentivo à Inclusão de Pessoas com Deficiência no Rio Grande do Sul, de iniciativa da Superintendência Regional do Trabalho, e vinculado ao projeto do governo federal Viver Sem Limites.

6. A Lei 8213/1991 estabelece que empresas com mais de 100 funcionários, devem ter de 2 a 5\% de pessoas com deficiência em seu quadro laboral. Ao longo dos processos de inclusão a partir do Projeto de Aprendizado, são três as políticas públicas com as quais meus interlocutores "interagem": o Benefício da Progressão Continuada, a Lei do Aprendiz (L.10.097/00) e a Lei de Cotas (L. 8213/91). Uma análise aprofundada das implicações destas políticas nos processos de inclusão e na vida e na produção de subjetividade de meus interlocutores pode ser encontrada em Aydos (2016) e Aydos \& Fietz (2017).

7. Refiro-me a participantes do "Movimento da Neurodiversidade" e de ONGs de promoção do "orgulho autista” na Inglaterra, com os quais conversei durante o doutorado sanduíche (2015-2016) e/ou pelo facebook.

8. Todos os nomes são fictícios.

9. Por coprodução refiro-me ao que Jasanoff (2004) destaca como sendo a influência mútua dos diferentes atores na construção de uma rede, ao modo como estes atores são induzidos uns pelos outros a agirem.

10. A CID-10 (Classificação Estatística Internacional de Doenças) indica as deficiências reconhecidas em lei para obtenção de benefícios e políticas sociais. Sobre os debates em torno destas produções diagnósticas, ver: Diniz, Barbosa \& Santos (2010) e Mattos (2016).

11. Utilizo o termo biomédico TEA quando me refiro ao diagnóstico médico. Ao longo do texto utilizarei "autismo" por ser a nomeação mais corriqueira em meu campo e abranger várias concepções diferentes sobre a “condição". Utilizo também “condição” ao invés de "transtorno" para marcar minha postura despatologizante com relação ao autismo.

12. A partir da atual edição do DSMV (Diagnostic and Statistical Manual of Mental Disorders), a Síndrome de Asperger situa-se no Espectro do Autismo.

13. Nos debates sobre o Festival "E assim vivemos", de 2013, podemos encontrar algumas narrativas de pessoas diagnosticadas tardiamente com autismo. Disponível em: https://vimeo. com/78497001.

14. Refiro-me aqui, por exemplo, aos vários estudos inspirados pela análise do diagnóstico como um dispositivo de subjetivação (Foucault, 2006); de produção de biossocialidades (Rabinow, 2008) e biolegitimidades (Maluf, 2015).

15. As mães que participam de associações e/ou estão mais envolvidas na busca por direitos de seus filhos autodenominam-se "mães azuis", pelo autismo ser predominantemente um diagnóstico encontrado em meninos (a cada cinco, quatro são meninos).

16. Cascio, Andrada e Bezerra, (2018) mostram que também nos CAPIs existe demora na produção do diagnóstico, mas por outro motivo: a resistência da linha psicanalítica em "rotular a criança" e em identificar o autismo como "deficiência". Para as controvérsias internas no campo psi ver também Rios \& Andrada (2015) e Ortega (2018). 
17. Transtorno do Déficit de Atenção e Hiperatividade.

18. Ecolalia é um distúrbio que causa repetição da fala (palavra ou frase).

19. Cabe comentar que Cascio, Andrada \& Bezerra Jr (2018) indicam uma forte influência da psicanálise nos atendimentos nos CAPSs e CAPSIs brasileiros. No entanto, nas escolas e no mercado de trabalho, a linha comportamental e biomédica é hegemônica.

20. Também foi rechaçada a ideia de que autistas não teriam uma "Teoria da Mente”, ou, em resumo, a capacidade de ter empatia (Silverman, 2008; Ochs et al., 2004).

21. A Lei 12.764, de 2012 foi uma luta política principalmente das chamadas "mães de autistas" (Rios \& Andrada, 2015; Nunes, 2014), lideradas por Berenice Pianna, do Rio de Janeiro.

22. No Brasil, a contratação de autistas é ainda incipiente, mas na Inglaterra é comum vermos autistas em cargos de Tecnologia da Informação. Tal experiência foi um dos destaques de uma feira anual sobre Autismo, chamada de The Autism Show (http://autismshow.co.uk/), da qual participei em 2016.

23. Capacitismo, do inglês, ableism, é um termo utilizado para indicar o preconceito e a discriminação contra a pessoa com deficiência; em geral denunciando o julgamento das capacidades da pessoa a priori e a partir de sua lesão ou impedimento.

24. Esta frase foi repetida diversas vezes em palestras sobre autismo de que participei, e é um dos lemas da organização não governamental Autistic UK, cujas atividades nas redes sociais tenho acompanhado no momento.

\section{Referências bibliográficas}

AYDOS, Valeria; FIETZ, Helena. 2017. When citizenship demands Care. Disability Studies Quarterly, v. 37, n. 4. Disponível em: http://dsq-sds.org/article/view/6087. Acesso em: 30 de janeiro de 2019.

AYDOS, Valéria. 2016. Agência e subjetivação na gestão de pessoas com deficiência: a inclusão no mercado de trabalho de um jovem diagnosticado com autismo. Horizontes Antropológicos. Porto Alegre, ano 22, n. 46, jul/dez, p. 329-358. Disponível em: http://www.scielo.br/pdf/ha/v22n46/ 0104-7183-ha-22-46-0329.pdf. Acesso em: 30 de janeiro de 2019.

CAMPBELL, Fiona. 2009. Contours of ableism: The production of disability and abledness. New South Wales: Springer.

CAMPOY, Leonardo. 2015. Autismo em ação: reflexões etnográficas sem aprovação de comitês de ética sobre a clínica e o cuidado de crianças autistas. Revista de Ciências Sociais Política e Trabalho, n. 42, jan-jul, p. 155-174. Disponível em: http://www.periodicos.ufpb.br/ojs/index.php/politicaetrabalho/ article/view/22803. Acesso em: 23 setembro de 2018.

CASCIO, M. Ariel; ANDRADA, Barbara Costa; BEZERRA Jr., Benilton. 2018. Psychiatric Reform and Autism Services in Italy and Brazil. In: FEIN, Elizabeth; RIOS, Clarice (eds.). Autism in Translation. An Intercultural Conversation on Autism Spectrum Conditions. Culture, Mind and Society, University of Tulsa, USA. p. 53-88.

COSTA, Jurandir Freire; GRINKER, Roy Richard. 2018. Autism and First-Person Accounts: The cognitive problem. In: FEIN, Elizabeth; RIOS, Clarice (eds.). Autism in Translation. An Intercultural Conversation on Autism Spectrum Conditions. Culture, Mind and Society, University of Tulsa, 
USA. p. 155-174.

DIAS DUARTE, Luiz Fernando. 2018. Ciências Humanas e Neurociências: um confronto crítico a partir de um contexto educacional. RBCS, v. 33, n. 97.

DIAS DUARTE, Luiz Fernando. 1983. Três ensaios sobre pessoa e modernidade. Boletim do Museu Nacional. Rio de Janeiro (datilografado).

DINIZ, Débora. 2012. O que é deficiência. São Paulo: Brasiliense.

EYAL, Gil; HART, Brendan. 2010. How parents of autistic children became experts on their own children: Notes towards a sociology of expertise. Annual Conference of the Berkeley Journal of Sociology.

EYAL, Gil et al. 2010. The autism matrix. The social origins of the autism epidemic. Cambridge, Maden: Polity Press.

FASSIN, Didier. 2009. Another Politics of Life is Possible. Theory, Culture and Society, v. 26, n. 5, p. 44-60. Disponível em: https://journals. sagepub.com/doi/abs/10.1177/02632764091063 49. Acesso em: 23 de abril de 2018.

FEIN, Elizabeth. 2018. Autism as a mode of engagement. In: FEIN, Elizabeth; RIOS, Clarice (eds.). Autism in Translation. An Intercultural Conversation on Autism Spectrum Conditions. Culture, Mind and Society, University of Tulsa, USA. p. 129-154.

FEIN, Elizabeth. 2011. Innocent machines: Asperger's syndrome and the neurostructural self. Sociological reflections on the neurosciences. Advances in medical sociology. Emerald Group Publishing, v. 13, p. 27-49.

FERREIRA, F. 2015. A negociação do diagnóstico de autismo. Monografia [Trabalho de Conclusão de Curso], Universidade Federal do Rio Grande do Sul, Porto Alegre.

FITZGERALD, Des. 2015. Autism, ignorance and love. Science and Culture, v. 22, n. 3, p. 394-400. FOUCAULT, Michel. 2006. O nascimento da clínica. Rio de Janeiro: Forense Universitária.

GIDDENS, Anthony. 1993. The Transformation of Intimacy. Sexuality, Love and Erotism in Modern Societies. Cambridge: Polity Press/Blackwell Publishers.

GINSBURG, Faye; RAPP, Rayna. 2013. Disability worlds. Annual Review of Anthropology, Palo Alto, v. 42, p. 53-68.

GRINKER, Roy Richard. 2010, Commentary: On being autistic, and social. Ethos: Journal of the Society for Psychological Anthropology, v. 38, issue 1, p. 172-178. Disponível em: https: / /anthrosource.onlinelibrary.wiley.com/doi/full/10.1111/j.1548-1352.2010.01087. Acesso em: 23 de maio de 2018.

GRINKER, Roy Richard; MANDEL, David. 2015. Notes on a puzzle piece. Autism, SAGE publications, p. 1-3. Disponível em: https://journals.sagepub.com/doi/full/10.1177/ 1362361315589293. Acesso em: 23 de maio de 2018.

HACKING, Ian. 2009. Autistic autobiography. The Philosophical Transactions of the Royal Society, n. 364, p. 1467-1473. Disponível em: https://royalsocietypublishing.org/doi/pdf/ 10.1098/ rstb.2008.0329. Acesso em: 23 de maio de 2018.

HACKING, Ian. 2007. Kinds of people. Moving targets. Proceedings of the British Academy, n. 151, p. 285-318.

HACKING, Ian. 2006. Making up people: clinical classifications. London Review of Books, v. $28, \mathrm{n}$. 16, August. Disponível em: https: / /www.lrb.co.uk/v28/n16/ian-hacking/making-up-people. 
Acesso em: 23 de maio de 2018.

HART, Brendan. 2014. Autism parents \& neurodiversity: radical translation, joint embodiment and the prosthetic environment. Biosocieties, v. 9, n. 3, p. 284-303.

HOLLIN, Gregory. 2014. Autism, sociality, and human nature. Somathosphere. Science, Medicine, and Anthropology. June, 18th. Disponível em: http: / / somatosphere.net/2014/06/autism-sociality-and-human-nature.html. Acesso em: 30 de maio de 2018.

HOLLIN, Gregory. 2014a. Construction a social subject:Autism and human sociality in the 1980s. History of the Human Sciences, v. 27, n. 4, p. 98-115.

JASANOFF, Sheila. 2004. The idiom of co-production. In: duction of science and social order. New York: Routledge. . States of knowledge: the copro-

LOPEZ, Rosa Maria Monteiro; SARTI, Cynthia. 2013. Eles vão ficando mais próximos do normal... Considerações sobre normalização na assistência ao autismo infantil. Ideias. Campinas, n. 6, nova série, 1, p. 77-98. Disponível em: https://periodicos.sbu.unicamp.br/ojs/index.php/ideias/article/ view/8649399. Acesso em: 10 de abril de 2017.

MALUF, Sônia W. 2015. Biolegitimacy, rights and social policies: New biopolitical regimes in mental healthcare in Brazil. Vibrant: Virtual Brazilian Anthropology, Brasília, v. 12, n. 1, June, p. 321-350.

MATTOS, Lisiane G de. 2016. Como se decide a (in)capacidade e a deficiência? Uma etnografia sobre moralidades e conflitos em torno da perícia médica previdenciária. Tese [Doutorado em Antropologia Social], Universidade Federal do Rio Grande do Sul, Porto Alegre.

MELLO, Anahi. G. de. 2016. "Deficiência, incapacidade e vulnerabilidade: do capacitismo ou a preeminência capacitista e biomédica do Comitê de Ética em Pesquisa da UFSC”. Ciência \& Saúde Coletiva, v. 21, n. 10, p. 3265-3276. Disponível em: http://www.scielo.br/scielo.php? pid=S1413-81232016001003265\&script $=$ sciabstract\&tlng=pt Acesso em: 10 de abril de 2017.

MELLO, Anahi Guedes; NUERNBERG, Adriano Henrique. 2012. Gênero e deficiência: intersecções e perspectivas. Estudos Feministas, Florianópolis, v. 20, n. 3, p. 635-655. Disponível em: https: / / periodicos.ufsc.br/index.php/ref/article/view/S0104-026X2012000300 003. Acesso em: $10 \mathrm{de}$ abril de 2017.

NUBILA, Heloisa Brunow Ventura Di. 2007. Aplicação das classificações CID-10 e CIF nas definições de deficiência e incapacidade. Tese [Doutorado em Saúde Pública], Universidade de São Paulo, São Paulo.

NUNES, Fernanda. 2014. Atuação política de grupos de pais de autistas no Rio de Janeiro: perspectivas para o campo da saúde. Dissertação [Mestrado em Saúde Coletiva], Instituto de Medicina Social, Rio de Janeiro.

OCHS, Elinor et al. 2004. Autism and the social world: an anthropological perspective. Discourse Studies, v. 6, n. 1, p. 147-183. London; Thousand Oaks; New Delhi: SAGE Publications.

ORTEGA, Francisco et al. 2013. A construção social do diagnóstico do autismo em uma rede social virtual brasileira. Interface. Comunicação, Saúde, Educação, v. 17, n. 44, jan/mar, p. 119-132. Disponível em: http://www.scielo.br/pdf/icse/v17n44/a10v17n44.pdf Acesso em: 10 de abril de 2017.

ORTEGA, Francisco. 2010. Deficiência, autismo e neurodiversidade. In: DINIZ, Débora \& SANTOS, Wederson (orgs.). Deficiência e Discriminação. Brasília: Letras e Livres. p. 143-168.

ORTEGA, Francisco. 2008. O sujeito cerebral e o movimento da neurodiversidade. Mana, v. 14, n. 2, p. 477-509. Disponível em: http://www.scielo.br/pdf/mana/v14n2/a08v14n2.pdf. Acesso em: 10 
de abril de 2017.

ORTEGA, Francisco. 2018. Commentary. Why not both? Negotiating ideias about autism in Italy, Brazil and the US. In: FEIN, Elizabeth; RIOS, Clarice (eds.). Autism in Translation. An Intercultural Conversation on Autism Spectrum Conditions. Culture, Mind and Society, University of Tulsa, USA. p. $89-108$.

ORTEGA, Francisco; CHOUDHURY, Suparna. 2011. 'Wired up differently: Autism, adolescence and the politics of neurological identities. Subjetivity. Macmillan Publishers, v. 4, n. 3, p. 323-345.

RABINOW, Paul. 2008. Afterword: concept work. In: GIBBON, Sahra; NOVAS, Carlos. Biosocialities, genetics and the social sciences: making biologies and identities, Taylor \& Francis e-Library.

RIOS, Clarice; ORTEGA, Francisco; ZORZANELLI, Rafaela; NASCIMENTO, Leonardo Fernandes. 2015. Da invisibilidade à epidemia. A construção narrativa do autismo na mídia impressa brasileira. Interface: Comunicação, Saúde, Educação. Rio de Janeiro, v. 19, n. 53, p. 325-336. Disponível em: http://www.scielo.br/pdf/icse/v19n53/1807-5762-icse-1807-576220140146. pdf. Acesso em: 10 de abril de 2017.

RIOS, Clarice. 2018. Experts on your own child, expert on your own world. Reinventing autism expertise(s). In: FEIN, Elizabeth; RIOS, Clarice (eds.). Autism in Translation. An Intercultural Conversation on Autism Spectrum Conditions. Culture, Mind and Society, University of Tulsa, USA, p. 185-206.

RIOS, Clarice; ANDRADA, Bárbara Costa. 2015. The changing face of autism in Brazil. Culture, Medicine and Psychiatry, v. 39, issue 2, April, p. 213-234. Disponível em: https:/ / leicufrj.files. wordpress.com/2017/05/rios-clarice-the-changing-face-of-autism1.pdf. Acesso em: 10 de abril de 2017.

ROSE, Nikolas. 1997. Assembling the modern self. In: PORTER, Roy (ed.). Rewriting the self. Histories from the Renaissance to the present. London; New York: Routledge, p. 224-288.

ROSE, Nikolas. 2008. Psicologia como uma ciência social. Psicologia e Sociedade, v. 20, n. 2, p. 155 164. Disponível em: http://www.scielo.br/pdf/psoc/v20n2/a02v20n2.pdf. Acesso em: 23 de maio de 2018.

ROSE, Nikolas. 2013. The human sciences in a Biological Age. Theory, Culture and Society, v. 30, p. 1, p. 3-34.

ROSENBERG, Charles E. 2002. The tyranny of diagnosis: Specific entities and individual experience. The Milbank Quarterly, v. 80, n. 2, p. 237-260. Disponível em: https://www.ncbi.nlm.nih.gov/pmc/ articles/PMC2690110/. Acesso em: 23 de maio de 2018.

SILVERMAN, Chloe. 2008. Fieldwork in another planet: Social Science Perspectives on the Autism Spectrum. Biosocieties, v. 3, issue 03, Sept., p. 325-341, Cambridge: Cambridge Journals.

SOLOMON, Olga. 2013. Autism affordances of achievement. Narrative genres and parenting practices. In: LONG, Nicholas J.; MOORE, Henrietta L. The social life of achievement. New York; Oxford: Berghahn. p. 120-138.

VALTELLINA, Enrico. 2018. A. S. Classification, Interpellation. In: FEIN, Elizabeth; RIOS, Clarice (eds.). Autism in Translation. An Intercultural Conversation on Autism Spectrum Conditions. Culture, Mind and Society, University of Tulsa, USA, p. 207-230. 
$A$ (des)construção social do diagnóstico de autismo no contexto das políticas de cotas para pessoas com deficiência no mercado de trabalho

Resumo: No cenário de uma crescente propagação midiática sobre o autismo, a flexibilidade e a complexidade da sua produção como um “diagnóstico clínico" e situado em um espectro altamente diversificado, somam-se aos debates sobre esta condição ser uma deficiência ou uma neurodiversidade uma “maneira de ser". A partir de uma etnografia que contou com entrevistas em profundidade com neurologistas e psiquiatras; uma convivência de três anos com dois jovens diagnosticados com autismo em seus espaços de trabalho e sociabilidade; e o acompanhamento do cotidiano de trabalho de assessoria em inclusão de uma especialista no assunto, analiso a construção social do diagnóstico do autismo e os efeitos das diferentes formas de entender, "habitar" e agenciar esta condição nos espaços laborais. Tal pesquisa permitiu-me problematizar a centralidade do conhecimento neurobiológico e dos especialistas psi e relativizar estes saberes na produção diagnóstica do autismo e na efetivação da política de cotas. Analiso também as estratégias de inserção do autismo na agenda pública, mostrando, na prática, como os diversos atores envolvidos nas disputas em torno do seu status nosológico coproduzem novos sujeitos, relações e sensibilidades sociais no Brasil.

Palavras-chave: Autismo, Deficiência, Processos Diagnósticos, Trabalho, Políticas Públicas.
The social (de)construction of the autism diagnosis in the context of quota policies for people with disabilities in the labour market

Abstract: In the context of a growing representation of autism in the media, the flexibility and complexity of its production as a "clinical diagnosis" and the fact that it is situated in a highly diversified spectrum, add to debates about this condition being a disability or neurodiversity - a "way of being”. Through an ethnographic work that ranged from in-depth interviews with neurologists and psychiatrists; a participant-observation of three years with two young people diagnosed with autism in their labour routines and spaces of sociability; and the follow-up of the day-by-day work of an expert in autism, I analyse the social construction of the autism diagnosis and the effects of different modes of understanding, "inhabiting" and agenting this condition in the workplace. My research allowed me to both problematize the centrality of neurobiological knowledge and psi specialists, and to relativize these knowledges both within the production of the autism diagnostic and the implementation of the quota policy. I also discussed the strategies of insertion of autism in the public agenda, showing, in practice, how the various actors involved in the disputes around autism's nosological status co-produce new subjects, relations and social sensibilities in Brazil.

Keywords: Autism, Disability, Diagnostic Processes, Work, Public Policies. 


\title{
Sobre gramáticas emocionais e violência sexual. Notas a partir de dois casos de interrupção legal de gestação realizados por mulheres com deficiência intelectual $^{1}$
}

\author{
Julian Simões \\ Universidade Estadual de Campinas - Brasil
}

\section{Apresentação ${ }^{2}$}

O objetivo deste artigo é apontar para como a justaposição do conceito de 'deficiência mental ou intelectual'3 às figuras jurídicas do 'incapaz' e do 'vulnerável' é efeito de uma estratégia na qual dor, sofrimento e vitimização são formulados como uma tecnologia de gestão. Isso porque, como bem afirma Sarti (2014), essas noções têm se convertido em figuras importantes para acesso a dispositivos de justiça, reparação e garantia de direitos. Além disso, estas categorias estão presentes em parte dos documentos oficiais sobre o enfrentamento à violência contra pessoas com deficiência no Brasil. A fim de demonstrar meu argumento, trago dois casos de interrupção legal de gestação. Um deles é o de uma garota de 13 anos de idade e o outro o de uma mulher de 27 anos de idade. Ambas são pessoas com deficiência intelectual que foram atendidas pelo Ambulatório de Violência Sexual localizado em uma cidade do Estado de São Paulo4.

O Ambulatório é um espaço interdisciplinar composto por cinco especialidades, a saber: Enfermaria, Ginecologia, Serviço Social, Psicologia e Psiquiatria. A sistematização do Serviço se deu seguindo um fluxo sustentado pela ideia de atenção integral à saúde que representa uma mudança radical em relação ao modelo de atenção médico tradicional. Para essa concepção, a ideia é priorizar atenção primária, bem como retirar do centro do modelo de atuação o papel do hospital e das especialidades médicas. Outro ponto importante para essa concepção é concentrar-se no usuário como um ser integral, abandonando o princípio médico de fragmentação do cuidado que, afirma Fracolli (2011), "transforma as pessoas em órgãos, sistemas ou pedaços de gente doentes” (:1136).

Como me foi explicado pela equipe médica, o primeiro contato das meninas e mulheres com as profissionais de saúde se dá a partir do Pronto Atendimento do Centro de Atenção. Lá elas são atendidas por profissionais da enfermaria que reali- 
zam acolhimento, triagem e avaliação do tipo de violência relatada pela 'paciente' Se identificada violência sexual em meninas não púberes menores de 14 anos ou violência física e/ou psicológica em crianças ou adolescentes, essas são encaminhadas ao Pronto Atendimento da Pediatria do Hospital. Se identificada violência física e/ou psicológica em mulheres adultas, sejam ou não menopausadas, essas são encaminhadas ao Pronto Socorro Adulto do Centro de Saúde em que fiz minha investigação.

Contudo, quando identificada violência sexual em mulheres pós-púberes, mulheres que entraram na fase da menopausa ou meninas não púberes maiores de 14 anos, essas são avaliadas por médico especialista e enfermaria. O objetivo, afirmavam as médicas, é qualificar e determinar o tempo decorrido do episódio da violência até a chegada da atendida ao Serviço. Tal fato se justifica devido ao tratamento profilático a ser adotado. No caso de mulheres que chegaram ao hospital em até 5 dias após a violência sexual, são realizados os seguintes procedimentos: 1) exames físicos e ginecológicos e, se possível, coleta de material forense; 2) anticoncepção de emergência; 3) quimiprofilaxia ABR; 4) sorologia HIV e DSTs, bem como outros exames bioquímicos pertinentes; 5) vacina gamablobulina; 6) atendimento psicológico e social; e 7) agendamento de retorno ambulatorial. Nos casos de mulheres que chegaram ao hospital decorridos 5 dias do episódio de violência sexual, são adotados os seguintes procedimentos: 1) exames físicos e ginecológicos; 2) teste rápido de B-HCG urinário para suspeita de gravidez; 3) sorologia HIV e DSTs, bem como outros exames bioquímicos pertinentes; 5) atendimento psicológico e social; 6) agendamento de retorno ambulatorial.

Dessa maneira, assim que elas chegam ao atendimento imediato do Centro de Saúde e relatam a situação de violência sexual, são realizados todos os procedimentos de profilaxia acima indicados. Conforme também descrevi nas páginas anteriores, somente em um segundo momento é que as meninas e mulheres são encaminhadas para o Ambulatório. Por ser um atendimento em caráter especial e não obrigatório, cabe às mulheres em situação de violência decidirem se seguem ou não o acompanhamento. De qualquer maneira, após optarem seguir no serviço ambulatorial, no primeiro dia elas passam por todas as cinco especialidades acima mencionadas. Nas consultas subsequentes, as meninas e mulheres passam apenas pelas consultas que foram agendadas.

Acompanhei as discussões dos casos pela especialidade da Psiquiatria, contudo, vez ou outra, mantive contato com a Assistência Social. O Protocolo criado pelo 
Serviço do Centro de Saúde recomenda que as meninas e as mulheres fiquem em acompanhamento médico por 6 meses. Esse tempo tem a ver com segmento Sorológico e não por questões de saúde mental ou demais protocolos Psiquiátricos. Como presenciei várias vezes, algumas da 'atendidas' recebiam alta médica da psiquiatria, porém continuavam a frequentar o Ambulatório em outras especialidades. $\mathrm{Na}$ psiquiatria eram realizadas entre 1 e 4 consultas. Segundo o protocolo criado por essa especialidade, o ideal é que todas as mulheres passem por ao menos 2 consultas, sendo 1 consulta no primeiro dia de ambulatório quando elas passam por todas as especialidades e 1 consulta que chamam de retorno de segurança. Evidentemente que o número de consultas varia com a necessidade de cada uma das 'pacientes'.

Por questões éticas, eu não tive acesso às meninas e mulheres em situação de violência e, tampouco, aos seus Prontuários Médicos. Dessa maneira, minha estratégia foi acompanhar a leitura e a discussão dos casos pela especialidade da psiquiatria. Assim, os dados recolhidos advêm das informações descritas nos referidos prontuários, mas que são narradas pelos e pelas residentes psiquiatras ${ }^{6}$. Esclarecidos esses pontos iniciais, apresentarei nas seções seguintes os dois casos de interrupção legal de gestação, bem como as tecnologias de gestão operadas pela 'vitimização' dessas meninas e mulheres em situação de violência sexual que, nem sempre, se identificam ou se dizem vítimas. A ideia é explicitar a ambivalência de garantir direitos e de impossibilidade do exercício desses mesmos direitos por mulheres assignadas com deficiência.

\section{Sobre afetos, narrativas de violência sexual e pedidos de abortamento legal}

Antes de iniciar as narrativas, se faz necessário uma pequena consideração a respeito dos episódios aqui apresentados. Penso ser importante reforçar que nos dois eventos de violência sexual narrados, além das discussões advindas do atendimento pré-abortamento, acompanhei as discussões realizadas pós-interrupção de gestação que foram atendidas pelas e pelos residentes. Dessa maneira, é importante ter em mente que as situações descritas também foram produzidas a partir de meu esforço narrativo. Os termos técnicos, as enunciações a partir da forma-formulário (NADAI, 2018) das fichas de avaliação e os engajamentos emocionais da equipe (e os meus também) são os principais elementos que compõem minha descrição dessas situações. Também é preciso enfatizar que a coerência e a aparente linearidade da 
sucessão dos acontecimentos foram produzidas a fim de organizar as várias vozes fragmentadas durante os atendimentos e discussões.

Afirmo isso porque nem sempre eram os mesmos residentes que atendiam as meninas em mulheres em situação de violência. Dessa maneira, as fichas de avaliação elaboradas na primeira consulta serviam de referência para todos os médicos que viessem a atender alguma dessas mulheres. Já a evolução do caso, os novos desdobramentos do episódio da violência ou mesmo dos antecedentes clínicos da 'paciente' comumente eram relatados nas consultas subsequentes. Tendo em conta esse aspecto fragmentário do próprio caso clínico em sua elaboração e desenvolvimento, organizei e produzi as duas narrativas das situações de violência sexual tal como apresento aqui. Em outras palavras é dizer que essas narrativas são um efeito etnográfico (Strathern, 2014). São formas descritivas que visam ampliar o escopo de análise dos meus argumentos, já que a singularidade de cada caso mobiliza o repertório compartilhado pela prática médica e também o repertório sociojurídico que se justifica a partir de uma gramática emocional. Por isso, como afirma Strathern (2014), minha "questão não é simplesmente como trazer certas cenas à vida, mas como trazer vida às ideias" (:175).

\section{Laura $^{7}$}

Diferentemente da maioria de outras meninas e mulheres que frequentavam o serviço do Ambulatório de Atendimento Especial, Laura tinha um Prontuário Médico bastante extenso. Com 27 anos, a mulher parecia conhecer bem a praxe de um Hospital. Segundo a residente, a 'paciente' fazia acompanhamento no Centro de Saúde desde que tivera seu diagnóstico de 'retardo mental' confirmado. Por isso, ela não estava tão deslocada e assustada com a rotina de espera, consultas e exames, bem como com os característicos cheiros, sons e cores de um hospital. O Prontuário Médico de Laura registrava uma história institucional que ia além do caso em questão. A residente, sem tempo hábil para ler toda a volumosa pasta, iniciou sua narrativa enunciando algumas das informações repletas de termos técnicos ${ }^{8}$. Conforme avançava a narração, descobrimos que Laura vivia com a avó, era diagnosticada com 'retardo mental de gravidade não especificada'. Descobrimos também que passava por acompanhamento psicológico, que não era alfabetizada, apesar de saber assinar seu próprio nome e ser copista.

Já a descrição da situação de violência foi narrada com mais atenção e continha informação de várias vozes. Devido à sua condição 'especial', a avó, a tia e a própria 
Laura relataram o que havia passado. Durante a discussão do caso foi enfatizada a timidez da mulher, a fala pouco elaborada ainda que suficiente para contar o ocorrido e destacado que a vivência do episódio de violência como algum ruim, mas não traumático. Seu sono, apetite e sua disposição física foram pouco alterados, afirmou a residente. No entanto, o fato de se encontrar em um Hospital e ter ouvido palavras como 'internação', 'gravidez' e 'explicar o procedimento' a deixou bastante ansiosa. Segundo o que me foi narrado durante a discussão do caso, a ansiedade se justificava por Laura não estar segura de que a avó, pessoa com quem morava, estava ciente do que pudesse passar com ela.

Em conversa com a avó da mulher de 27 anos, a assistente social nos informou que esta se sentia culpada pelo que ocorreu com sua neta. Ainda segundo a assistente social, desde o nascimento da neta, ela sempre fora muito participativa na vida da garota, mesmo quando esta vivia com o pai na cidade de São Paulo. Participação que fora intensificada quando a neta passou a residir com ela 12 anos atrás. A avó de pronto sabia informar quais remédios e quais as horas em que cada um deles deveriam ser ministrados à neta. Sabia também que esses mesmos medicamentos embaralhavam o ciclo menstrual de Laura e, por isso, a atenção a essa esfera da vida da neta devia receber cuidado especial. Exatamente por tal motivo, não foi difícil intuir que um atraso menstrual de dois meses indicava uma gravidez. Estava segura disso, afirmou a residente, porque, semanas antes, a neta havia lhe contado sobre as 'coisas estranhas' que o vizinho Joaquim lhe fizera na ocasião em que esteve sozinha em casa.

A partir de um esforço de sistematização das várias e fragmentadas vozes registradas na ficha de atendimento imediato a mim descritas, a médica residente iniciou sua narrativa sobre a situação de violência em questão. Segundo o que foi exposto, a avó de Laura havia ido à festa de aniversário de uma conhecida do bairro e deixado a neta sozinha em casa por algumas horas. As tais 'coisas estranhas' enunciadas pela 'paciente' de 27 anos, afirmou a residente, incluíam carícias, brincadeiras e jogos em que os perdedores precisavam tirar, aos poucos, as peças de roupas que vestiam. Contudo, enfatizava a médica dando destaque à fala de Laura, a mulher garantiu que o vizinho não lhe havia machucado. $\mathrm{O}$ vizinho, afirmou a avó à assistente social, era casado, pai um de uma menina com 4 anos de idade e sempre muito prestativo com as pessoas. Até o episódio, nunca dera indícios de que poderia cometer um ato de violência sexual contra alguém 'incapacitado' por sua condição de 'deficiente'.

Por conta de tal situação, Laura estava grávida e necessitava fazer um processo 
de 'interrupção legal de gestação'. A avó, assumia todas as reponsabilidades de cuidado emocional e econômico da neta. Por isso, afirmou à equipe médica que ela não tinha mais idade, condições emocionais e financeiras para cuidar de um novo membro na família. Assim, a mulher acreditava que a melhor decisão a ser tomada era o aborto. Sem titubear, afirmou a assistente social, a avó da paciente registrou Boletim de Ocorrência e acreditou ter tomado todos os procedimentos legais necessários para dar fim ao caso iniciado pela situação de violência sexual sofrida pela neta.

Já a residente, nos narrou o que foi dito em consulta por Laura. Segundo conta, a mulher de 27 anos estava vendo seu programa de televisão favorito quando ouviu alguém chamar à porta. Vendo que era Joaquim, Laura o convidou para entrar para que conversassem um pouco. Tempo depois, contou a mulher à residente, o vizinho e ela passaram a realizar um jogo. No começo, seguiu narrando a médica, Laura disse ter achado tudo muito divertido, já que as cócegas realizadas por Joaquim a faziam rir. Depois, confessara a mulher, não gostou muito de ter que tirar a roupa e de sentir o bigode e a barba do vizinho roçando em seu corpo. Também não lhe agradara o desconforto vaginal que ela sentiu quando Joaquim se deitou por cima dela e fazia alguns desconfortáveis movimentos. Ainda assim, garantia Laura, ele não a machucou e não manteve relações sexuais consigo. Tal narrativa contada pela residente de psiquiatria deixou claro à equipe médica que a garota não sabia o que de fato era uma relação sexual.

Durante as demais consultas, a equipe médica me informou o que havia sido explicado pela tia sobre o quão sofrido era para a avó cuidar de Laura. Segundo a tia, desde o momento em que a paciente passou a viver com sua mãe, o irmão, pai de Laura, deixou de se responsabilizar economicamente pela garota. A tia contou ainda que com a mãe da garota nunca se pode contar emocional, física ou economicamente. Segundo ela dizia, havia fortes suspeitas de que a mãe da moça fosse, ainda que em grau menor, 'incapaz' e 'deficiente mental' como Laura. De todo modo, isso não impedira de que a mulher se casasse novamente e tivesse mais duas filhas pequenas com as quais Laura adorava brincar. Por fim, contou à equipe que a garota ajudava a avó nos afazeres do lar, bem como participava de oficinas para pessoas com 'necessidades especiais' do bairro onde viviam.

A equipe me disse que a 'paciente' havia confirmado toda a história contada pela tia. Porém, quanto à decisão do abortamento, Laura parecia mais ambivalente e dizia que não estava segura de que o melhor para si seria realizar o aborto. A residente enfatizou que durante as consultas, a mulher pareceu bastante 'pueril' 
e dizia que gerar uma criança parecia algo prazeroso, já que ela via tantas pessoas felizes quando descobriam uma gravidez. No entanto, quando a equipe do Centro de Saúde explicou todas as responsabilidades que uma gestação implicava, Laura disse que talvez houvesse demasiada responsabilidade. Disse também que a chegada de uma criança dificultaria seus passeios, suas brincadeiras com as irmãs mais novas, assim como sua participação nas oficinas que tanto gostava. Desse modo, me disse a equipe médica, foi pesando os prós e os contras, mas também levando em consideração o desejo de sua avó, que Laura se convenceu de que a melhor escolha era pela 'interrupção da gestação'.

Passados alguns dias, foi-me informado que o pedido de 'interrupção legal de gestação’ de Laura havia sido aprovado. Contaram-me ainda que houve uma explicação detalhada sobre o que se passaria, enfatizando que a internação ocorreria em data agendada e que assim ela poderia avisar à avó. Fato esse, sublinhou a equipe médica, bastante importante para a mulher que sorriu e se sentiu mais aliviada ao ouvir tal informação. Já a explicação sobre os procedimentos técnicos parecia mais distante da compreensão por parte da 'paciente'. Ainda assim, disseram a Laura que ela estava grávida de 12 semanas, que sentiria algumas dores e que seria acompanhada durante todo o procedimento por profissionais do hospital. Nas demais consultas pós-abortamento, fui informado que Laura somente chorou quando, no final do processo, viu o pequeno feto fora de seu corpo. Por fim algo me pareceu interessante nessa história. Apesar de bastante envolvidos e dedicados ao caso, o engajamento com a história de Laura não foi unânime. Por isso, intuí que sua condição de pessoa com deficiência intelectual não ressoava tanto nas e nos residentes como ressoou o caso de Maria, que narrarei a seguir.

\section{Maria}

Dessa vez não havia choros estridentes, ruídos de ventiladores ou mesmo vozes sussurradas de mulheres que esperavam ser atendidas. Não havia enfermeiras chamando insistentemente por algumas das 'pacientes'. Igualmente não havia um painel que, abruptamente, apitava chamando por um número de identificação e tampouco havia televisões emudecidas. Diferentemente das demais 'atendidas', Maria, de 13 anos de idade, não estava fisicamente no Ambulatório para as habituais consultas. A equipe médica e eu já havíamos discutido outros casos, contudo, foi apenas com a chegada da história da garota que uma espécie de comoção generalizada mobilizou a atenção e o envolvimento tanto da equipe como o meu. 
Internada na obstetrícia do Hospital, Maria compareceu ao serviço ambulatorial por meio de seu Prontuário Médico. A garota, como me foi narrado, estava ali materializada em palavras. Estas, por sua vez, estavam acompanhadas de termos médicos que diziam muito sobre o quadro de saúde da garota. Segundo narrou a equipe, diagnosticada em seu nascimento como 'Retardo Mental Leve' e 'Paralisia Cerebral' ${ }^{10}$ do lado direito, Maria vivia com sua mãe, com seu irmão mais novo, de 10 anos, e com seu irmão mais velho, de 16 anos. Por seu delicado estado de saúde, uma dupla camada de cuidado continuamente lhe fora destinada, enfatizou a residente da psiquiatria. Segundo me contou a equipe do Ambulatório, a mãe da garota de 13 anos disse que desde muito pequena, a saúde da filha apresentara um quadro elevado de 'fragilidade', bem como ela havia perdido as contas dos inúmeros episódios convulsivos que a filha passara ao longo dos anos. As responsabilidades de cuidado todas eram realizadas por ela, já que o pai alcoolista os abandonou pouco depois do nascimento de filho mais novo.

Não bastasse o complexo quadro de 'vulnerabilidade' e 'incapacidade', conforme narrado e registrado nas fichas do Prontuário, a garota fora trazida ao Hospital por sua mãe com uma gravidez bastante adiantada. A equipe informou que todos os exames pelos quais a 'paciente' passou lhe causavam crises de choro e também a assustavam. Bastante sensibilizadas e envolvidas, as profissionais pacientemente acalmavam a garota quando uma crise dessas era iniciada. Na narrativa realizada sobre o episódio de violência vivenciado por Maria, as palavras descritas pela equipe pareciam retratar uma espécie de situação improvável mesclada com outra situação impossível. Segundo o que me foi descrito, a mãe da garota contara que havia deixado sua filha e seu filho mais novo brincando em um dos cômodos da casa enquanto realizava alguns dos afazeres domésticos. Percebendo que já se passava algum tempo em que os filhos estavam 'sozinhos', mas também com o silêncio atípico para crianças naquela idade, decidiu ir até o quarto. Para sua surpresa, afirmou a mulher aos médicos, ela se deparou com o filho mais novo de calça abaixadas em cima de sua filha Maria. Angustiada, relatou durante o atendimento de urgência descrito na ficha, ela tentou de todo o modo esquecer o que presenciara.

Segundo uma das assistentes sociais, a mulher instruiu os filhos que não contassem o episódio para mais ninguém, nem mesmo para o irmão mais velho de 16 anos, que não estava em casa na hora do ocorrido. Porém, narrou a assistente visivelmente sensibilizada, alguns dias depois o esforço por esquecer o ocorrido foi abruptamente interrompido. Pelo segundo mês consecutivo, Maria não mens- 
truou. Segundo a equipe, a mãe da garota sabia que por conta dos problemas de saúde, assim como pela quantidade de remédios que a filha tomava, era comum certa desordem no clico menstrual da menina. Mas nunca a desordem superou o período de dois meses. Assim, logo intuiu que algo de errado podia estar se passando com a filha. Conforme foi narrado, a mulher levou algum tempo para tomar qualquer decisão, já que uma espécie de paralisia emocional tomou conta de seus pensamentos. Segundo afirmara para a equipe do ambulatório em algumas das consultas, foram necessários alguns dias até que começasse a tentar pensar no que poderia fazer. Ela disse ter atrasado qualquer tomada de decisão o quanto pôde, mas a barriga da filha podia crescer e denunciar a possível gravidez que tão veementemente ela queria esconder.

Depois de tomada a decisão, a mulher contou à equipe que a filha e ela seguiram o caminho para o Hospital. O filho mais velho, afirmou a mãe de Maria à assistente social, nem imaginava a complicada situação pela qual a família estava passando. Já o filho mais novo, aquele que se convertera no 'agressor', tampouco sabia que havia engravidado a própria irmã. No hospital, a confirmação da gravidez somente aumentou o problema que viviam. Segundo a médica residente, a mãe da garota fora logo informada dos procedimentos legais que necessitava realizar caso decidisse pela interrupção legal da gestação da filha. No entanto, afirmou a mulher em consulta, registrar um boletim de ocorrência contra o seu próprio filho não era uma decisão fácil. Além do mais, dizia ela, estava crente de que um registro como esse podia colocar em risco a única fonte de renda com a qual se mantinham, ou seja, o Benefício de Prestação Continuada (BPC ${ }^{11}$ concedido à filha.

Já a equipe médica tinha inúmeros dilemas técnicos a enfrentar. Nas discussões que presenciei, a equipe sabia que precisava tomar uma decisão institucional delicada que envolvia dois 'sujeitos vulneráveis'. Os procedimentos adotados pela equipe do Hospital e do Centro de Atenção, explicados a mim com a mesma atenção que explicaram à família, consistia primeiramente em confrontar as narrativas de mãe e filha, a fim de se certificarem da coerência da história. Logo perceberam que, guardadas as devidas diferenças dos modos de narrar, os fatos contados eram fundamentalmente os mesmos. Por longas e exaustivas horas, discutiram a delicada situação emocional enfatizando a mudança na qualidade do sono, as alterações no apetite, os sintomas de ansiedade, os sintomas de 'sofrimento psíquico', assim como a saúde física da garota, em uma reunião. Conforme foi narrado em discussão por um dos médicos da obstetrícia, foram realizados todos os exames físicos para asse- 
gurar a viabilidade de um procedimento de interrupção. Ainda segundo o médico, também se certificaram de que todos os procedimentos legais para a realização de tal processo fossem cumpridos.

Vale lembrar, como me disseram, além de 'deficiência mental', a garota era menor de idade, o que implicava lidar com uma normativa específica que precisava ser cumprida à risca ${ }^{12}$. Categorias médicas e jurídicas precisavam dizer as mesmas coisas, o que explica as várias menções que escutei durante a elaboração das fichas de termos como 'vulnerável', 'incapaz', 'retardo mental', 'tutelado'. Somado a esses procedimentos, foi realizado um cuidadoso exame psiquiátrico em Maria, bem como explicaram à garota os procedimentos, as possíveis dores e outras manifestações físicas decorridas do aborto. Durante todo o processo, que durou pouco mais de uma semana, ambivalente, a garota chorava e ora dizia querer realizar, ora não queria realizar a interrupção. As alterações no sono, do apetite e mudanças na rotina da 'paciente' foram constantemente reforçadas nas narrativas da equipe.

Já a mãe, afirmaram alguns dos médicos com que discuti o caso dias depois, não via a hora de que tudo aquilo acabasse. Foi-me narrado que, um pouco desorientada, Maria chorava muito e reclamava das dores durante todo o procedimento. Só conseguiu se sentir mais tranquila depois que o feto de pouco mais de 500 gramas já não se encontrava mais em seu corpo. Após o procedimento, Maria permaneceu mais calada e um pouco chorosa. Um pouco mais aliviada, porém visivelmente afetada pela situação, contou-me uma das assistentes sociais também muito sensibilizada, a mãe não tinha tempo para se tranquilizar. Ela agora precisava criar uma estratégia para dividir os cuidados entre a filha com deficiência intelectual, que havia passado por um procedimento de aborto, e o filho de 10 anos que além das crises convulsivas, apresentava um quadro psicológico bastante singular.

\section{Categorias justapostas e suas gramáticas emocionais}

Os casos de Laura e Maria ajudam a formular como o sofrimento e a vitimização se tornam um idioma pelo qual alguns direitos são acionados. Mais, como o sofrimento e a vitimização passam a ser fundamentais para que alguns direitos sexuais e reprodutivos sejam justificados e reconhecidos não em sua positividade, mas em sua negatividade. Segundo Corrêa (2006), a positividade dos direitos sexuais e reprodutivos indicaria que Laura e Maria teriam garantido o direito de interrupção legal de gravidez, caso assim o desejassem. No entanto, como os direitos sexuais foram formulados a partir de sua negatividade, o exercício destes direitos indica que o 
aborto só pode ser realizado quando o bem jurídico da dignidade sexual, e não a própria pessoa, é violado. Assim, nos dois casos se faz uso de uma economia moral (Fassin, 2012, 2014) em que dor, sofrimento e tristeza se convertem em uma linguagem mediante a qual o direito de interrupção de gravidez se converte em uma possibilidade.

Tal formulação pode parecer um pouco deslocada, contudo, penso que faz sentido quando se pensa na maneira como o procedimento de 'interrupção legal de gestação’ é autorizado no país. Segundo o Código Penal, não se configura crime a interrupção de gestação em situações de violência sexual, de risco de morte da mãe ou, mais recentemente, em casos de anencefalia ${ }^{13}$. De fato, tanto Laura como Maria se encaixariam na condição de 'mulher em situação de violência sexual' e por isso poderiam realizar legalmente a interrupção de gravidez. Contudo, as possíveis repreensões morais e a questão da ambiguidade jurídica em que elas se encontram (são pessoas em situação de 'curatela'), fizeram fez com que a decisão passasse por artifícios narrativos que reforçavam e justificavam também por uma economia moral a realização do aborto.

Maria, além de uma pessoa com deficiência intelectual, é uma criança. Isso implica que, do ponto de vista legal, existe uma legislação específica por meio da qual seus direitos são regulados, ou seja, o ECA. Desta forma, a 'tutela', e não a 'curatela', é o instituto jurídico ao qual ela está submetida. Entretanto, tanto a 'curatela' como a 'tutela' constroem alguém como 'vulnerável' e 'incapaz'. Além disso, as concepções morais sobre a infância constroem uma representação em que inocência e pureza são as principais características desse período da idade. Por isso, uma situação de gravidez decorrida de um episódio de violência sexual se converte em uma situação que gera uma unanimidade. A gravidez só trará 'dor' e 'sofrimento' para a menina. Mais, a 'dor' e o 'sofrimento' decorrentes da violência extrapola o corpo de Maria e se direciona também a todos os seus familiares. Essa é uma estratégia que constrói a figura da 'vítima' no corpo que sofre, mas também na relação que esse corpo que sofre cria com as demais pessoas (Fonseca \& Maricato, 2013). Vitimizar Maria e também seus familiares é uma maneira de justificar moralmente o aborto realizado. Além disso, vitimizar Maria é também extrapolar a condição de pessoa com deficiência para todas as relações que ela estabelece.

Laura também é uma pessoa com deficiência intelectual e, por isso, está submetida ao 'instituto jurídico da curatela'. Isso quer dizer, que tal situação poderia atrapalhar a realização do abortamento legal, uma vez que a mulher é marcada por 
pelo menos três categorias sociojurídicas que têm implicações distintas. 'Deficiência mental' é uma categoria que descreve uma condição de saúde de pessoas independentemente da idade e que possua algum tipo de 'comprometimento'. 'Incapacidade' é uma categoria que descreve a não capacidade de pessoas (com ou sem deficiência intelectual) em decidir sobre os seus próprios atos, sejam eles políticos, civis, sexuais ou patrimoniais. Eis o caso de crianças e adolescentes, bem como o caso das pessoas que são chamadas de "deficientes intelectuais". 'Vulnerável' é uma categoria das mais complexas, já que tem uma variedade imensa de definições e utilizações. De qualquer maneira, na articulação saúde e conceitos sociojurídicos, 'vulnerável' é uma pessoa ou um grupo de pessoas em que a possibilidade de escolha é severamente limitada, sujeitas frequentemente à coerção em sua decisão.

Pelo Código Civil Brasileiro de 2002, todas essas categorias têm implicações distintas que vez ou outra se cruzam e acionam direitos e deveres específicos. Esses cruzamentos se dão, sobretudo, nos processos de 'interdição' referentes ao 'instituto jurídico da curatela'. É bem verdade que a Lei Brasileira de Inclusão (LBI) $n^{\circ}$ 13.146/2015 acrescentou um novo dispositivo sociojurídico denominado 'Tomada de Decisão Apoiada'. Esse acréscimo ocasionou uma reconfiguração de todo o 'Regime de Incapacidades' do Código Civil Brasileiro. Explico. Anteriormente à promulgação da LBI, existiam as figuras da 'tutela' e da 'curatela'. A essas estavam coladas as figuras da 'incapacidade relativa' e da 'incapacidade absoluta'. Trocando em miúdos, a 'tutela' era um instituto que cessaria após os 18 anos, já que seu objetivo era garantir e proteger o desenvolvimento social e psicológico dos que a ela estavam submetidos ${ }^{14}$.

Quanto à 'incapacidade' há uma disputa de interpretação entre os operadores da lei. Alguns afirmam ser o 'tutelado' um 'incapaz absoluto' e outros garantem ser o 'tutelado' um 'incapaz relativo', em especial no que tange à sexualidade destes. Igual procedimento se dava com a 'curatela'. No entanto, os submetidos a esse instituto jurídico eram maiores de 18 anos e deviam passar por um processo de 'interdição', para que a eles fossem destinados 'curadores'. Ainda que a recomendação dos ordenamentos jurídicos fosse levar em conta a 'incapacidade' dos sujeitos (relativa ou absoluta), a maior parte das vezes, as decisões colavam 'curatela' à 'incapacidade absoluta'.

Com a promulgação da LBI em 2015, há uma mudança substancial nesse complexo jogo de 'capacidades' e 'incapacidades'. Os 'absolutamente incapazes' somente seriam os menores de 16 anos (Art. $3^{\circ}$ do CC, 2002 NR). Os 'relativamente incapazes' são os maiores de 16 anos e os menores de 18, os chamados 'ébrios naturais e os viciados em tóxicos, os que por causa transitória ou permanente não puderem exprimir sua vontade e 
os pródigos' (Art. $4^{\circ}$ do CC, $2002 \mathrm{NR}$ ). Nota-se que tanto a 'enfermidade ou deficiência mental' (Art. $3^{\circ}$ ) como os chamados 'excepcionais sem desenvolvimento mental completo' (Art. $4^{\circ}$ ) são tornados 'capazes'. Isso porque, o novo 'instituto de Tomada de Decisão Apoiada' garante a 'capacidade civil' assistida por apoiadores escolhidos pela pessoa a ser apoiada. Essa nova forma de conceber as pessoas com deficiência intelectual ainda é um tanto nebulosa. A polêmica entre os especialistas e os operadores da lei foi tamanha que há um projeto de lei que visa operar uma nova mudança na teoria das incapacidades ${ }^{15}$. No entanto, não detalharei essa polêmica aqui.

O que busco indicar com os dois casos é que as categorias sociojurídicas parecem perder suas especificidades e se justificam a partir de uma gramática emocional. Assim, noções como dor, sofrimento e vitimização criam uma gramática de sentidos mais eficiente para justificar alguns direitos a serem acionados, como é o caso dos direitos sexuais e reprodutivos nessas situações de abortamento. Desse modo, quando o 'sofrimento' e a figura de 'mulher vítima' se cruzam, acabam por se transformar em um idioma de inteligibilidade entre o campo médico e o campo sociojurídico. Em outros termos, é dizer que todas as diferenças médico-jurídicas são significadas nesse processo como semelhanças. Assim, mulher com 'deficiência mental' que é 'curatelada', 'mulher incapaz'e 'mulher vulnerável' são descrições de uma mesma condição de existência, ou seja, a 'mulher com deficiência vítima de violência sexual'.

Foi criando a figura incontestável de 'vítima' que faz sofrer seu próprio corpo e que faz sofrer o corpo de seus familiares, bem como as relações que estabelecem com estes, que se constrói e se legitima o acesso de Laura e Maria ao abortamento legal. Preocupadas pela possibilidade de não realização de um aborto legal já garantido por lei, a equipe descrevia os efeitos políticos do sofrimento na vida dessas pessoas. Foi demarcando o peso financeiro, mas também emocional, de mais uma pessoa na família que teria de ser ajudada pela mãe de Maria ou pela avó Laura que se justificou o aborto. Foi explicitando o sofrimento que as duas mulheres passaram com toda a situação de violência sexual que o aborto foi legitimado. Foi reforçando a dor de uma memória traumática na vida de todos os envolvidos nas relações ordinárias que gravitavam em torno da vida das mulheres que se justificou o aborto. Enfim, foi articulando o sofrimento e a vitimização como categorias úteis que os direitos sexuais já garantidos foram acionados na ocasião.

É bem verdade que técnicas de gestão pela dor e sofrimento ou as técnicas de governos pela figura da vítima têm sido analisada por diversos pesquisadores ${ }^{16}$. Em um primeiro momento, minha investigação parece se somar a esses esforços. No 
entanto, tenho me debatido com algumas questões bastante específicas do campo da deficiência que parecem me ajudar a pensar outros horizontes (ainda incertos). O que chamo de tecnologias de gestão a partir da figura da vítima com deficiência intelectual é, em realidade, um conjunto de técnicas de controle bastante diversas. Uma delas tem a ver com o regime de cuidado e proteção que é visibilizado pela figura da vítima. Cuidar e proteger as mulheres em situação de violência é o horizonte de todo o atendimento realizado pelo serviço.

No entanto, ao vitimizar as 'atendidas' no ambulatório, também são protegidas as famílias das atendidas que não serão responsabilizadas econômica e moralmente por abandono, descuido ou negligência. É protegida a equipe médica de repreensões morais e legais de autorizarem e concretizarem procedimentos de interrupção legal de gestação, haja vista a enorme polêmica que envolve o assunto de abortamento no país ${ }^{17}$. Dessa maneira, ao justificarem via dor e sofrimento um procedimento envolto em tantas polêmicas, penso que se cria uma camada de proteção adicional a esses profissionais que fazem esses procedimentos, ainda que estes sejam realizados de acordo com todos os preceitos legais.

Por outro lado, vitimizar explicita os dilemas e paradoxos que envolvem a ampliação dos direitos à sexualidade para uma população socialmente tomada como 'vulneráveis' e 'incapazes'. Por um lado, garante e protege que mulheres com deficiência intelectual possam exercer seus direitos. Por outro, vitimizar é retirar a agência dessas mesmas meninas e mulheres que são protegidas e garantidas. Tendo em conta a delicadeza desse tema, assim como as moralidades que envolvem esse processo, a vitimização tem sido uma estratégia de proteção a possíveis repreensões morais. No entanto, a vitimização também explicita uma complexa técnica de gestão de corpos, direitos e sexualidades. Dessa maneira, mais do que ser uma solução é o início de inúmeros outros dilemas que ainda precisam ser enfrentados para que a condição de sujeitos de direitos possa ser plenamente exercida por pessoas com deficiência intelectual.

Recebido:13/02/2019

Aprovado: 14/05/2019 
Julian Simões é doutor em Ciências Sociais e Mestre em Antropologia Social pela Universidade Estadual de Campinas. Membro do Núcleo de Estudos de Gênero (PAGU), do Ateliê de Produções Simbólicas e Antropologia (APSA) da UNICAMP, do GESD/NAU da USP e do Grup de Treball en Discapacitat i Antropologia do Institut Català d'Antropologia. Desenvolve pesquisas nas temáticas de deficiência, violência sexual, direitos sexuais e reprodutivos e ordenamentos e práticas jurídicas. ORCID: 0000-0002-3252-893X.Contato: julian_sociais@yahoo.com.br

\section{Notas}

1. A investigação que deu origem a este artigo foi financiada pelo Conselho Nacional de Desenvolvimento Científico e Tecnológico (CNPq), processo n ${ }^{\circ}$ 14104/2014-7, e pela Fundação de Amparo à Pesquisa do Estado de São Paulo (FAPESP), processo n ${ }^{\circ}$ 2015/19346-0 e processo ${ }^{\circ}$ 2016/16682-1. Diante dos ataques recentes que as Universidades e as Instituições Públicas de amparo à pesquisa e desenvolvimento científico vêm sofrendo, importa enfatizar que sem tais aportes financeiros, nada do aqui apresento seria possível. Produção de conhecimento e pesquisa científica necessitam de investimento e não corte ou qualquer tipo de contingenciamento de verba.

2. Agradeço a Maria Filomena Gregori, Larissa Nadai, Cilmara Veiga, Juliana de Farias Mello e Souza, Carolina Branco de Castro Ferreira, Rafael Nascimento César, Ana Laura Lobato, Carolina Parreiras Silva, Cynthia Andersen Sarti, Guita Grin Debert e Claudia Fonseca, pelas leituras e sugestões em diferentes fases do texto que originou este artigo.

3. Este artigo adotará as seguintes padronizações de categorias: 1) grafados em itálico e aspas simples dizem respeito ao modo como minhas interlocutoras de pesquisa utilizavam os termos, exemplo, "paciente'; 2) grafados com aspas simples indicam os termos sociojurídicos, por exemplo, “vulnerável'; 3) grafadas com aspas duplas são citações de textos. No entanto, será possível notar um trânsito de categorias entre as práticas médicas e jurídicas indicando, assim, a construção de uma tecnologia de gestão da deficiência intelectual.

4. Vale destacar que o Ambulatório de Violência Sexual é um serviço oferecido para mulheres com e sem deficiência e deficiência intelectual.

5. Para uma discussão mais aprofundada sobre a noção de atenção integral à saúde da mulher, ver: Osis (1994).

6. A estratégia em questão mereceria uma análise mais adensada. No entanto, diante das limitações de espaço, contento-me apenas em enunciar o que aqui exponho. Para mais, ver capítulos 2 e 3 da minha tese de doutorado (Simões, 2019).

7. A fim de preservar a identidade das meninas, mulheres e equipe do ambulatório, todos os nomes são fictícios.

8. Apenas para elucidar: MEN (idade da menarca), DUM (data da última menstruação), HS (história sexual), MED C (medicação em curso), REAC (reações alérgicas), TS (tentativa de suicídio), TEPT (transtorno de estresse pós-traumático).

9. Segundo definição do DSM-5, "aplica-se quando existe uma forte suposição de Retardo Mental, 
mas o indivíduo não pode ser adequadamente testado pelos instrumentos habituais de medição da inteligência. Isto pode ocorrer no caso de crianças, adolescentes ou adultos que apresentam demasiado prejuízo ou falta de cooperação para serem testados, ou com bebês, quando existe um julgamento clínico de funcionamento intelectual significativamente abaixo da média”. Para uma perspectiva ligada aos estudos sobre deficiência, ver: Autor (2014) e Lopes (2015).

10. Segundo a Associação Brasileira de Paralisia Cerebral (ABPC), a Paralisia Cerebral (PC) descreve um grupo de desordens do desenvolvimento do movimento e da postura, causando limitações nas atividades. São atribuídas a distúrbios não progressivos que ocorrem no cérebro em desenvolvimento. As desordens motoras da PC são geralmente acompanhadas por alterações na sensação, percepção, cognição, comunicação e comportamento, podendo também ser acompanhadas por crises convulsivas. (Associação Brasileira de Paralisia Cerebral - ABPC. Disponível em: http: // www.paralisiacerebral.org.br/ saibamais06.php. Acesso em: 11 jun. 2017).

11. Benefício de Prestação Continuada - Lei Orgânica de Assistência Social (BPC-LOAS) - benefício assistencial em que a pessoa com deficiência tem direito ao recebimento de um salário mínimo mensal, de forma continuada, de acordo com os termos da Lei Federal nº 8.742, de 07/12/1993. Para uma discussão sobre os procedimentos de avaliação do BPC-LOAS, ver Diniz, Medeiros \& Squinca (2007).

12. A normativa em questão é o Estatuto da Criança e do Adolescente (ECA).

13. Em decisão contrária à ADPF 54, o Supremo Tribunal Federal descriminaliza a interrupção de gestação de feto anencéfalo. Ver: http://www.stf.jus.br/arquivo/cms/noticianoticiastf/anexo/ adpf54.pdf

14. Para uma discussão mais aprofundada, ver capítulos 1 e 3 da minha tese de doutoramento (Simões, 2019)

15. Projeto de Lei do Senado n ${ }^{\circ} 757 / 2015$. O Projeto prevê a alteração da 'a Lei n ${ }^{\circ} 10.406$, de 10 de janeiro de 2002 (Código Civil), a Lei no 13.146, de 6 de julho de 2015 (Estatuto da Pessoa com Deficiência), e a Lei n ${ }^{\circ}$ 13.105, de 16 de março de 2015 (Código de Processo Civil), para dispor sobre a igualdade civil e o apoio às pessoas sem pleno discernimento ou que não puderem exprimir sua vontade, os limites da curatela, os efeitos e o procedimento da tomada de decisão apoiada'. Ou seja, uma nova revisão à Teoria de Incapacidades do Código Civil brasileiro.

16. Ver Arosi (2013), Coelho (2010), Fassin (2012, 2014), Fonseca e Maricato (2013), Sarti (2009, 2011, 2014)

17. Recentemente vimos manifestações raivosas sobre a ADPF 442, que propõe a descriminalização do aborto até a $12^{\mathrm{a}}$ semana de gestação. A Professora Doutora Débora Diniz sofreu ataques físicos por ser uma defensora da descriminalização do aborto. Ver: https: / /www.conjur.com.br / 2018-jul-30/stf-faz-audiencia-publica-aborto-dias-agosto e https: / / www.redebrasilatual.com.br / cidadania/2018/07/antropologa-debora-diniz-e-ameacada-por-defender-aborto

\section{Referências Bibliográficas}

AROSI, Ana Paula. 2003. Os usos da categoria vítima: o caso dos movimentos de familiares de vítimas de violência no Rio Grande do Sul e do Rio de Janeiro. Intersecções: Revista de Estudos Interdisciplinares, ano 15, n. 2 , p. 356-373.

BRASIL. 2002. Código Civil Brasileiro n 10.406. Brasília: Diário Oficial. 
BRASIL. 2015. Lei Brasileira de Inclusão (Estatuto da Pessoa com Deficiência) no 13.146. Brasília: Diário Oficial.

COELHO, Maria Cláudia. 2010. Narrativas da violência: a dimensão micropolítica das emoções. Mana, Rio de Janeiro, v. 16, n. 2, p. 265-285.

CORRÊA, Sonia. 2006. Cruzando a linha vermelha: questões não resolvidas no debate sobre direitos sexuais. Horizontes Antropológicos, Rio de Janeiro, v. 12, n. 26, p. 101-121.

DINIZ, Débora \& MEDEIROS, Marcelo \& PENALVA, Janaína. 2010. O Benefício de Prestação Continuada no Supremo Tribunal Federal. Sociedade e Estado, v. 25, n. 1, p. 53-70.

FASSIN, Didier. 2012. Humanitarian Reason: a moral history of the present. California: University of California Press.

FASSIN, Didier. 2014. Compaixão e Repressão: a economia moral das Políticas de Imigração na França. Ponto Urbe, São Paulo, n. 15, p. 1-26.

FONSECA, Claudia \& MARICATO, Glaucia. Criando Comunidades: emoção, reconhecimento e depoimento de sofrimento. Interseções: Revista de Estudos Interdisciplinares, ano 15, n. 2, 2013.

FRACOLLI, Lislaine Aparecida et al. 2011. Conceito e prática da integralidade na Atenção Básica: a percepção das enfermeiras. Revista da Escola de Enfermagem da USP, v. 45, n. 5, p. 1135-1141.

LOPES, Pedro. 2014. Negociando deficiências: identidades e subjetividades entre pessoas com "deficiência intelectual”. Dissertação [Mestrado em Antropologia Social]. IFCH/UNICAMP, Campinas.

MINISTÉRIO DA SAÚDE (MS). 2007. A declaração de óbito: documento necessário e importante. Brasília: Ministério da Saúde.

NADAI, Larissa. 2018. Entre pedaços, corpos, técnicas e vestígios: O Instituto Médico Legal e suas tramas. Tese [Doutorado em Ciências Sociais]. IFCH/UNICAMP, Campinas.

OSIS, Maria José Martins Duarte. 1994. Atenção Integral à Saúde da Mulher, o Conceito e o Programa: História de uma Intervenção. Dissertação [Mestrado em Antropologia Social]. IFCH/UNICAMP, Campinas.

SARTI, Cynthia. 2009. Corpo, violência e saúde: a produção da vítima. Sexualidad, Salud y Sociedad Revista Latinoamericana, v. 1, p. 89-103.

SARTI, Cynthia. 2011. A vítima como figura contemporânea. Cadernos do CRH. Salvador, v. 24, p. 51-61.

SARTI, Cynthia. 2014. A construção de figuras da violência: a vítima, a testemunha. Horizontes Antropológicos, Porto Alegre, ano 20, n. 2 - p. 77-105.

SIMÕES, Julian. 2014. Assexuados, Libidinosos ou um Paradoxo Sexual? Gênero e sexualidade em pessoas com deficiência intelectual. Dissertação [Mestrado em Antropologia Social]. IFCH/UNICAMP, Campinas. SIMÕES, Julian. 2019. Dos sujeitos de direitos, das políticas públicas e das gramáticas emocionais em situações de violência sexual contra mulheres com Deficiência Intelectual. Tese [Doutorado em Ciências Sociais]. IFCH/UNICAMP, Campinas.

STRATHERN, Marilyn. 2014. O efeito etnográfico e outros ensaios. São Paulo: Cosacnaif. 
Sobre gramáticas emocionais e violência sexual. Notas a partir de dois casos de interrupção legal de gestação realizados por mulheres com deficiência intelectual

Resumo: Neste artigo buscarei explicitar como as estratégias de acesso aos direitos sexuais e reprodutivas de mulheres com deficiência intelectual em situação de violência sexual são elaboradas por um idioma moral articulando dor, sofrimento e vitimização. A partir de uma pesquisa empírica realizada no Ambulatório de Violência Sexual de uma cidade do interior de SP, apresentarei dois casos de interrupção legal de gravidez. Um deles é realizado por uma garota de 13 anos e o outro por uma mulher de 27 anos, ambas com deficiência intelectual. O intuito é colocar em análise as técnicas de regulação e controle social operadas no entrecruzamento da prática médica e da prática jurídica. Também é objetivo refletir as ambiguidades e os paradoxos do reconhecimento de pessoas com deficiência intelectual como sujeitos de direitos sexuais e reprodutivos. Por fim, intentarei indicar que a vitimização expõe um processo ambivalente de garantia de direitos e de impossibilidade do exercício desses mesmos direitos.

Palavras-Chave: deficiência intelectual, violência sexual, interrupção legal de gestação; direitos sexuais e reprodutivos.
About emotional grammars and sexual violence. Notes from two cases of legal abortion performed on women with intellectual disability.

Abstract: In this article I will try to explain how the strategies of access to sexual and reproductive rights of women with intellectual disabilities in situations of sexual violence are developed as a moral language articulating pain, suffering and victimization. From an empirical research carried out at the Sexual Violence Ambulatory of a city in the state of São Paulo, I will present two cases of legal abortion. One is performed on a 13-year-old girl and the other on a 27-year-old woman, both with intellectual disabilities. The purpose is to analyze the techniques of regulation and social control operated in the intersection of medical practice and legal practice. It is also intended to reflect the ambiguities and paradoxes of the recognition of people with intellectual disabilities as subjects of sexual and reproductive rights. Finally, I will try to indicate that victimization exposes an ambivalent process of guaranteeing rights and the impossibility of exercising those rights.

Keywords: intellectual disability, sexual violence; legal abortion, sexual and reproductive rights. 


\title{
A Inclusão e suas práticas aspectos socioantropológicos da produção de materiais pedagógicos inclusivos para Surdos
}

\author{
Ana Luisa Borba Gediel \\ Universidade Federal de Viçosa - Brasil
}

Victor Luiz Alves Mourão Universidade Federal de Viçosa - Brasil

Isabela Martins Miranda Universidade Federal de Viçosa - Brasil

\section{Introdução}

A trajetória das políticas públicas voltadas para inclusão de populações minoritárias mostra que, apesar dos avanços que tivemos desde a Constituição de 1988, ainda há muito a ser feito. Se pensarmos, por exemplo, no âmbito econômico e distributivo, é histórica e negativamente notória a desigualdade social que marca nossa sociedade, em que pese a diminuição das diferenças de renda nos últimos anos (Dedecca, 2014). Em outro registro, os processos recentes de ampliação das políticas que envolvem o reconhecimento (Fraser \& Honneth, 2003; Fraser, 2006) da diversidade existente na sociedade brasileira também avançaram nas últimas décadas.

Algumas destas políticas são protagonistas no cenário de modificações do campo educacional envolvendo a educação de pessoas surdas. Podemos citar a Lei 10.436/2002, a qual dispõe sobre a Língua Brasileira de Sinais (Libras) e a reconhece como meio legal de comunicação e expressão; o Decreto 5.626/2005, que regulamenta a mencionada lei, estabelece a obrigatoriedade, por parte das instituições federais de ensino, a oferta de condições de comunicação, informação e educação às pessoas surdas, garantindo sua inclusão e estipulando a obrigatoriedade da disciplina de Libras nos cursos universitários de licenciatura, além de uma série de direitos correlatos. Ainda, a Lei 13.146 institui o Estatuto da Pessoa com Deficiência e visa garantir o exercício das liberdades e dos direitos das pessoas com deficiência e sua inclusão social. Posteriormente, em 2015, foi decretada a Lei ${ }^{\circ}$ 13.146/2015, conhecida também como Lei de Inclusão, que tem o objetivo de 
assegurar e de promover condições de igualdade. Destacamos, por último, a Lei $\mathrm{n}^{\circ}$ 13.409/2016, referente à reserva de vagas para pessoas com deficiência nas Universidades Federais brasileiras, garantindo-lhes o acesso no âmbito do ensino superior.

Este novo cenário pressionou um conjunto de novos arranjos nas instituições para a adequação dos espaços para a inclusão de pessoas com deficiência no ensino superior. De forma geral, a pauta de discussões concentrava-se anteriormente na formação de professores e nas adaptações curriculares e da estrutura física no âmbito da escola básica. No entanto, aquelas pessoas passam a adentrar as instituições de ensino superior, provocando a necessidade de transformações metodológicas e de formação docente. Esse espaço, anteriormente caracterizado como campo de discussões teóricas e de formação inicial para atuação futura com a inclusão, torna-se, também, alvo da necessidade imediata de adaptações referentes à inclusão. Neste artigo, apresentamos algumas reflexões relativas à experiência de uma instituição de ensino superior, na região da Zona da Mata Mineira, que teve alunos Surdos matriculados em diferentes áreas de ensino e aderiu a algumas estratégias para a inserção e a permanência dos alunos em sala de aula. Como recorte da pesquisa e como posicionamento frente às diferentes discussões no campo da Deficiência, Surdez e Movimentos Surdos, a utilização do termo Surdo com sua letra inicial maiúscula foi escolhida, seguindo uma convenção estabelecida por um grupo de lideranças Surdas envoltas nos espaços acadêmicos. Em específico, identificação refere-se aos grupos de pessoas surdas que utilizam a Libras como primeira língua e usufruem dessa como meio político, cultural e identitário de reconhecimento (Padden \& Humphries, 2006). No presente trabalho, Surdo é definido (em oposição a surdo) como uma categoria êmica, ou seja, utilizamos a nomenclatura conforme o estabelecido e considerado pelos próprios sujeitos.

A ideia inicial da pesquisa centrava-se no mapeamento das tecnologias que estavam sendo utilizadas para promover o ensino/aprendizagem da Libras na instituição. Tal recorte deve-se ao fato de que a instituição é reconhecida pelo seu investimento em Tecnologias da Informação e Comunicação (TIC's), entendida como um conjunto de recursos tecnológicos que, ao estarem integrados entre si, podem proporcionar a autonomia e/ou a comunicação de vários tipos de processos existentes no ensino e na pesquisa científica, mediando os processos informacionais e comunicativos (Da Silva, 2009; Imbérnom, 2010).

Para encontrar os profissionais na instituição que estavam atuando na elaboração das TIC's realizamos um Mapeamento por Redes de Contato (Barnes, 1987). 
A partir dessa metodologia, observamos a construção dos laços entre as pessoas da instituição que atuavam no desenvolvimento de TIC's e verificamos a sua capacidade de agência e de influência nesse sistema. Ao longo do processo de mapeamento nos deparamos com o projeto de criação de materiais didáticos bilíngues (Libras/Português), voltado para o ensino/aprendizagem em um dos cursos da instituição, o qual passou a ser nosso foco de análise. Passamos a acompanhar o percurso de constituição de demandas do aluno, a organização de professores, de gestores, da equipe técnica e do espaço institucional para o estabelecimento de condutas de modo a responder a essas demandas.

Durante o período de mapeamento e de contato com os profissionais envolvidos no processo de elaboração de TIC's inclusivas, identificamos e acompanhamos a construção de materiais didáticos, os quais começaram a ser desenvolvidos especificamente para as aulas de um aluno Surdo. Tal ação tornou-se protagonista no contexto de desenvolvimento de tecnologias para inclusão na instituição e, a partir de então, vários olhares voltaram-se para esse processo. A criação das denominadas "aulas sinalizadas" surgiu a partir de um grupo interdisciplinar, que elaborou um projeto com o objetivo de criar formas de apoio para que o aluno conseguisse acompanhar o andamento das disciplinas no ensino superior. Este percurso nos possibilitou observar também os conflitos e as situações de estigmatização dos sujeitos (Goffman, 2012). Nesse contexto, descrevemos os agentes implicados nas ações que passaram a ser desenvolvidas e as interlocuções realizadas para o atendimento das demandas advindas via políticas públicas e a real situação de entrada de um aluno Surdo na instituição.

\section{Abordando os sujeitos: impressões do campo}

Os desdobramentos iniciais do projeto e a descrição dos olhares que permearam o campo partiram da observação participante, notas e diários de campo (Cardoso de Oliveira, 1996). Ao acompanhar as ações que envolviam as TIC's na Instituição de Ensino Superior (IES) estudada, passamos a visualizar diferentes perspectivas para a elaboração e a execução das políticas públicas inclusivas.

O primeiro contato com os interlocutores da pesquisa ocorreu no meio do ano de 2016, com o mapeamento daqueles professores e gestores que atuavam em projetos e ações voltadas para o uso das TIC's na instituição. Assim como indicado por Barnes (1987) para a realização do mapeamento de redes, o primeiro contato foi feito com o gestor dos projetos de extensão da Instituição, o qual possuía uma 
visão ampla de todas as iniciativas. Desse modo, chegamos aos projetos existentes na instituição e em quais setores ou departamentos estavam concentrados, além de entender os vínculos entre os projetos.

Tal contato possibilitou descobrirmos as unidades da instituição envolvidas com o tema da pesquisa. O responsável citou várias que atuavam na elaboração desses materiais, como a Unidade de Ensino à Distância, de Línguas, de Informática e o setor de acessibilidade, assim como seus representantes. Dessa maneira, criou-se uma rede de contato, em que cada um dos entrevistados citava outros profissionais influentes da rede, acreditando que o colega poderia enriquecer o trabalho da pesquisa. Com isso, consolidou-se a rede de contatos, que neste artigo ficou restrita à Unidade de Ensino à Distância, pois é a única parte da instituição que produz materiais didáticos com a finalidade de suporte para estudo dos alunos surdos. A partir disso, os colaboradores da pesquisa são evidenciados conforme o quadro que segue:

\section{Quadro 1: Identificação dos entrevistados}

\begin{tabular}{|c|c|}
\hline Nome & Vínculo para atuação no projeto \\
\hline João Daniel & Funcionário da Unidade de Ensino à Distância \\
\hline João Eduardo & Funcionário da Unidade de Ensino à Distância \\
\hline João Felipe & $\begin{array}{c}\text { Estagiário da Unidade de Ensino à Distância; } \\
\text { único da equipe que possui conhecimentos em } \\
\text { Libras. }\end{array}$ \\
\hline Maria Beatriz & Diretora da Unidade de Ensino à Distância \\
\hline
\end{tabular}

Os nomes das pessoas, dos setores e da instituição foram preservados por questões éticas. Ao passo que fomos mapeando e encontrando as pessoas, fomos denominando as mulheres de "Maria" e os homens de "João", seguido por segundo nome aleatório com a inicial de letra em ordem alfabética de acordo com a ordem que apareceram no mapeamento. Em relação à formação, temos uma equipe interdisciplinar, em que João Daniel é o único que tem sua formação voltada para a área de Informática. João Eduardo tem formação na área da Comunicação, João Felipe, embora desempenhe papel vinculado à área de Libras, tem formação nas Ciências Sociais e, por fim, Maria Beatriz tem formação voltada para a Educação a distância. Desse modo, três dos quatro colaboradores da pesquisa advêm do campo das Ciências Sociais e Humanas. 
Após o estabelecimento da rede, passamos para a segunda etapa da pesquisa, com a realização de entrevistas com os membros das equipes responsáveis pelo desenvolvimento de materiais. Todas as entrevistas foram de cunho semiestruturado (Triviños, 1987), e os professores assinaram o termo de consentimento livre e esclarecido, o qual informa o sigilo da pesquisa ${ }^{1}$

A partir das entrevistas, tivemos a oportunidade de conhecer mais a respeito de cada projeto citado. A observação participante e o acompanhamento de algumas ações nos levaram a um projeto específico, voltado para um aluno Surdo. Tal destaque se deve ao fato de que os olhares dos próprios informantes estavam voltados para esse projeto, o qual pretendia a criação de uma versão das aulas narradas para aulas sinalizadas. As aulas narradas são entendidas como um modelo de exposição de conteúdo didático em formato de vídeo-aulas, utilizado na instituição como material disponível para acesso teórico aos conteúdos das disciplinas realizadas à distância. Desse modo, a adequação desse modelo pedagógico para aulas sinalizadas possibilitaria o entendimento do conteúdo para um aluno Surdo que havia se matriculado na instituição.

\section{O projeto de criação de materiais didáticos e a reflexão autóctone}

O cenário de entrada de alunos Surdos no contexto universitário tem proporcionado trocas de saberes, adição de agentes com conhecimentos educacionais e linguísticos específicos, além das adaptações no cenário de sala de aula. Santos (2015) apresenta um panorama de pesquisas que remetem ao processo de inclusão no ensino superior, as quais apontam para um número ainda pequeno de pessoas surdas matriculadas. Também, em seus achados, descreve a importância dos profissionais tradutores e intérpretes de Libras/Português para realizar a mediação linguística durante as aulas, visto que a partir desse mapeamento realizado pela autora não há a percepção de uma mudança considerável na didática dos professores com a entrada desses alunos. Percebemos, então, a criação de algumas iniciativas, como o projeto mencionado. Este nasceu de uma demanda relativa à entrada de um estudante Surdo que necessitava de materiais didáticos para levar adiante seus estudos. Ainda que a universidade oferecesse intérpretes para as aulas, os momentos de estudo fora da sala apresentavam problemáticas anteriormente não identificadas, qualificadas retrospectivamente como "drama” por João Felipe: “Só o intérprete na sala de aula não era o suficiente porque toda a interação em Libras fica restrita na sala de aula. Se o Surdo quisesse rever o material e tal, ele não teria possibilidade na língua dele, 
se não fosse com mediação do intérprete e isso dentro da sala de aula. E fora da sala de aula?".

A segunda maior instância administrativa da instituição, a coordenação do curso da área das exatas, os professores de diferentes departamentos e o setor de acessibilidade da instituição, preocupados em atender às especificidades do aluno, contataram a Unidade de Ensino à Distância para que produzisse materiais capazes de atender tal demanda.

Inicialmente, o grupo de profissionais entendia que era necessário apenas legendar as aulas narradas - formato de apresentação do conteúdo da aula em vídeo gravado em estúdio pelo professor - das disciplinas. Nesse estágio, a percepção da equipe responsável pelo projeto demonstrava o desconhecimento em relação à especificidade linguística do sujeito Surdo, que tem a Libras como primeira língua e a Língua Portuguesa como segunda língua. Por isso, o grupo de professores das exatas e a equipe de tecnologias considerava que a questão seria resolvida com a adição de uma legenda nos conteúdos vinculados à disciplina, uma espécie de aula narrada legendada. Estimava-se que, em poucos meses, os materiais estariam prontos para uso. No entanto, assim que as atividades tiveram início, a falta de conhecimentos por parte da equipe em relação às especificidades culturais e linguísticas das pessoas Surdas foi o primeiro entrave reconhecido. Como menciona Maria Beatriz, diretora da Unidade, "um projeto que a princípio parecia ser simples, chegar aqui e fazer uma aula narrada para atender e viu-se que era muito complexo que isso". Havia, portanto, uma subestimação em relação às dificuldades de realização do projeto, tendo em vista a falta de conhecimento no que tange à "complexidade" da Libras e do modo como o Surdo interage, comunica-se e aprende.

Esse momento foi permeado por várias características que identificamos semelhantes ao pontuado nos estudos de Goffman (2012), em torno de uma situação normal-estigmatizado: perplexidade, desconforto, inquietação, momento esse no qual o grupo começou a identificar a necessidade de um conjunto de ações, as quais não eram explícitas na legislação e que deveriam ser articuladas de maneira interdisciplinar, conforme afirma Maria Beatriz:

[...] é um desafio diferente porque são áreas temáticas diferentes, pessoas diferentes e que nos tiram um pouco dessa zona de conforto de atuar em coisas que você domina no dia a dia e isso acaba que mexe com essa estrutura que já tá consolidada e você tem que buscar, tem que estudar, aí você percebe, "ah, eu não tenho nem 
essa competência, nem essa habilidade", preciso identificar pessoas para virem compor, para ajudar esse grupo [...] (grifos nossos).

A elaboração das aulas sinalizadas teve início com um conjunto de questões pragmáticas que deveriam ser resolvidas para dar continuidade à ideia proposta: era necessário organizar uma equipe de trabalho, elaborar o projeto de treinamento dos envolvidos na execução e planejar a articulação das diferentes áreas que iriam atuar colaborativamente. Esse esforço organizacional deveria ainda estar de acordo com as demandas que envolvem o âmbito das políticas públicas inclusivas de maneira mais geral, para além do caso específico.

Maria Beatriz relata ainda que a partir da compreensão das dificuldades inicialmente subestimadas que o grupo precisou “contratar alguém que soubesse Libras para compor nosso quadro de estagiários, tivemos que trabalhar com estagiários voltados para essa área, fazer parcerias ou trabalhar mais conectados com os intérpretes [...]”. A percepção da ausência de competências, de conhecimentos e de habilidades acumuladas para concretizar a tarefa estipulada levou à busca de mais integrantes para a equipe. Foi quando ocorreu a contratação de um estagiário com conhecimentos na Libras, João Felipe, para compor a equipe responsável pela produção do material. A partir desse momento, a organização da equipe, a divisão de atividades e responsabilidades e os próprios produtos do projeto são reformulados.

Esse processo levou a uma reflexão coletiva na qual três questões emergiram: 1) necessidade de reorganização o material didático apostilado em uma apresentação compatível com as especificidades do modo de comunicação e aprendizagem do aluno Surdo, com a utilização da Libras e de sinônimos de algumas palavras técnicas por classificadores ${ }^{2}$ e explicação do conceito (Quadros \& Karnopp, 2004); 2) a Libras, por ser uma língua espaço visual, requer o uso de imagens associadas aos conceitos para trazer a explicação para o universo do aluno Surdo; desse modo, as imagens ilustrativas apoiam a compreensão; 3) constatou-se uma falta de tradução de conceitos da área das exatas para a Libras.

A partir das constatações pela equipe, chegou-se à conclusão de que nem somente a legenda, tampouco a interpretação de conteúdos para a Libras utilizando os mesmos slides, previamente criados pelos professores para as aulas, não garantiria o acesso do aluno aos conhecimentos que estavam sendo ministrados nas diferentes disciplinas nas quais ele estava matriculado. Era necessária a elaboração de conteúdos didaticamente reformulados, adequando-os aos três pontos acima mencionados. Isso também demonstrava a necessidade de criar de um glossário especí- 
fico da área para que o material fosse considerado inclusivo e didaticamente eficaz.

Todos esses fatores linguísticos, conceituais e metodológicos surgem em um contexto complexo, com pessoas integrantes da equipe possuindo diferentes perspectivas a respeito do tema, relacionadas às especificidades da pessoa Surda e das ações necessárias frente ao cumprimento das políticas públicas.

O projeto foi então na direção de conseguir capacitar a equipe no processo de reformulação da equipe e das rotinas de atividades, para posteriormente lidar com o desafio de criar materiais didáticos para Surdos, para formação referente aos modos de aprendizagem e de interação das pessoas Surdas que utilizam a Libras. Entendemos que esse processo permeia a execução das políticas públicas, no sentido de localizar o que é transcendente; complexificar o homogêneo - trata-se de evitar cair na concepção autocongratulatória dos textos oficiais para desenvolver uma perspectiva que consiga captar as "práticas etnopolíticas na efetivação de direitos de cidadania” (Fonseca et al. 2016, p. 11). Essas práticas que envolvem os sujeitos, os objetos, as linguagens, as línguas, as redes, precisam ser mobilizadas para alcançar os objetivos da política pública inclusiva.

\subsection{A tomada de consciência mediada}

Com a reorganização inicial da equipe, o estagiário estaria responsável pelas atividades relacionadas a Libras no âmbito da produção do material didático. No entanto, sua atividade efetiva ultrapassou as funções inicialmente previstas, abarcando a função de coordenador geral das atividades do projeto, de apresentador da cultura Surda aos membros leigos da equipe do projeto e de mobilizador dos vários grupos que o compunham. João Felipe relembra dessa maneira o momento inicial de sua participação no projeto:

eu entrei na [Unidade de Ensino à Distância] em maio [e] comecei a fazer o estágio aqui para o material ficar pronto para o mês de agosto [...] Uma das primeiras coisas que eu procurei saber assim e fazer foi: vamos organizar uma equipe, [e] para organizar essa equipe não tinha nem projeto [...]. Veio [tudo] numa desorganização [...] Meu depoimento é meio crítico, porque não foi [nada] pensado, veio assim, a demanda veio e 'ó' : 'a gente precisa de material para o período que vem'.

Novamente, a ausência de competências para levar adiante o projeto dentro do prazo estabelecido se tornou explícita. Desde os anos 1990, com as reivindicações dos movimentos Surdos, do envolvimento da academia e do endossamento de 
documentos legais, houve também uma construção interdisciplinar do campo de atores sociais que envolve a Libras. Surge, então, um nicho de atividades que insere a língua e as experiências advindas desse grupo de pessoas em projetos educacionais nas frentes do ensino, pesquisa e extensão (Brito, 2016). A participação desses sujeitos no campo acadêmico, por exemplo, trouxe influências na própria construção de sentidos das categorias científicas que estão sendo criadas na Libras, levando em consideração o olhar do próprio movimento Surdo.

No entanto, há um processo de adequação e, no caso da produção do material didático, eram "poucas pessoas, só eu no caso que sabia um pouco da Libras", como afirma João Felipe. Essa constatação leva à reformulação das funções, e João Felipe se assume enquanto "cientista social":

o meu papel nesse momento foi de mediador, então eu entrei com o papel de cientista social mesmo, articulei a equipe, fui articular as pessoas, fui chamar as pessoas, organizar grupos de estudo, as reuniões, discussão sobre o que era língua de sinais, discussão de como usar as tecnologias até tem um texto que gente discutiu da Marianne Stumpf, uma Surda especialista na escrita da língua de sinais, e aí discutimos esses textos e eu fiquei na parte de produzir relatórios, então eu sempre produzia relatório e mandava para o grupo e articulava: "pessoal, vamos reunir" e tal, os dias, então esse foi o meu papel, de trazer os intérpretes, então os intérpretes começaram a participar das reuniões sempre tinha dois ou um intérpretes [do setor de acessibilidade], os Surdos, conseguia uma articulação, aproximei o estudante Surdo da equipe para ele participar também do processo nesse primeiro momento, nesse primeiro semestre.

João Felipe se assume como aquele que, além de ter conhecimento fundamental da língua, trabalha para além desta habilidade, atuando principalmente como um mediador de culturas, de línguas e práticas sociais distintas, de maneira a colocá-las em contato e permitir que o trabalho coletivo de produção dos materiais didáticos aconteça. Ele organizou e promoveu durante dois meses um grupo de estudos para conscientização sobre a língua e surdez, composto pelos funcionários da unidade, os estagiários do curso de exatas, os intérpretes vinculados ao setor de acessibilidade e o estudante Surdo. De tradutor de textos ele passa a mediar culturas e promover a reflexividade sobre os modos distintos de ser e de aprender, possibilitando o aperfeiçoamento das competências ligadas à produção de materiais didáticos. Aqui a autopercepção deste cientista se aproxima muito da problemática instaurada de 
uma dupla hermenêutica que permite apresentar, traduzir e comunicar redes de significados que pertencem a certos contextos de vida social a outras pessoas que não tem acesso a eles (Giddens, 2007). Desse modo, o estagiário atuou no sentido de realizar uma análise crítica do social e, consequentemente, provocar transformações sociais no sentido de uma maior reflexividade.

A partir de outro ponto de vista, é possível compreender a diferenciação de olhares dos participantes do projeto, das concepções em relação ao movimento Surdo e aos espaços ocupados pela língua e por seus interlocutores. João Felipe assume a posição contrária à categoria deficiente, que conforme Assis (2011), está vinculada à concepção biomédica, que caracteriza a pessoa a partir da perda auditiva. A promoção das ações foram encaminhadas de acordo com uma perspectiva que se alinha à categoria surdo(s $)^{3}$. Ambas as posições são legitimadas e assumem caráter político, uma voltada para a perspectiva da reabilitação e aproximação do sujeito à normatização que pode ser adquirida por meio de tecnologias, como o aparelho auditivo ou o implante coclear. E, a outra, está respaldada pela particularidade linguística, que consecutivamente, relaciona-se à construção de identidades e cultura alinhadas à especificidade da língua. As ações de João Felipe, além de serem conduzidas pela afinidade à categoria surdo(s), evidencia também que a equipe se posicionava de maneira diferente em relação ao modo de entender os sujeitos alvo da produção do material didático ou ainda não tinham um conceito formado a respeito de tal discussão. As interações da equipe e o processo de aproximação das crenças referentes à categoria surdo(s) previamente obtidas por João Felipe foram sendo incorporadas por meio de textos acadêmicos, vídeos com depoimentos de pessoas Surdas descrevendo a importância da língua em suas vidas e a apresentação de pesquisas que levavam ao entendimento que os materiais didáticos elaborados com o uso da Libras e o suporte imagético ampliavam o desempenho de apreensão de conhecimentos das pessoas Surdas que utilizavam essa língua como principal meio de comunicação.

Em aliança com essas atividades de estudos e de apresentação do modo de ser Surdo, a divulgação de um fórum promovido pelo Instituto Nacional de Educação de Surdos (INES) motiva parte da equipe a participar e conhecer um dos locais considerado ícone do movimento Surdo na perspectiva que João Felipe havia apresentado ao grupo. Nesse evento, foram expostos trabalhos relacionados à construção do projeto e foi feita também uma visita à TV INES, onde são produzidos materiais audiovisuais parecidos com o objetivo do projeto. Maria Beatriz descreve que, após 
a visita à instituição, houve uma maior integração do grupo e entendimento do foco para as reais necessidades de desenvolvimento das atividades, conforme descrito a seguir: "As visitas que foram feitas no INES e formou-se um grande grupo aqui na [Unidade de Ensino à Distância] buscando conhecer um pouco mais o que que é a Libras, procurando saber que tipo de material de didático seria mais adequado pra atender mais, não só o Surdo mas o ouvinte também”.

Isso suscitou, na equipe responsável, um processo de tomada de consciência da categoria instituída, a qual evocava o discurso da diversidade e das diferenças que envolvem a condição surda e, por conseguinte, da necessidade de se capacitar para levar adiante o projeto. João Daniel reconhece o aspecto diferencial do modo de ser Surdo, se afastando da negatividade do diagnóstico médico típico do senso comum: "os Surdos pensam diferente, o mundo deles é diferente do nosso, isso não é ruim é só diferente, a gente tem que entender isso". Em uma fala retrospectiva, ele consegue identificar a principal problemática inicial do projeto, relativa à falta de conhecimento do modo de interagir e aprender do Surdo: "A grande dificuldade inicial foi entender o público alvo porque nós não somos Surdos e não temos contato com pessoas Surdas o tempo todo aqui”. E o modo de ser Surdo passa, na compreensão dos próprios entrevistados, pela percepção de que o Surdo possui uma língua diferente, específica e distinta, e que coloca problemáticas no âmbito pedagógico-comunicacional.

Na acepção biomédica da deficiência são consideradas apenas as limitações sensoriais, fisiológicas e/ou cognitivas em relação a um parâmetro de normalidade auditiva; já no sentido da diferença, construído no âmbito da equipe, essa condição é construída a partir das elaborações do próprio grupo, que pretende uma identificação cultural ligada à questão linguística, no ponto de vista êmico. Os Surdos se constroem enquanto grupo minoritário para a reivindicação de direitos sociais e educacionais. Assim como menciona Carniel (2013), o campo da educação torna-se um espaço de construção de significação para as políticas que estão sendo implementadas, as quais são autorizadas seguindo os rumos adotados pelo Estado. No entanto, esse campo é fecundo para disputas de poder por meio de práticas estabelecidas nas instituições, as quais possibilitam a invenção pedagógica, conforme as categorias e crenças apropriadas pelos agentes envolvidos.

Isso é evidenciado nos discursos dos colaboradores da pesquisa quando o grupo se posiciona politicamente diante do debate sobre a surdez, assumindo a perspectiva de sua especificidade linguística, não tomada como uma deficiência e sim como uma diferença. Levando em conta esse viés, as pessoas Surdas formam grupos e intera- 
gem em associações, fortalecendo posições ideológicas e políticas e reivindicando visibilidade, acessibilidade e inclusão. Assim, essa perspectiva coloca que a Língua de Sinais desafia os padrões a serem aceitos na sociedade, mesmo tendo importância significativa para o grupo de pessoas Surdas que a utiliza, com forte papel de demarcação da cultura sentida e expressa corporalmente. Ao considerarmos as categorias de "normalidade" e "anormalidade" definidas por Michael Foucault (2001), os Surdos podem ser pensados como "anormais", da mesma maneira que o autor se refere às pessoas que estão fora dos padrões do direito civil ou do direito religioso. Os indivíduos descritos pelo autor, como aqueles deformados por enfermidades ou diferentes dos padrões sociais legitimados "normais", não estavam previstos na área do direito ou religião. Isso os tornava entraves no processo de tomada de decisões sociais. Ainda hoje, percebemos que, embora haja mudanças na legislação, a problemática de como lidar com essas pessoas e inclúí-las em diferentes espaços permanece.

João Daniel afirma que, para conseguir produzir o material didático, é necessário "saber da importância da valorização da cultura Surda [...]. Porque as pessoas acham que os Surdos sabem português fluentemente, as pessoas não sabem que a primeira língua deles é Libras, muita gente nem sabe que a Libras é uma língua oficializada no Brasil e é a segunda”. João Eduardo, discorrendo sobre as especificidades do modo comunicacional do Surdo e da problemática de produção de material didático para este público, faz sobre isso a seguinte reflexão: "você tem que ter uma preocupação para que realmente tenta se colocar no lugar do Surdo para ver se você conseguiria realmente entender aquilo”. João Felipe reforça tal entendimento da especificidade comunicacional-linguística dos Surdos e o impacto desta compreensão na produção de materiais didáticos:

é como se fosse a segunda língua dele e não a primeira língua dele, e aí começou a surgir os problemas, as problemáticas, [...], qual problemática? Que é uma outra língua, é uma outra modalidade linguística, é mais difícil para o Surdo ler uma palavra em português do que às vezes ver uma sentença em Libras, ainda mais para esse Surdo [o estudante, que] tinha um bom domínio da língua brasileira de sinais

As especificidades da Libras, enquanto língua gestual e imagética, foram elaboradas pela equipe como um próprio modo de organização interna do trabalho de construção dos materiais didáticos. Para João Eduardo, 
a Libras é uma linguagem extremamente objetiva, então os Surdos têm a necessidade de serem extremamente objetivos, se você está colocando uma imagem que ela não é muito óbvia em cima da mensagem que você quer colocar, isso não é uma boa imagem, arruma outra que vai bater o olho e vai ligar num conceito, se tiver uma subjetividade ali não é muito bom, eu prefiro você ser direto e mais objetivo possível.

Observa-se o que o entrevistado nota como sendo "objetividade" poderia ter sido chamado de concretude imagética: o sentido e o significado devem ser concretos e visuais, o que destoa do modo como a ciência, em sua parte teórica e abstrata, se especializou em desenvolver. Nas falas apresentadas acima, percebe-se o processo reflexivo de tomada de consciência da diferença negada em relação ao Surdo, da "complexidade" que é a comunicação através da língua de sinais. Glat e Pletsch (2010), consideram que para uma educação inclusiva é necessário mais do que adaptações, é preciso buscar uma nova concepção curricular, reconhecendo as especificidades dos alunos.

A tomada de consciência e de aprendizagem em relação à cultura Surda e do modo de aprender do Surdo foi fundamental para o processo, concomitante e posteriormente, de construção do material didático. A Unidade de Ensino à Distância concluiu que a proposta de legenda simples não seria eficaz ao aprendizado do estudante: seria necessário realizar algo na primeira língua desse aluno, em Libras. A desnaturalização do português escrito como primeira língua dos Surdos foi, assim, um processo fundamental dessa tomada de consciência para que a equipe se afastasse da concepção inicial da produção de materiais didáticos voltados para Surdos enquanto legendagem do material disponível para se aproximar de um processo que envolvesse a tradução/interpretação dos conteúdos didáticos das disciplinas. Isso adicionou um nível de complexidade ao processo inicialmente imaginado que implicou em uma reformulação do projeto e na percepção de uma série de problemas que deveriam ser enfrentados. Aqui, percebemos igualmente que em consonância com outras pesquisas, os membros da equipe de produção de material didático funcionam como "intermediários" pensantes, reflexivos, que se voltam para a construção de pontes que permitam não só a realização da atividade restrita a eles colocada (qual seja, a produção de materiais didáticos acessíveis) mas que problematizam, de maneira mais ampla, o lugar e os modos de acesso à cidadania e ao reconhecimento daqueles que são seus objetos/sujeitos de ação (Fonseca et al., 2016). 


\subsection{Desenvolvimento da metodologia de criação de materiais didáticos acessíveis}

Um grande desafio foi criar uma metodologia para elaboração do material didático acessível. A unidade já possuía vários modelos de construção de materiais didáticos, mas nenhum foi capaz de prover acessibilidade aos Surdos. É nesse momento que a já citada visita à INES foi fundamental para averiguar as metodologias utilizadas na criação de materiais acessíveis em Libras, como explicita João Daniel:

O que a gente percebeu lá [na TV INES] é que até existem metodologias, mas existem várias formas de se fazer e cada lugar tem um jeito. E esse jeito é gerado a partir da particularidade da equipe que eles têm, porque o ideal num caso desses é que tenha Surdos na equipe, no caso deles têm e dentro da TV INES tem várias maneiras de fazer o mesmo produto porque tem um Surdo que ele prefere pegar uma câmera de computador, pegar o texto em português e aí ele sinaliza e aí ele manda aquilo para o colega dele revisar, ele manda para o intérprete, tem uns que preferem que o intérprete faça o texto e aí o Surdo vai analisar o vídeo, então lá dentro da TV tem vários Surdos, vários ouvintes, vários intérpretes, eles têm formas diferentes de trabalhar o mesmo material, métodos diferentes mas para gerar um mesmo vídeo no final, depende da [composição da] equipe.

A reflexividade possibilitou demonstrar que a metodologia e a construção técnica dos materiais estão atreladas à composição social diversa da equipe voltada para este objetivo: ou seja, o tecnograma (o complexo de técnicas, tecnologias, materiais, equipamentos e produtos) é correlato ao sociograma (o complexo de pessoas, técnicos, professores, estudantes, etc.) que são arroladas para a construção dos materiais didáticos acessíveis (Latour, 2000). E é essa correlação entre a particularidade da equipe e a composição específica tecnológica que promove um tipo particular de resolução metodológica da problemática de criação de conteúdo didático.

Como mencionado, outro enfrentamento do projeto foi a falta de sinais específicos do jargão técnico da disciplina. Vários termos técnicos não possuíam sinais, e isso dificultava o trabalho. Isso decorre, em parte, de outras especificidades relativas à Libras. A Libras sempre foi considerada uma língua marginalizada, em especial por ser uma língua visual, que começou a ganhar proeminência apenas no século XXI. É importante ressaltar que ela é a língua da comunidade Surda e eles conseguem se expressar como qualquer pessoa ouvinte, inclusive em conceitos abstratos (Gesser, 2009). Ela possui gramática e suas variações são dadas em configurações de mãos, expressões faciais e também corporais, que provêm sentido à língua (Quadros 
\& Karnopp, 2004). Trata-se de uma língua em processo de reconhecimento e de expansão do seu léxico. Os estudos linguísticos das línguas de sinais no Brasil são muito recentes e isso gera uma lacuna de palavras, conceitos e expressões, principalmente em áreas pouco exploradas ainda, como os termos técnicos nas áreas das ciências exatas.

Neste âmbito, buscou-se capacitar a equipe a partir dos processos de criação de sinais da Libras. Uma fonte fundamental de informação foi uma comunidade de Surdos no Facebook na qual havia um trabalho de criação de sinais. A equipe contou com o apoio da pessoa surda, beneficiada pelo material didático, para auxiliar no processo de criação dos sinais e no feedback avaliativo de outras pessoas surdas. Primeiramente, ele entrou em um grupo de pessoas surdas sinalizantes que realizavam cursos no campo das ciências exatas do país, a partir de uma mídia interativa digital, para conhecimento e troca de sinais que vinham sendo utilizados e criados. Posterior a este momento, tendo em vista que um número considerável de conceitos ainda não tinha sinais, o aluno Surdo, em conjunto com a equipe de criação de material didático, começou o processo de mapeamento dos sinais específicos e daqueles que ainda não haviam sido registrados por meio de sinais convencionados pelos Surdos participantes do contexto acadêmico e inseridos nos movimentos de liderança Surda.

Após a elaboração prévia de um sinal para um conceito realizada pelos intérpretes e pelo Surdo, em conjunto com o monitor da área, este sinal era enviado para lideranças surdas, residentes em diferentes regiões do país, para que houvesse uma avaliação acerca da criação de determinado sinal. Conforme João Felipe, a interação das pessoas Surdas por meio de mídias de interação online para a catalogação e constituição dos sinais específicos de determinada área acadêmica auxiliaram aprofundar a reflexão sobre o modo de aprender Surdo: "como ele [o estudante Surdo] e mais outros Surdos criaram um grupo no Facebook das [ciências exatas] para propor sinais para conceitos que não existiam, [...] a gente estudou como que foi a interação a partir do Facebook".

Nesta etapa, pensou-se em criar os sinais que ainda não existiam, com um método que envolvia vários integrantes (professor, estagiário, Surdo, intérprete). Foram feitas algumas tentativas de elaboração destes sinais, e novos obstáculos começaram a aparecer. João Eduardo coloca que "a ideia inicial é que todo termo [em português] que não possui sinal [em Libras], esse sinal seria criado, o problema é que isso gera muito tempo, você não cria um sinal, "ah eu criei um sinal e é esse", 
não, você tem que conferir com o Surdo, o intérprete, etc.”. João Daniel completa ao perceber o aspecto cultural e de reconhecimento no processo de criação destes termos, que "tem que ser feito por um Surdo, ele tem que criar, a comunidade tem que aceitar” os sinais criados. Mas, complementa: como havia várias "disciplinas que possuem muitos termos técnicos próprios [e] que não [possuem] sinais, a gente caiu de novo num outro problema com relação a isso". Houve assim uma dupla problemática identificada: (1) o processo demorado de criação dos sinais, que envolve várias fases e diferentes pessoas; (2) o processo de aceitação por parte da comunidade Surda, que poderia não adotar (e, por conseguinte, rejeitar) o sinal criado. Era necessário um momento criativo e de aceitação por parte da comunidade Surda. Como havia uma data estipulada de curto prazo para entrega dos materiais, tal caminho, ainda que mais eficaz no âmbito da comunicação dos significados, foi abandonado. A alternativa encontrada foi utilizar a datilologia da palavra, imagens ilustrativas e classificadores.

Após esse processo de idas-e-vindas, chegou-se a uma metodologia de criação de materiais para Surdos intitulada aula sinalizada (Souza \& Júnior, 2016). Este método é uma adaptação de um método já existente, aula narrada, porém em versão de sinais. Esse método estipula alguns passos. Inicialmente, os estagiários em conjunto com os professores da disciplina, montam um material em slide. Esse slide é passado para o estagiário com conhecimento em Libras que traduz o material, com revisão do coordenador do setor de acessibilidade, também fluente em Libras. Depois, é montada uma glosa, ou seja, a transposição escrita da sintaxe do que é sinalizado em Libras para Língua Portuguesa, com a adição de códigos que levem ao entendimento da gramática que compõe a Libras (Ferreira Brito, 1995). Com o auxílio de um audioguia, faz-se um vídeo do intérprete sinalizando a glosa. Ainda que o vídeo seja em Libras, há necessidade de um audioguia que instrua o intérprete na sinalização e também auxilie o editor no momento da edição do vídeo.

Com todos esses materiais prontos, o processo de edição do vídeo é feito. Essa fase também precisou passar por adaptações, pois se percebeu que o quadro com o intérprete costuma ser muito pequeno, o que dificulta a visualização dos detalhes. Para a confecção desse material, da tela foi destinada para a interpretação em Libras. O enquadramento do vídeo foi assim adaptado. Para possibilitar livre movimento, a distância definida foi espaço de um palmo acima da cabeça, nas laterais, a distância dos cotovelos abertos formando dois triângulos com as mãos entrelaçadas no peitoral. 


\subsection{Os reflexos do projeto: efeitos inesperados}

Todo este complexo, esta trama levada adiante por uma demanda de construção de materiais didáticos acessíveis ao estudante Surdo teve uma série de subefeitos não esperados: disseminação de conhecimentos referentes a Libras e às especificidades culturais e cognitivas dos Surdos, necessidade de formação especializada no ensino superior, intensificação das discussões a respeito da produção de materiais didáticos acessíveis. Isso gerou um processo de tomada de consciência e a retificação das "racionalizações" estigmatizadas que Goffman (2012) identifica.

Percebe-se assim uma mudança na posição e na perspectiva dos próprios técnicos, que passaram paulatinamente a compreender a situação do Surdo. Como coloca João Eduardo:

Outra coisa que eu achei interessante foi muito importante, criou até um descompasso entre os professores que geram o conteúdo, é que como a gente teve o grupo de estudos e foi convivendo com os Surdos, a gente entendeu como eles agem e aprendem, que é totalmente diferente da gente.

Por um lado, o que João Eduardo identifica como descompasso se refere a uma tensão conflituosa entre professores da instituição (tidos como especialistas na área em que lecionam) e os próprios membros da equipe de produção do material didático acessível que, ao passarem pelo processo de tomada de consciência da especificidade do modo de ser e de aprender Surdo, acabam por colocar em xeque a capacidade plena dos professores de exercer seu ofício.

Por outro, trata-se de uma potencial multiplicação de informados, daqueles que possuem uma trajetória de experiência que lhes capacita a identificar as dificuldades pelas quais passam os Surdos e a reconhecer essa comunidade como dotada de especificidades e de direitos e, ainda, de competências profissionais e sociais próprias, valorizadas. João Daniel expressa bem essa aprendizagem quando afirma que

o grande avanço para [uma produção sistemática do material didático acessível e, por conseguinte, de uma inclusão social efetiva] acontecer aqui na [Instituição] seria a gente ter o Surdo para trabalhar aqui com a gente, trabalhar aqui em a gente que eu falo tanto no nosso setor de texto, de produção textual, também um Surdo poderia ajudar muito lá, entendeu? Teria que ter um funcionário Surdo fazendo parte da equipe porque é aquela história, como que eu vou trabalhar numa segunda língua, numa outra linguagem sem ter uma pessoa que é nativa daquela língua, precisaria ter. 
É nesse processo dinâmico de interação que os processos reflexivos e os conflitos que os permeiam adquirem relevância já que permitem evidenciar que as "práticas de construção da cidadania” (Fonseca et al., 2016, p. 14) estão longe de serem consensuais, remetendo antes a um renitente fazer cotidiano e reflexivo que configura antes um sociação simmeliana que um realização estática de uma cidadania ideal prevista legalmente. É neste sentido que estamos de acordo com Simmel quando afirma que o conflito é indispensável à coesão grupal, já que é uma condição para a manutenção do processo que unifica e, ao mesmo tempo, transforma grupos sociais. Ele atua não apenas de uma força desagregadora, mas também enquanto força integradora do grupo (Simmel, 1983a).

No nosso caso aqui analisado, a tensão aparece no processo de absorção de conhecimentos da cultura Surda, do modo de ser e comunicar Surdo, que deslocam a posição dos membros da equipe no sentido de se afastarem da posição típica do senso comum (dos “normais”) e se aproximar da posição dos "informados” criando, não obstante, uma ponte possível de relações sociais entre "normais" e "estigmatizados" (Goffman 2012). Essas "antíteses e sínteses" (Simmel, 1983c), sobrepostas umas às outras, provêm do caráter dinâmico deste processo que tem efeitos não apenas sobre a população-alvo da política de inclusão, mas principalmente sobre os encarregados de executar as atividades voltadas para tal propósito. Essas forças centrípetas e centrífugas são dinâmicas e pautam o processo de construção identitária dos vários grupos envolvidos. A importância da forma das relações sociais em Simmel aparecem, no caso aqui trabalhado, como os modos padronizados de relações entre estigmatizados-informados-normais (Simmel, 1983b).

Foi absorvendo e refletindo sobre a problemática da cultura Surda, da comunidade Surda, das especificidades desta população e dos modos adequados de construção de materiais didáticos voltados para esse grupo que se logrou acumular a competência técnica e cultural para criar não só os materiais didáticos específicos das disciplinas mas também desenvolver uma metodologia adequada de construção de materiais didáticos acessíveis.

\section{Considerações finais}

Foi possível perceber, ao longo do texto, que a execução de políticas públicas voltadas para a diminuição da desigualdade social, permeando o avanço formal e o reconhecimento jurídico-legal dos direitos de grupos e populações minoritárias não soluciona por si só o déficit de cidadania que marca nossa existência social. A 
execução concreta dos preceitos igualitários destas políticas nos leva a uma complexificação ainda maior destes processos sociais de transformação. Tendo em vista tal problemática, a reflexão sobre as experiências de formulação e de execução de políticas são fundamentais não só para se poder avaliar o grau de eficácia na sua implementação mas também para se extrair lições no sentido de aperfeiçoá-las e corrigi-las em suas trajetórias.

A análise do processo pelo qual passou uma equipe responsável pela produção de materiais didáticos acessíveis a partir do seu próprio relato dessa experiência nos auxilia a compreender melhor o processo de execução de projetos que visam a efetivar uma política de inclusão social e, ainda, de reconhecimento da diversidade no âmbito de uma instituição de ensino superior. Pode-se dizer que não basta que as equipes dos projetos criem as tecnologias e os materiais didáticos com a intenção e o objetivo de promover a acessibilidade e inclusão. É necessário ainda - e este é um ponto fundamental - que a própria comunidade de usuários aceite e reconheça o material enquanto apto a tal objetivo.

Tais considerações justificam não só a inclusão dos usuários dos materiais nas equipes de criação de materiais didáticos voltados para seu usufruto mas igualmente nos comitês de formulação das políticas públicas voltadas para inclusão. Como diz Michel Callon (1995), os processos de concepção e de difusão das tecnologias não se separam nitidamente entre si: os usuários das tecnologias estão presentes desde o processo inicial de concepção, e esta nunca termina, mesmo após o processo de difusão da tecnologia ter se tornado relevante. A eficiência e a eficácia destes materiais didáticos voltados para inclusão não se limitam a seus aspectos técnicos ou mesmo pedagógicos: há um elemento social e cultural fundamental no qual a tecnologia só poderá existir se for reconhecida enquanto tal pelo grupo de usuários. Qual é a rede que permitirá a adoção e utilização destes materiais? Quem são as pessoas encarregadas em disseminar as informações e as competências que permite tal utilização?

A problemática metodológica e inclusiva apareceu de maneira clara: o processo de construção do material didático inclusivo deve levar em conta o Surdo enquanto parte ativa neste processo de modo a aumentar a eficácia pedagógica do conteúdo elaborado. A temática da aprendizagem Surda, que passa de maneira central na imagem e nas configurações visuais de sua língua, demanda não apenas uma sensibilidade por parte dos professores e daqueles responsáveis pela criação pedagógica: demanda, sim, uma incorporação do Surdo e de sua cultura nos modos de se realizar 
os processos de ensino/aprendizagem. Ao longo do processo, a sua inclusão é, ao mesmo tempo, uma transformação recíproca que enriquece o processo pedagógico ao promover a reflexividade sobre os modos de ensino/aprendizagem.

Tendo em vista que é através da interação que alguns dos processos fundamentais de aprendizagem se dão, devemos notar que esta aprendizagem se refere ao processo que os responsáveis pela produção dos materiais têm que passar para poderem construir as tecnologias didáticas inclusivas. Para superar tais dificuldades, foi possível demonstrar a importância do intermediador na resolução de problemáticas ligadas à diversidade cultural e, ainda, evidenciar os efeitos não-esperados de uma política voltada para a inclusão.

Percebe-se, ao fim do processo de elaboração das aulas sinalizadas, que vários dos impactos provocados pela política pública de acessibilidade e inclusão não se restringem à população alvo: são os "normais" de Goffman que passam por um processo de ressituação no mundo e de aprendizagem cidadã. A execução das atividades tendo em vista a política mais ampla de inclusão provoca, assim, um efeito não-intencional-porém-desejado das ações promovidas em seu nome: o de multiplicar as pessoas aptas a promoverem processos de inclusão social. É isso que provê uma maior capacidade de identificar os nós centrais e problemáticos das políticas de inclusão social e, por conseguinte, de propor soluções viáveis para que um processo de transformação social inclusiva, via prática pedagógica, se dê.

É possível ver que a problematização da situação de interação normal-estigmatizado provocada pelos projetos foi elaborada a partir de um processo reflexivo comandado por um informado (aquele que sabe Libras e que de maneira correlata tem acesso à cultura Surda) via um trabalho coletivo que envolveu a apresentação dos modos de comportamento da comunidade Surda e a organização da memória deste processo de interação - via relatórios e outras produções textuais - com vistas a viabilizar e desenvolver a produção do material didático acessível. Pode-se nelas perceber: (1) a importância de um "informado" para criar as pontes com a comunidade de Surdos e viabilizar o acesso às informações e conhecimentos necessários para a criação do material; (2) a transformação destas pessoas no processo de tomada de consciência de uma diferença que deixa, paulatinamente, de ser estigmatizada e passa a ser normatizável, aproximando-os da posição de "informado".

O processo de elaboração de aulas sinalizadas demonstrou que, embora ocorressem várias dificuldades ligadas à produção de material didático inclusivo, foi possível gerar momentos de reflexão acerca das políticas inclusivas e da imersão delas na rea- 
lidade educacional. Esses entraves provocam novos olhares no sentido de reescrever as trajetórias e de apontar ações passíveis de incluir. Tais desdobramentos serão contextualizados como meio de análise que repercutem nos saberes, nas rotinas, nas experiências e nos efeitos que constituem as políticas de inclusão no Brasil e que adentram o ensino superior.

E, adicionalmente, é possível defender o argumento que as políticas públicas de inclusão ensinem mais àqueles que aparentemente se posicionam no ponto "estabelecido" da normalidade social ao perceberem que há muito a ser aprendido sobre si próprio daqueles que, habitualmente, estão na posição subalterna de nossa sociedade.

Recebido: $14 / 02 / 2019$

Aprovado: 10/04/2019

Ana Luisa Borba Gediel é antropóloga e professora do Departamento de Letras da Universidade Federal deViçosa. Atua na área de Língua Brasileira de Sinais - LIBRAS e é vinculada ao programa de pós-graduação em Letras, na linha de pesquisa Linguística Aplicada: Formação de Professores e Ensino e Aprendizagem de Línguas. Também é professora do Mestrado interinstitucional em Antropologia Social realizado em parceria entre o PPGAS/Museu Nacional/UFRJ e o DCS/UFV. Número de ORCID: 0000-0001-5755-2592.Contato: ana.gedielufv@gmail.com

Victor Luiz Alves Mourão é professor Adjunto do Departamento de Ciências Sociais da Universidade Federal de Viçosa, é doutor em sociologia pelo Programa de Pós-graduação em Sociologia no Instituto de Estudos Sociais e Políticos (IESP-UERJ). Graduado em Ciências Sociais pela UFMG, é mestre em sociologia pelo antigo IUPERJ, realizando estudos na área de estudos sociais da ciência e tecnologia, teoria sociológica, desenvolvimento e inovação. Número de ORCID: 0000-00032770-721X. Contato: vmourao@ufv.br 
Isabela Martins Miranda é graduada em Secretariado Executivo Trilíngue pela Universidade Federal de Viçosa. Atua nos campos de pesquisa voltados para produção de tecnologias da informação e comunicação (TICs) a fim de atender a comunidade surda. Número de ORCID: 0000-0003-1401-0528. Contato: isabelamartinsmiranda@gmail.com

\section{Notas}

1. O projeto de pesquisa foi submetido ao Comitê de Ética em Pesquisa, sendo aprovado pelo mesmo. CAEE: 81077517.6.0000.5153.

2. Classificadores são constituintes do léxico nativo da Libras, em que as configurações de mãos e a orientação de mão são elementos importantes para exercer uma função descritiva, auxiliando na qualificação e significação do que está sendo expresso.

3. Descrevemos no corpo do texto a palavra surdo(s), seguindo a descrição específica utilizada por Assis (2011), referente às categorias deficiente e surdo.

\section{Referências Bibliográficas}

ASSIS SILVA, César A. 2011. Entre a deficiência e cultura: análise etnográfica de atividades missionárias com surdos. Tese [Doutorado em Antropologia Social]. São Paulo: FFLCH/USP.

BARNES, John. A. 1987. Redes sociais e processo político. In: FELDMAN-BIANCO, Bela et al. (ed.). Antropologia das sociedades contemporâneas. São Paulo: Global. p. 159-193.

BRITO, Fábio B. de. 2016. O movimento surdo no Brasil: a busca por direitos. Journal of Research in Special Educational Needs, v. 16, n. s1, p. 766-769.

CALLON, Michel. 1995. Technological Conception and Adoption Network: Lessons for the CTA Practitioner. In: RIP, Arie; MISA, Thomas J. et al. Managing Technology in Society. London, New York: Pinter. p. 307-330.

CARNIEL, Fagner. 2013. A invenção (pedagógica) da surdez: sobre a gestão estatal da educação especial na primeira década do século XXI. Tese [Doutorado em Sociologia Política]. Florianópolis: Universidade Federal de Santa Catarina, Centro de Filosofia e Ciências Humanas.

CARDOSO DE OLIVEIRA, Roberto. 1996. O trabalho do antropólogo: olhar, ouvir, escrever. Revista de Antropologia (USP), v. 39, n. 1, p. 13-37.

Da SILVA, Marilda. 2009. Complexidade da formação de professores: saberes teóricos e saberes práticos. São Paulo: Editora UNESP.

DEDECCA, Claudio S. 2014. A queda da desigualdade de renda corrente e a participação do $1 \%$ de domicílios de maior renda, 2000-2001. Revista de Economia Política, v. 34, n. 2, p. 249-265.

FERREIRA-BRITO, Lucinda. 1995. Por uma gramática de línguas de sinais. Rio de Janeiro: Tempo Brasileiro.

FONSECA, Claudia.; JARDIM, Denise.; SCHUCH, Patrice \& MACHADO, Helena. 2016. Apresentação. Horizontes Antropológicos, v. 22, n. 46, p. 9-34. 
FOUCAULT, Michael. 2001. Os anormais. São Paulo: Martins Fontes.

FRASER, Nancy. 2006. Da redistribuição ao reconhecimento? Dilemas da justiça numa era "pós-socialista". Cadernos de Campo, n. 14/15, p. 31-239.

FRASER, Nancy; HONNETH, Axel. 2003. Redistribution or recognition? A political-philosophical exchange. New York: Verso.

GESSER, Audrei. 2009. LIBRAS? Que língua é essa? Crenças e preconceitos em torno da língua de sinais $e$ da realidade surda. São Paulo: Parábola.

GIDDENS, Anthony. 2007. A constituição da sociedade. São Paulo: Martins Fontes.

GLAT, Rosana; PLETSH, Márcia D. 2010. O papel da Universidade no contexto da política de Educação Inclusiva: reflexões sobre a formação de recursos humanos e a produção de conhecimento. Revista Educação Especial, Santa Maria, v. 23, n. 38, p. 345 -356.

GOFFMAN, Erving. 2012. Estigma: notas sobre a manipulação da identidade deteriorada. 4. ed. Rio de Janeiro: LTC.

IMBERNÓN, Francisco. 2010. Formação docente e profissional: formar-se para a mudança e a incerteza. 7. ed. São Paulo: Cortez.

LATOUR, Bruno. 2000. Ciência em Ação. Como seguir cientistas e engenheiros sociedade afora. São Paulo: Editora Unesp.

PADDEN, Carol; HUMPHRIES, Tom. 2006. Inside Deaf Culture. Cambridge, Massachusetts: Harvard University Press.

QUADROS, Ronice M. \& KARNOPP, Lodenir. 2004. Língua de Sinais brasileira: estudos linguísticos. Porto Alegre: Artmed.

SANTOS, Emmanuelle F. 2015. Tecendo leituras nas pesquisas sobre Libras: sentidos atribuídos ao seu ensino na educação superior. In: ALMEIDA, Wolney G. (ed.). Educação de surdos: formação, estratégias e prática docente [online]. Ilhéus, BA: Editus, p. 67-91.

SIMMEL, Georg. 1983a. A natureza sociológica do conflito. In: MORAES FILHO, Evaristo (ed.). Georg Simmel: sociologia. São Paulo: Ática. p. 122-134.

1983b. Como as formas sociais se mantêm. In: MORAES FILHO, Evaristo (ed.). Georg Simmel: sociologia. São Paulo: Ática. p. 46-58.

. 1983c. Conflito e estrutura de grupo. In: MORAES FILHO, Evaristo (ed.). Georg Simmel: sociologia. São Paulo: Ática. p. 150-164.

SOUZA, André. L. S. D.; JÚNIOR, José T. 2016. O uso de tecnologias (TIC) na produção de material didático bilíngue libras/português na Universidade Federal de Viçosa. Revista Fórum (INES), n. 33, p. 92-109.

TRIVIÑOS, Augusto N. S. 1987. Introdução à pesquisa em ciências sociais: a pesquisa qualitativa em educação. São Paulo: Atlas. 
A inclusão e suas práticas: aspectos socioantropológicos da produção de materiais pedagógicos inclusivos para Surdos

Resumo: O cenário da expansão de políticas públicas que ocorreu nas últimas décadas pressionou por um conjunto de novos arranjos nas instituições educativas tendo em vista a inclusão de pessoas com deficiência. $\mathrm{O}$ presente artigo tem o objetivo de descrever o trabalho de elaboração de materiais didáticos para a inclusão de uma pessoa Surda em uma instituição de ensino superior. Nos interessa refletir acerca da reflexividade e dos conflitos envolvendo os pontos de vista dos profissionais de diferentes áreas de especialidade que atuam na Unidade de Ensino à Distância para o processo de elaboração dos materiais e as ações institucionais que conformam essa conjuntura. Acessamos os agentes envolvidos a partir da metodologia de redes e pontuamos os principais elementos norteadores e transformadores do processo. Entendemos que as políticas públicas são de extrema importância para gerar oportunidades de mudança e observamos a complexidade na delimitação e efetivação de ações para atender à diversidade socialmente existente, e que as transformações que suscitam ultrapassam o âmbito dos seus destinatários explícitos.

Palavras-chave: políticas públicas, ensino superior, inclusão social, pessoas Surdas.
Inclusion and its practices: socio-anthropological aspects of the production of Deaf-inclusive pedagogical materials

Abstract: The trajectory of Brazilian public policies in the last decades promoted new arrangements in educational institutions which had at its objectives the effective inclusion of people with disabilities. This article aims to describe the experience of developing didactic materials for the inclusion of a Deaf person in a higher education institution. We are interested in reflecting on the reflexivity and conflicts involving distinct points of view of the professionals from different areas of knowledge surrounding the process of elaboration of those materials and the institutional actions that conformed this conjecture. We accessed the agents involved through the methodology of networks and we point out the main guiding and transforming elements of this process. We understand that public policies are extremely important in order to generate opportunities for social change and we observe the complexity in delimiting and implementing actions to meet current social heterogeneity, and that the transformations which it provoked went beyond their explicit destinataries.

Keywords: public policy, higher education, social inclusion, Deaf people. 


\title{
A “janela da expressão": reflexões sobre corpo, movimento e gesto nas relações entre visão e cegueira
}

\author{
Olivia von der Weid \\ Universidade Federal Fluminense - Brasil
}

Eu acho que tem uma coisa que é muito maior para nós, cegos, nesse trabalho... o mundo é um lugar onde você está sendo visto. Na verdade, o mundo é um grande teatro né? (...) nessas últimas experiências eu fui ficando menos ingênua e me dando conta.

E isso me marcou.

Não é a forma de entender, porque não é uma mudança intelectual. Muda a forma de estar no mundo. Abriu a janela da expressão.

(Dora)

A primeira vez em que estive com Dora para uma conversa mais prolongada em sua casa provocou sensações de estranhamento que talvez possam ser associadas àqueles momentos da pesquisa de explosão de significados, em que cada fato observado na cultura nativa tem significado para o pesquisador (Malinowski, 1986). Enquanto conversávamos, ia me dando conta, de uma forma até então inédita para mim, do meu próprio corpo no ato de conversar. Gesticulo enquanto conto uma história ou revelo algo do meu pensamento. Como se tais movimentos ajudassem a expressar o que digo, mesmo que naquela conversa também parecessem inúteis. Percebo a necessidade de completar todas as frases, as insinuações gestuais de nada servem. Assim como não comunicam expressões como "lá", "ali", "ele”, ou o ato de apontar ou demonstrar fisicamente alguma coisa.

Dirijo o olhar para os olhos dela, ainda que sejam olhos com movimento, mas sem retorno. Presto atenção na entonação da voz, como se despendesse um esforço maior em expressar sonoramente as mudanças de estado na conversa. A própria fala surge com uma urgência, uma ascendência maior nesse encontro e os silêncios vibram mais enigmáticos quando não se tem a cumplicidade do olhar. O corpo inteiro precisa ser através do que digo, expressar o que sinto ou penso pela impos- 
tação e variação da voz. Uma aparente invisibilidade promove o sobressalto tanto da fala quanto da própria expressividade corporal, como se a ausência do seu olhar voltasse o foco a mim mesma.

A interação e o convívio com olhos que não veem me colocam em contato com a própria corporalidade, densidade carnal em ação no ato de comunicar. A ausência de seu olhar derrama luz sobre meus gestos, a fala, a postura, o fluxo dos movimentos, a direção de meus olhos. O corpo, para Merleau-Ponty (1971), é um "sensível exemplar” porque sensível para si - se sente ao sentir que sente. O invisível dos olhos de Dora torna visível a mim, ao corpo de alguém que percebe a si mesma, vendo.

O estranhamento posteriormente suscitou reflexões sobre o destaque que se dá à linguagem verbal e à funcionalidade corporal na educação e/ou reabilitação de pessoas cegas, e uma espécie de lacuna que senti naquela conversa. É claro que pude me fazer entender e compreendia suas colocações, a lacuna não estava no que era dito, mas nos gestos. Não podiam se transformar em recursos visuais explícitos de comunicação, mesmo que implicitamente pudessem e fossem utilizados como uma espécie de auxílio, um adicional de ênfase na fala, ajudando a fazer variar a tonalidade e a cadência do que era dito.

Neste artigo proponho considerar os meios não discursivos que medeiam a relação entre expressividade e comunicação entre pessoas cegas e não cegas. Quais as implicações advindas de uma interação que se baseia na dupla condição de ver e não ser visto/não ver e ser visto? Qual o papel dos movimentos e dos gestos nessa experiência comunicativa? Falar em gesto é uma tentativa de trazer para a reflexão não apenas o aspecto prático ou funcional da ação, mas também suas dimensões corporais e afetivas, sua poética e plasticidade (Silva, 2016).

A percepção de mundo de pessoas cegas se constrói nas brechas de uma dupla fronteira: uma limitação física e um impedimento social. Com a ausência da visão, os outros sentidos e o corpo inteiro se colocam como mecanismos de apreensão do mundo, do espaço e das pessoas, mas na vida cotidiana, o conhecimento pelo tato esbarra na restrição social ao toque entre pessoas (Le Breton, 2011). A reflexão desenvolvida se localiza na fronteira entre um conhecimento tátil do mundo por um corpo privado da visão e as barreiras sociais para o conhecimento corporal do outro através do tato.

A restrição social ao toque traz implicações para a apreensão, por pessoas cegas, de uma linguagem corporal comunicativa presente nos gestos, seja como forma 
de conhecimento da cultura, seja como recurso expressivo nas relações de interação. Abordo as consequências desse hiato a partir das possibilidades criativas que se abrem para o resgate e a construção desta linguagem corporal por intermédio da arte, a partir da participação, como parte do trabalho de campo, em oficinas de teatro com pessoas cegas e não cegas ${ }^{1}$. O engajamento nessas experiências colocou desafios importantes e levantou questões sobre as potencialidades dos dispositivos propositivos de pesquisa para a investigação antropológica que desenvolvi em outro lugar (von der Weid, 2017). A análise aqui elaborada se volta especialmente para a interlocução desenvolvida com Dora ${ }^{2}$, a partir dos questionamentos suscitados por suas vivências anteriores em oficinas teatrais e pelas experiências que partilhamos na Oficina Inclusiva.

Como sugeriu Hammer (2013), realizar uma etnografia da cegueira levanta complexidades específicas resultantes das relações desequilibradas de poder em torno do olhar do pesquisador. A pesquisa exige que se desenvolva uma sensibilidade sensorial alternativa capaz de desafiar a associação comum do conhecimento com a visão e o olhar. Um segundo aspecto decorrente da relação entre visão e cegueira a partir de uma etnografia em que a pesquisadora enxerga e os pesquisados não, é o efeito de intensificação da consciência para certas propriedades das interações sociais que normalmente poderiam passar despercebidas. Neste artigo enfatizo, sobretudo, a dimensão da corporalidade na comunicação, com especial atenção ao movimento, aos gestos e à expressividade.

\section{Silêncios e ruídos: suspensões da comunicação}

Trato inicialmente as interações entre pessoas cegas e pessoas que enxergam como "ocasiões situadas", pensando-as a partir da abordagem interacionista de Goffman $(1966,2011)$. Encontros onde existe a copresença de outros e em que grande parte das informações veiculadas depende não só daquilo que é falado, mas da atividade corporal dos agentes. O autor destaca o papel organizador do olhar na vida social comunicativa, o que ajuda a entender o estranhamento inicial na conversa com Dora em sua casa. Em encontro posterior, ela reconhece que uma das possíveis dificuldades das pessoas que enxergam na relação com a cegueira está vinculada à falta da visualidade na conversa:

Às vezes as pessoas têm dificuldade de lidar com uma pessoa cega pela dificuldade de comunicação. Porque como não rola o olho no olho, as pessoas ficam meio 
perdidas e elas não conseguem ver se elas estão sendo ouvidas, se elas estão sendo entendidas... sabe, eu acho que rola essa agonia nas pessoas, essa dificuldade assim em um primeiro momento.

Goffman (2011) identifica que, nas interações faladas, um sistema de práticas, convenções e regras de procedimentos entra em jogo, funcionando como um meio para orientar e organizar a troca de mensagens. Os receptores, através de gestos apropriados, comunicam ao orador que estão dando a ele a sua atenção. A visualidade organiza o fluxo da fala em uma interação. A função organizadora do olhar é também destacada por Le Breton (2009), quando diz que os olhos, ao receberem e simultaneamente transmitirem informações, concorrem para o desenrolar de uma conversa. O próprio contato ocular dá aos indivíduos o sentimento de estar em interação. Em uma "ocasião social” em que um indivíduo se apresenta diante de outros, o silêncio pode parecer enigmático para uma pessoa cega.

Eu me lembro de um treinamento que fui dar para um pessoal em Florianópolis. Eu comecei a falar e um silêncio absoluto (na plateia). E eu falava e aquele silêncio absoluto. Aquilo foi me dando uma agonia, porque eu ficava pensando "meu Deus, será que esse povo está dormindo? Tão bocejando? Tão achando esse negócio muito chato? Tô chovendo no molhado, eles já sabem isso? Ou eu estou falando muito difícil e eles não estão entendendo? O que está acontecendo?”A té que alguém falou assim “olha, quando quiser fazer o coffee break...”, eu digo, “opa, então pessoal, vamos dar um pequeno intervalo para a gente tomar um café e depois continuamos". Aí cheguei pros meus colegas e disse "gente, o quê que é isso? Por que esse silêncio? Esse povo está dormindo?" e aí as pessoas disseram para mim “não, eles estão anotando. Tudo o que você está falando eles estão anotando no verso da apostila que você deu. Eles estão ouvindo tudo, prestando atenção e anotando”. Eles estavam alucinados, copiando tudo e eu achando que o povo estava dormindo, tava entediado... Por quê? Aqui no Rio as pessoas até podiam estar copiando, mas o carioca copia e fala. Não é? O pessoal do Sul é menos falante, mais quieto, é mais disciplinado. Então eu estava sentindo dois choques, tinha o choque de eu não estar vendo e tinha o choque cultural, de não estar com o povo da minha cidade. O treinamento aqui no Rio eu tinha que pedir silêncio de $5 \mathrm{em} 5$ minutos e lá eu tinha que pedir "falem, por favor", tinha que pedir retorno (Dora).

No universo perceptivo da cegueira, as pessoas entram ou saem da invisibilidade por seu silêncio ou sua sonoridade. Essa é uma das características que Hull (1997) atribui ao espaço acústico, de natureza efêmera, cujos habitantes transitam dentro e 
fora da existência pelos ruídos que emitem. No caso trazido por Dora, não é apenas o silêncio em si que perturba o fluxo da interação, mas o contexto cultural também influencia na sua percepção da cena. Por não estar em sua cidade, onde consegue perceber os sinais pelo comportamento rumoroso das pessoas, Dora teve maior dificuldade em se orientar pela conduta da plateia e codificar o seu silêncio.

Le Breton (2009) fala da comunicação em ambientes rumorosos, em que a qualidade da conversa pode ser mantida pela focalização visual. Quando é assim, muitas pessoas conversando, Dora acha mais difícil acompanhar:

Numa situação que está só você e uma pessoa é mais fácil, não interessa o primeiro contato, você está mais no controle. Agora numa situação que são várias pessoas é meio complicado você ter certeza que a pessoa te ouviu, porque tem outras pessoas falando ao mesmo tempo. Você ter certeza que a pessoa te ouviu e você ter certeza que o outro está falando é com você mesmo ou se é com o outro que está do seu lado. (...) Eu sinto que tem uma questão do contato visual que facilita a comunicação. Se eu estou olhando para você, se eu posso ver o seu rosto, se eu posso ver principalmente os seus olhos eu estou sabendo se você está prestando atenção no que eu estou falando. Ou se eu não estou falando com você, eu estou sabendo se eu posso falar agora, se você vai prestar atenção no que eu vou falar. E quando você não tem isso fica complicado. A pessoa que não enxerga não sabe se pode falar e a pessoa que enxerga não sabe se o cego está falando com ele, ou com quem que o cego está falando. Então fica um ruído de comunicação.

Le Breton (2009) destaca que o olhar orienta a troca de enunciados em uma conversação, funcionando como apoio para os atores, que buscam o assentimento do olhar alheio para suas reflexões ou investigam o momento propício de entrar em uma conversa ou de tomar a palavra. Nessas situações, Dora se sente em desvantagem por não poder usufruir de tal código. É comum acontecer em ambientes com mais gente, com conversas paralelas. Mas também pode acontecer em um encontro face a face quando a outra pessoa, temporariamente, esquece que ela é cega e por isso esquece de avisá-la, por exemplo, que vai atender ao telefone celular:

Eu digo: - “o quê, fulano? O que você está perguntando? Eu vou onde?”. E fulano está falando no telefone, mas eu não percebi que o telefone tocou, estava no vribracall, entendeu? Ou então eu não tava nem perto, não estou nem prestando atenção, mas a pessoa começou a falar e aí eu comecei a achar que era comigo. 
Para Mitchell (2010), o gesto tem a função comunicativa de enquadrar a ação e organizá-la em termos de importância. Ele também pode interromper o discurso e pode interromper as próprias ações, precisamente para reordenar a relação entre palavras e feitos, palavras e coisas. No caso mencionado, o gesto de atender o celular e com isso, sinalizar a interrupção de uma conversa. Nós não apenas fazemos coisas com as mãos ou com a face, mas dizemos coisas com elas. Coisas que nem sempre confirmam o que estamos dizendo verbalmente com as palavras. Silva (2016) identifica aí o potencial ambivalente do gesto, capaz de suspender o movimento, que se desenvolve sobre movimentos, expressando aquilo que importa em uma ação. $\mathrm{O}$ gesto faz e diz, mas às vezes diz justamente ao não fazer, ao interromper ou suspender um movimento.

A reflexão nos coloca diante de situações que envolvem a cegueira, as expectativas sociais de conduta e as possíveis técnicas e estratégias desenvolvidas por pessoas cegas e seu "coletivo" (manuais de desenvolvimento e educação de crianças cegas, profissionais dos programas de reabilitação, materiais utilizados nesses ambientes, etc.) para cumprir as convenções sociais em uma interação de tipo pública.

\section{Gestos sociais e estratégias corporais na interação}

O conjunto particular de regras que transformam um indivíduo em um membro da sociedade deriva de requerimentos estabelecidos na organização ritual dos encontros sociais (Goffman, 2011). Em ocasiões desse tipo, qualquer pessoa manifestará a preocupação de adotar uma conduta socialmente aceitável. Como vimos, a falta da visão pode interferir no ajustamento da conduta de pessoas cegas já que, ao se guiarem pela audição, as situações muitas vezes enganam e a comunicação fica suspensa.

Uma regra de conduta é definida por Goffman como um guia para a ação, recomendada não por ser agradável ou eficiente, mas por ser considerada apropriada. A ligação a regras leva à constância e padronização dos comportamentos e é uma fonte de regularidade nas atividades humanas. As infrações podem levar a sentimentos de desconforto e a sanções sociais negativas. Na pesquisa, alguns entrevistados demonstraram preocupação especial em cumprir certas regras ou posturas de conduta nas interações, desenvolvendo técnicas não visuais para se adequarem a elas ou demarcando a sua diferença em relação a uma condição visual.

Depois que ficou cega, Camila diz que não queria que mudasse a postura de olhar na direção da pessoa com quem está conversando, mesmo que não possa enxergá- 
-la. Aprendeu como fazer perguntando para outras pessoas cegas, que lhe disseram: "quando a pessoa estiver falando com você, você percebe a voz e olha na direção da pessoa, se você erguer a sua cabeça você vai olhar na direção da boca certinho, do queixo, começa a fazer isso que dá certo”. Ela deseja manter a postura por saber que socialmente é isso que se espera de uma pessoa. Preocupação semelhante aparece quando Beatriz assiste à televisão. Às vezes está assistindo à novela e, de repente, repara que sua cabeça está voltada para o corredor. Ela corrige e se volta para a televisão; pelo som percebe se está mais para cima ou mais para baixo. Também desenvolveu um exercício para comandar o olhar durante uma conversa, não deixar "solto", e acha que isso ajuda na aparência, impacta menos na interação. As estratégias desenvolvidas por Beatriz e Camila para controlar seus gestos e ajustar suas posturas têm por objetivo não apenas adequar sua conduta a uma expectativa social, mas diminuir o impacto da diferença da cegueira na relação com quem enxerga.

Le Breton (2009) diz que toda interação começa e encerra com uma série ritual de gestos e de palavras que colocam os atores em posição favorável para iniciar ou concluir uma troca. Começar um assunto demanda certas formas de saudação que são social e culturalmente variáveis. É o que o autor chama de "etiquetas corporais de integração". Um dos sinais indicativos da falta de visão, para Camila, foi quando as pessoas estendiam a mão para cumprimentá-la e ela não conseguia mais enxergar para estender a sua de volta. Depois aprendeu que entre pessoas cegas existe uma técnica, ou uma estratégia pensada para remediar o desconforto social gerado pela infração a uma regra de etiqueta, que é ensinada na reabilitação ou passada por outra pessoa cega: a de estender a mão primeiro para que a outra pessoa a pegue.

Embora sejam olhos que não veem, nos depoimentos fica marcada uma preocupação com o direcionamento do olhar que, como indica Goffman (1966), é uma importante ferramenta na interação focada nas situações sociais. As posturas, a correção do corpo, as alternativas desenvolvidas para o aperto de mão e para sustentar o olhar na direção da pessoa em uma conversa, ainda que não a estejam vendo, são estratégias de manipulação de sinais desenvolvidas por pessoas cegas para manter a fachada em uma interação face a face. Dora fala sobre essa preocupação de estar ou não voltada para o lugar "certo" quando conversa com uma pessoa, e do quanto demorou a perceber que essa era uma convenção social que ela, por ser cega, não cumpria, já que não encontrava utilidade para a postura na sua comunicação com as outras pessoas. 
Eu custei a perceber, porque eu acho que foi um erro das pessoas da minha família não me terem chamado a atenção disso. Acho que também não chamaram a atenção porque se acostumaram, né? Porque é o seguinte, cego começa a falar, e aí eu levanto para pegar água e continuo falando lá da cozinha, eu sei que se você pode me escutar, você está escutando o que eu estou falando. Mas as pessoas que veem, elas normalmente não fazem isso, elas falam e tem ao mesmo tempo um contato visual. Elas têm aquela ponte. E o cego não tem isso, ele fala de qualquer maneira, fala em qualquer postura, ele está fazendo alguma coisa e está falando, ele não está olhando para você, não está nem virado para você e está falando. Ele está prestando atenção em você, mas não está necessariamente olhando pra você, direcionado pra você como se fosse... visualmente, né? Porque a pessoa que vê ela entende direcionado como direcionado visualmente, mas ele pode estar direcionado auditivamente, ele pode estar virado de costas, mas ele pode estar direcionado, a atenção dele está toda em você. Só que ele não precisa estar virado, não vai adiantar nada se ele tiver virado para você, entende? Eu só descobri isso depois de velha, que eu fazia uma coisa que não era o normal que as pessoas faziam. Aí as pessoas podem não entender que eu posso não estar olhando para você, mas que eu estou prestando atenção em você.

Destaca-se no depoimento a diferença entre os estados de atenção auditivo ou visual em uma conversa. Prestar atenção com a audição não exige uma postura corporal pré-determinada, enquanto prestar atenção com os olhos demanda uma retidão e um direcionamento específico - face a face -, que inclusive limita a movimentação. Uma comunicação não visual demanda outros gestos e capacidades distintamente constituídas de prestar atenção nas dinâmicas sonoras e auditivas de uma conversa. Mas, como lembra Goffman (2011), as regras de conduta invadem o indivíduo, seja diretamente - uma obrigação que estabelece como ele é moralmente coagido a se conduzir -; seja indiretamente - uma expectativa que indica como os outros são moralmente forçados a agir em relação a ele.

\section{A funcionalidade do gesto}

Um ponto delicado, mas também importante de se trazer para a discussão sobre o gesto nas relações entre a visão e a cegueira é a ênfase predominantemente adaptativa ou funcional que muitas vezes recebe nos serviços especializados voltados para a reabilitação/habilitação. O enfoque principal dos programas de reabilitação, desde a sua origem, tem sido na recuperação ou desenvolvimento da independência funcional da pessoa com deficiência (Moreira, 2008). Especialmente a partir 
das discussões que deram origem à Classificação Internacional de Funcionalidade, Incapacidade e Saúde (CIF) ${ }^{3}$, o termo "funcionalidade" passa por um alargamento, abrangendo não apenas a funcionalidade física, mas incorporando as noções de atividade e participação social.

A pergunta que costuma nortear o trabalho clínico de profissionais da saúde que realizam os atendimentos é a de como sintonizar os corpos e os ambientes de modo a tornar a vida cotidiana de uma pessoa suportável, ou até mesmo prazerosa, apesar de impedimentos que, algumas vezes, podem ser seriamente perturbadores (Mol, Struhkamp \& Swierstra, 2009). O plano de reabilitação deve se basear não somente na presença de um órgão considerado lesionado, mas também levar em conta as necessidades do indivíduo, a relevância das tarefas para a sua vida cotidiana e seus objetivos. Devem ser planejadas metas individuais a partir das quais os resultados da reabilitação possam ser posteriormente medidos. O atendimento conhecido por Atividades da Vida Diária está pautado nas técnicas cotidianas do corpo, remetendo a certos costumes que também podem ser relacionados ao corpo civilizatório descrito por Elias (1994) - hábitos de higiene, vestimentas, modo de se alimentar, regras de etiqueta. A estimulação precoce, por sua vez, por estar voltada para crianças de 0 a 3 anos, traz uma forte preocupação com o desenvolvimento psicomotor. Dora coloca suas impressões sobre esses atendimentos:

As pessoas pensam no funcional, que aquela pessoa não pode ficar com um déficit motor, na marcha, na mobilidade. Não pode atrofiar. O que está muito certo, que não pode mesmo. Só que eu acho isso pouco. Você fala de estimulação. Primeiro questiono o precoce, por que precoce? É estimulação adequada, não é precoce. Segundo que você centrar só no funcional? Cada vez mais eu me dou conta do quanto de informação que eu não tenho e do quanto de feedback que eu não tenho por ser cega. E o fato de eu não ter esse feedback, nem dos outros, de não saber como é a expressão dos outros, nem a minha, faz com que eu também não tenha o controle dos meus músculos faciais, faz com que eu não tenha essa consciência e esse controle. Fora todas as informações posturais, das outras pessoas, eu não tenho essa informação. O que acontece com a estimulação precoce? Procura se desenvolver movimentos para a criança poder ter autonomia, poder se locomover bem, poder se desenvolver legal. Como questão motora, como função. Beleza. Agora, e o corpo como expressão? Acho que as pessoas não têm essa noção. Eu acho que a estimulação precoce tinha que incluir isso. Expressão corporal, expressão facial e essa comunicação de informação gestual. Para mim são três coisas. São três coisas que a gente fica fora, literalmente fora. 
Foi também o caráter social e eficaz da técnica que Mauss (2003) ressaltou quando fez um inventário das variações de movimentos corporais como a marcha, a educação do andar, as técnicas de higiene e de cuidado com o corpo. O autor considerou que não há técnica se não houver tradição, ainda que o ato seja sentido por aquele que o realiza como de ordem mecânica ou físico-química. O aprendizado das formas de se mover é mimético, fruto de um processo de adestramento somático que acaba reduzindo as técnicas corporais às normas sociais, cuja eficácia é medida pelo seu "rendimento" (Mauss, 2003: 410). A ênfase é no caráter utilitário e produtivo da ação: "as pessoas que têm o senso da adaptação de seus movimentos bem coordenados a objetivos, que têm hábitos, que 'sabem como fazer'. É a noção inglesa de craft, de clever (destreza, presença de espírito e hábito), é a habilidade em alguma coisa" (Mauss, 2003: 411).

Se, por um lado, a ênfase na funcionalidade da (re)habilitação traz a preocupação da autonomia, independência e da inclusão de corpos considerados diferentes na sociedade, por outro, não questiona as próprias bases e padrões sociais pelos quais a sociedade se constrói, voltada para um corpo único, normativo. O funcionamento do corpo deficiente e o grau de participação social da pessoa com deficiência ainda é medido em função de sua maior ou menor adaptação a regras e padrões sociais de interação que se constroem a partir do funcionamento de outro corpo, aquele considerado “capaz" ou "normal”. O ponto está também explicitado no item anterior, na preocupação com o desenvolvimento de estratégias corporais de adaptação de pessoas cegas às convenções sociais de interação.

O foco na funcionalidade pode acabar se mostrando uma tentativa de inclusão por meio de uma manobra excludente, por estar ainda pautada pela estratégia da normalização. Como lembra Reynold (2017), o corpo deficiente foi sempre considerado uma variação corporal do corpo normativo. Esse último, a figura ideal ou exemplar do capacitismo: forma de vida constituída por e assegurada pela sua participação na normalidade. O termo normativo (normate), conforme definido por Garland-Thomson (1997), designa a figura social por meio da qual as pessoas costumam se representar como seres humanos definidos. É essa figura socialmente constituída que definirá os padrões de funcionalidade em relação aos quais a deficiência será constituída como incapacidade, assegurando com isso as fronteiras da normalidade.

Moser (2000) identifica uma ambivalência que acredita ser uma consequência lógica, um efeito esperado quando políticas, inciativas e práticas de cuidado se norteiam pela normalização: o desejo de ajudar pessoas com deficiência e efetivamente 
melhorar suas vidas, por um lado, e o fato de que as diferenças são definidas como faltas ou desvios que devem ser compensados ou corrigidos, por outro. Tal como utilizada aqui, a noção de técnica ou de funcionalidade inspira um caráter utilitário para a ação. Ao final do programa teremos organismos que foram diferentemente “disciplinados" (Foucault, 2013), mas que estarão mais ou menos aptos a se (re)inserirem numa sociedade que, por sua vez, permanece intacta, ordenada pela mesma lógica produtiva, "normal”, capacitista e visuocêntrica.

A ênfase na funcionalidade imprime uma direção prática para os atendimentos, em detrimento das variações, das transformações, dos infinitos e criativos modos de se realizar um gesto ou um movimento. São ações voltadas para atingir determinado "fim" - seja o desenvolvimento sensório-motor, seja o desempenho de tarefas rotineiras, seja a aprendizagem de convenções sociais. A proposta que se descortina não é substituir a ênfase na funcionalidade e no desenvolvimento motor das ações educativas voltadas para pessoas cegas por outra ênfase supostamente mais "adequada", e sim adicionar novas vias que escapem aos processos de adestramento do corpo deficiente, instaurando proposições que o abram à experimentação e ao universo intensivo.

\section{“A palavra vence a cegueira?” Gesto, cultura e linguagem}

Os atores de Goffman (1966) parecem estar imersos em uma sucessão constante de cálculo, preparação e estratégias desenvolvidas para controlar suas condutas, ajustar suas máscaras, manter sua face diante de um outro genérico neste palco que é a vida social. A copresença física dos indivíduos no espaço público sob o prisma goffmaniano da "situação" envolve a ocorrência de, ao menos, três mecanismos normativos (Frehse, 2009): o manejo das impressões do self - a imagem que o indivíduo tem de si a partir da imagem que outros têm dele; a adoção de uma sequência densamente simbólica de gestos e posturas, de cunho ritual; a transmissão corporal de mensagens sobre os sentidos das interações através do chamado "idioma corporal". Como Dora coloca no depoimento anterior, o foco na funcionalidade e no desenvolvimento motor, se por um lado privilegia a independência e a autonomia, por outro aparta as pessoas cegas de um importante componente da cultura, atualizado na gestualidade comunicativa dos corpos. A comunicação pode ser entendida não como um ato individual, mas como instituição social, como performance da cultura (Winkin, 1998). Dora fala sobre a sua descoberta do papel dos gestos na interação: 
Eu minimizava isso, eu subestimava, a questão dos gestos e a questão da minha própria expressão facial. Porque é como se eu me achasse menos... menos diferente. Eu achasse que isso fosse menos relevante. E de repente eu saquei a relevância disso, tanto a relevância dos gestos que eu não estou vendo, a relevância de gestos que eu não estou fazendo. A relevância das caras que eu não estou vendo e como eu não estou vendo também não sei fazer. É como se eu achasse que isso fosse muito mais irrelevante para a minha relação com as pessoas, mas não é.

Birdwhistell (1990) se dedicou a compreender os movimentos do corpo durante as interações como uma forma de linguagem. No processo de nos tornarmos humanos, um sistema de comunicação é internalizado. Ganhar controle da linguagem, entretanto, não é a simples acumulação de um agregado de palavras ou um determinado tamanho de vocabulário. Envolve a corporificação de um complexo sistema de movimentos, comportamentos e gestos que também constituem formas comunicacionais. $\mathrm{Na}$ análise cinésica, as gestualidades, as mímicas ou as movimentações não são isoláveis do sistema global de comunicação, que também inclui a língua, os silêncios ou a tonalidade da voz. O espanto de Dora com a abrangência da gestualidade é significativo. Assim como não existem palavras universais, nenhum som complexo que carregue o mesmo significado mundo afora, não existem movimentos corporais, expressões faciais ou gestos que provoquem respostas idênticas. A comunicação corporal é moldada pela cultura.

A ênfase maior no corpo funcional começa na educação de cegos em torno de uma idade específica, 6 anos. Não é arbitrária a coincidência dessa faixa etária com o desenvolvimento da linguagem verbal. Se a posse do verbo foi sempre considerada a manifestação de uma espécie de prova de plena pertença à humanidade, como sugere Le Breton (2009), compreende-se porque Vygotsky considerou que, apesar das limitações físicas de movimento, o cego como personalidade, como unidade social, teria perdido menos que o surdo, uma vez que, para o autor, "a palavra vence a cegueira" (Vygotsky, 1997:108). Vygotsky defende que as possibilidades compensatórias deveriam ser a força motriz do processo educativo da criança deficiente. No caso da deficiência visual, a fonte da compensação não seria “o desenvolvimento do tato ou a maior sutileza do ouvido, mas a linguagem, quer dizer, a utilização da experiência social, a comunicação com os videntes” (1997:107).

A frase sugere um direcionamento para as práticas educativas que de certa forma esterilizam a possibilidade de se considerar as diferenças perceptivas - a maior sutileza do ouvido ou o desenvolvimento do tato - como potências singulares da 
cegueira. Acaba-se priorizando aquilo que supostamente aproxima ou iguala a experiência da cegueira da experiência da visão: a comunicação centrada na linguagem. Se pensarmos nos tempos atuais, em que a Libras foi reconhecida como segunda língua oficial do Brasil ${ }^{4}$, o destaque ainda atribuído à linguagem verbal na educação de cegos como compensação social da cegueira, ou mesmo na audiodescrição como forma privilegiada de acesso à cultura para pessoas com deficiência visual, parece ter como efeito colateral mantê-las apartadas de todo um universo cultural gestual significativo.

O enfoque no canal sonoro se explica, por um lado, pelo uso que pessoas cegas fazem da audição como forma de controle do ambiente e interação com as pessoas ${ }^{5}$, mas também parece se justificar pelo aspecto facilitador da interação com videntes. Há que se questionar se, nessas práticas, a cegueira não acaba sendo normatizada tendo como critério a experiência perceptiva de mundo centrada na visualidade. A pessoa cega compreenderá o que acontece em uma cena acessando "por tabela" a experiência visual de quem enxerga, que deve ser comunicada/traduzida verbalmente para aqueles que não veem, em um processo unidirecional de transmissão de informações.

Investir no Braille, no desenvolvimento de materiais táteis ou em formas multissensoriais de acesso à cultura significa, por outro lado, reconhecer a diferença e a especificidade de um modo de estar e agir no mundo que pessoas que enxergam não dominam, a não ser por meio de um esforço necessário de interesse pelo outro em sua singularidade e de abertura para o aprendizado. Mais uma vez, a questão aqui não deveria ser de substituição, mas de ampliação. Como coloca Dora,

essa questão da estimulação vem muito de uma linha da pedagogia, fisioterapia, educação física, psicomotricidade, entendeu? E não vem da arte. Não tem arte na educação da pessoa cega. Ou tem, mas fica pobre. Quando se pensa em educação, você pensa só a questão funcional. Na verdade, não tem arte para ninguém. Mas acontece que a criança que vê ela olha nem que seja o muro grafitado, ela olha uma foto, ela olha o desenho, ela faz o desenho, ela vê novela. Eu, por não ter o feedback visual, não consigo ter o domínio total da minha máscara. Eu não consigo ter controle.

Um rosto sem máscara é um rosto sem marca, sem cicatrizes que o remetam a novas composições. Rolnik chama de marca "os estados inéditos que se produzem em nosso corpo, a partir das composições que vamos vivendo” (Rolnik, 1993:242). 
Embora todos os corpos sejam tencionados pelas forças da produtividade que nos disciplinam, corpos que enxergam encontram linhas de fuga para o desenvolvimento de outras formas de viver e se expressar no seu cotidiano ao observarem uma fotografia ou o desenho grafitado em um muro, como diz Dora. O mesmo não acontece com corpos que não enxergam, que precisam não tanto de explicação verbal, mas de mediação e estímulo ao movimento como oportunidades para desenvolver a consciência corporal e expressiva. Esse não é um corpo submetido às exigências de uma ação sensório-motora - seja da saúde, do trabalho, do esporte, das ações cotidianas ou de qualquer outro tipo de atividade -, mas um corpo que existe como movimento, destacado de todas as determinações práticas, que se abre e se modifica pelos fluxos, ritmos e vibrações que o atravessam.

\section{Arte, movimento e expressividade}

Dora sente que houve um déficit na sua formação na parte da expressão. Ao se dar conta do alcance desse déficit, foi percebendo que está ligado à anatomia do rosto, aos músculos que não aprendeu a mexer, aos movimentos que não sabe como fazer. Ao longo da pesquisa, com o privilégio da relação de amizade que desenvolvemos, pude acompanhar mais de perto o alcance da temática e as marcas dessa exclusão, que ela corajosamente busca recuperar.

Tem duas coisas para mim, duas frustrações totais que eu nunca consegui participar. Uma é aquela brincadeira de mímica - "qual o nome do filme?" - eu sou incapaz. Mímica de filme, mímica de música, isso para mim não é uma brincadeira, isso para mim é uma morte, é uma tortura. Porque eu não tenho a menor noção, eu não sei fazer nada, eu não sei como fazer. Eu já não estou nem querendo como descobrir, como descobrir eu posso até passar a mão na pessoa, sei lá. É você não ter aquele vocabulário, é você não ter aquele universo, você não falar aquela língua. Para mim é uma coisa que sempre me deu curto-circuito. "Vamos brincar de mímica?", para mim era pânico, eu entro em pânico, porque é uma coisa que dá aquele sentimento de impotência, sabe essa sensação? De você dizer assim "ai, não vai dar para mim, essa aí eu estou fora”. Mesmo sabendo racionalmente que é tudo uma brincadeira, mas é um desconforto. A outra coisa é o motivo pelo qual eu nunca fui fazer Tai Chi, porque a sessão que eu fui de Tai Chi era aquele negócio de fazer os bichos. Eu não sei fazer bicho nenhum, gente. "Faz o bicho não sei qual, faz como o bicho não sei qual, faz o tigre”. Eu não sei fazer os bichos. Eu não vejo os bichos, eu não sei. 
Embora seja também linguagem (“é você não falar aquela língua”), entender pelas palavras não é o mesmo que entender pelo movimento, a descrição meramente verbal não dá conta. Uma coisa é saber o que é um tigre na sua relação prática com o ambiente em que ele vive - do que se alimenta, qual o seu habitat, se é gregário, se migra, se é um animal de hábitos noturnos ou diurnos. Outra coisa é entender o papel simbólico do tigre a partir da forma como a cultura o significa relacionando-o a outros signos - a ferocidade, a bravura, a força. Ter acesso ao conhecimento dos dois tipos anteriores esgota tudo aquilo que um tigre é?

Qual é a importância de conhecer o movimento do tigre para a compreensão do modo de existência do tigre? Tudo aquilo que um tigre é está marcado pela forma como ele se movimenta. Tanto a sua ferocidade quanto os seus hábitos alimentares não estão desvinculados das maneiras pelas quais um tigre se move. E, se nós não podemos ser tigres para compreender isso, podemos aprender um pouco mais sobre este animal e sua experiência vital ao imitar seus movimentos - ao menos é isso que práticas ancestrais como o Tai Chi Chuan, a capoeira ou rituais indígenas xamânicos nos ensinam. Este é um tipo de aprendizado prático e afetivo, que passa pela experiência corporificada, uma forma de "compreensão encarnada" (Rabelo, 2011). Não se trata de transmitir conteúdo, mas de, por meio de uma alteração nas formas ordinárias de engajamento e uso corpóreo (Jackson, 1989), abrir novos agenciamentos e novas possibilidades para a composição de imagens de um tigre.

Rodrigues (2014), que tem uma prática educacional há mais de 30 anos no IBC, especialmente dedicada ao trabalho com crianças pequenas na Estimulação Precoce, compartilha em sua tese o que os anos de experiência profissional a permitiram observar sobre como os corpos que não enxergam costumam se movimentar:

O pouco manejo com o corpo presente em grande parte das pessoas cegas é um fato que sempre me chamou a atenção, desde que iniciei como professora do IBC. A falta de molejo se mostra por uma postura um tanto rígida, caminhar tenso e movimentos pouco flexíveis, sem as dissociações de cintura próprias da marcha e, adicionalmente, muitos apresentam dificuldade de se expressar corporalmente. (...) A tensão da musculatura que assumem parece atuar como fator de proteção à dor quando obstáculos são frequentes e inesperados no cotidiano dessas pessoas. Elas ficam mais facilmente expostas a pancada e a quedas, que poderiam ser evitadas com a visão. (Rodrigues, 2014:86)

Laban (1978) considera que o aprendizado da língua não exige somente a 
memória linguística ou a capacidade de gerar frases, mas requer a encenação da palavra. Esta, por sua vez, demanda ritmo, tonalidade da voz, movimentos do corpo, do rosto, atitude, esforço, o desempenho de determinadas posturas. O movimento, apesar de ser um processo constante de mudanças contínuas, possui padrões singulares de ordenações rítmicas. O autor desenvolveu uma espécie de partitura de movimento, semelhante à musical, em que descreve ações corporais com o objetivo de introduzir o estudante do movimento a exercícios destinados a treinar o corpo, não tanto para aprender a se comunicar, mas para se tornar um instrumento de expressão, enfatizando tanto a parte fisiológica quanto a parte psíquica que levam o ser humano a se mover.

Trabalhar a percepção do gestual e elaborar propostas que incentivem formas distintas de se movimentar, de modo a ir além de um lugar objetivado do corpo como instrumento para realização de atividades práticas / funcionais, é uma demanda evidente de pessoas cegas para o desenvolvimento de sua expressividade. Dora, ao tentar explicar como sente esta lacuna, faz uma comparação com os movimentos desempenhados por um artista em seu processo criativo:

Imagina um pianista. O pianista ele tem o controle motor dos dedos, né? Preciso. Milimétrico. A pessoa que não tem aquele treinamento, ela nem sabe como é que faz para conseguir fazer aquilo que ele faz. Não é assim? A mesma coisa o pintor, o pintor tem aquela destreza, o pincel obedece ele no milímetro, no mínimo, naquele micro... é aquela técnica, mas é um treinamento, é um adestramento muscular. É como se eu não tivesse esse adestramento muscular da face, para fazer aquelas coisas, aquelas sutilezas... é como se eu não tivesse esse adestramento, que eu acho que eu realmente não tive. Então eu acho que tem coisas que me faltam. E eu não sei nem o que é que falta, eu sei que falta. E isso é uma coisa que eu nem sei medir o quanto que é diferente a minha expressão. Eu não sei medir.

A descoberta da abrangência e da expressividade do gesto teve, para Dora, o efeito revelador de um desajuste na sua própria autoimagem em relação ao mundo externo, aquele das pessoas que enxergam. Ela passa a notar em si, enquanto pessoa cega, uma diferença que antes não conhecia. Quando fala dos movimentos do artista, o adestramento é importante, mas a sutileza do gesto é distintiva. Se não há um código igualmente rigoroso para os movimentos do corpo como o alfabeto seria para a linguagem, se os gestos são fugazes, polissêmicos, ambíguos a ponto de não se deixar apreender em categorias transparentes, a arte, mais especificamente 
o teatro e a dança, são os campos que melhor aprofundaram, na prática, a compreensão e o desenvolvimento de técnicas de treinamento e estímulo da expressividade e dos movimentos corporais.

A intermediação da arte no trabalho com pessoas cegas vem sendo realizada na iniciativa precursora de alguns artistas e pesquisadores que desenvolvem oficinas que incluem recursos artísticos e expressivos como metodologias fundamentais ${ }^{6}$. São locais que abrem espaço para a experimentação corporal dos gestos por pessoas cegas para que se produzam variações nos modos de construção e expressão de si. A proposta não é necessariamente que se aprenda a executar este ou aquele gesto a ser utilizado em tal ou qual situação, mas ampliar o repertório de gestos, criar uma memória cinética e afetiva, estimulando uma atitude de abertura para o mundo com o corpo inteiro, um estado de atenção e conectividade com o outro e com o ambiente.

Uma das situações descritas por Moraes (2007) sobre uma atividade desenvolvida em uma oficina de expressão corporal no IBC em que se buscava fazer compreender o movimento da bailarina a uma aluna cega, ilustra bem a limitação das palavras para descrever um gesto, de que nos fala Le Breton (2009), e a diferença entre a gesto funcional ou verbal e o gesto expressivo que estamos tratando.

Uma menina cega congênita que representaria a personagem da bailarina não conseguia entender o que lhe diziam a respeito dos movimentos da sua personagem - rodopiar com leveza pelo palco. Ela entendia o sentido das palavras - que a bailarina é leve, que ela dança levantando as mãos e gira em torno do próprio corpo -, mas isso não era suficiente para que conseguisse devir-bailarina, isso é, encarnar, corporificar o movimento. A simples explicação do que é ser bailarina se mostrou pouco eficiente, a menina não era afetada pelas palavras, não conseguia se modificar a partir do que ouvia. Pesquisaram-se mecanismos de tradução que produzissem um deslocamento do universo das palavras para o dos sentidos e das experiências corporais. Para que a menina entendesse a personagem bailarina participaram o som da música, o tatear de peças do vestuário da bailarina e, para que compreendesse a leveza do movimento, a mediação de um grande balão de gás preenchido com grãos de arroz de forma que, com a circulação, produzisse um som suave. Com o movimento dos braços articulados ao balão - abraçar na frente do corpo, levantar no alto da cabeça, levar para o lado - foi possível construir com a menina os movimentos e a leveza dos braços da bailarina (Moraes, 2007; Moraes, Cardoso-Manso \& Lima-Monteiro, 2009). 
Não poder ver a bailarina não significa que o movimento não possa se desenvolver de outras formas que não a descrição verbal, que parecia incapaz de transmitir sua essência movente. A especificidade do gesto é justamente a de ser diferente da linguagem verbal, transferir um registro físico a um registro verbal faz com que se perca o contexto e a sua especificidade. Laban (1978) introduziu a ideia de se pensar em termos de movimento em contraposição a se pensar em palavras. O pensar por movimentos é considerado por ele como um conjunto de impressões de acontecimentos. Acontecimentos que têm que ser vividos.

Gil sugere existir um "espaço do corpo" que não se confunde com o espaço objetivo que ocupa, mas que "prolonga os limites do corpo para além dos seus contornos”, é um “espaço intensificado” (Gil, 2001:57,58). É a criação desse espaço corporal intensificado que o encontro entre arte e cegueira pode fazer emergir. Rodrigues considera que a oficina de expressão corporal que realizou com jovens cegos alunos do IBC proporcionou a abertura de um espaço onde eles podiam

quebrar a carapaça e produzir outro corpo, promovendo a conexão com outros elementos, com uma diversidade de materiais (bola, argila, bambolês), com os colegas, com a música, com o ambiente, na intenção de produzir um corpo mais confiante de si, bem diferente daquele que parecia uma armadura. (Rodrigues, 2014:86).

O trabalho com a arte pode, potencialmente, instaurar nos participantes, deficientes visuais ou não, aberturas para a criação de novos corpos intensivos e novas formas de subjetivação. A partir da proposição de composições - com os outros, com o ambiente, com materiais -, estimular rearranjos capazes de instaurar marcas (Rolnik, 1993), ampliando as formas de afetar e serem afetadas das corporalidades presentes. A experimentação é a condição desse tipo de trabalho, e a repetição será um dos meios de estabelecer não exatamente similitudes, mas diferenças.

Para um ator cego, a construção corporal da personagem ou a "expressão de si” (Goffman, 1996) não passa pela imitação, em um sentido estritamente visual. Outros recursos precisam ser criados. Na oficina "Teatro, Criatividade e Imaginação", que realizei em parceria com Clara de Andrade no IBC, desenvolvemos a "fotografia corporal" dos gestos, em que o toque dos participantes naquele que realizava uma postura permitia a apreensão da sua expressão corporal pelos colegas. Mas a técnica dependia da estratégia de "estátua", congelar o gesto por tempo suficiente para que os outros participantes pudessem tatear e compreender. Para esti- 
mular movimentos diferentes do cotidiano, como o mergulho no mar, ou a travessia por uma trilha densa em uma floresta imaginária, utilizamos nossos próprios corpos como estratégia para o direcionamento de algo que queríamos mostrar ou como forma de ampliar as possibilidades de movimento trazidas pelos participantes, de forma semelhante à descrita por Gonçalves: "atrizes videntes colavam o seu corpo ao corpo das atrizes cegas, esta junção corporal permitia que as atrizes cegas percebessem maneiras diferenciadas de utilizar o corpo no espaço cênico, seja com relação à lateralidade, planos e profundidade” (2009:49).

O que se vê aqui são estratégias inventivas que permitem a imitação dos movimentos por quem não enxerga. Bruno (2009), que desenvolve um trabalho atento às possibilidades expressivas do movimento na Educação, usa a expressão "movimento coativo" para se referir ao modo de ensinar a imitação para uma criança cega:

A criança com deficiência visual aprenderá a imitar, cumprimentar e a brincar se encontrar pessoas disponíveis para interagir, com movimentos coativos. Esses movimentos são importantes para a compreensão da ação, permitindo o jogo imitativo de um modo diferente daquele que a criança vidente realiza. Para produzir movimentos coativos, pode-se encaixar a criança no meio do corpo do educador (pais, professor ou outros profissionais) e pelo contato físico ela compreenderá tátil-cinestesicamente os movimentos e ações realizados pelo outro (Bruno, 2009:133).

O ser social é “imitador por essência” (Tarde, 2000:13) mas imitar, para Tarde, não é fazer igual. Pelo contrário, imitar é diferenciar-se, é na imitação que se engendra formas inovadoras. Com a proposta de arte encarnada, a oficina Imagens Vivas, criada por Gonçalves (2009), propõe a reprodução corporal de obras de artes plásticas conhecidas, que envolvem a figura humana, por atores que enxergam para que as pessoas cegas participantes, por meio do tato, possam primeiro conhecer a composição corporal das figuras e, em seguida, reproduzi-las em seu próprio corpo para experimentar os efeitos provocados pela postura. Dora, que participou das oficinas, descreve suas impressões:

Quando eu fui fazer através daquilo que eu tinha percebido no corpo dele, aí caiu uma montoeira de ficha, atolou o orelhão de tanta ficha. Primeiro eu me dei conta do quanto a gente não está acostumado, no dia a dia, a tocar o corpo das pessoas. Então quando a gente toca, mesmo que a proposta seja aquela, você fica 
meio tímido para fazer aquilo, de sair tocando, vendo assim músculo por músculo, dedinho por dedinho como é que está aquela pessoa. Segundo que mesmo que você consiga ultrapassar esse sem jeito, essa timidez, como você não está acostumado a tocar, a sua mente não está acostumada a reter toda aquela informação gestual, porque é uma coisa que você não está acostumado no seu dia a dia. (...) Você está conversando comigo e está olhando todos os gestos que eu estou fazendo, se eu boto a mão para cima, se eu boto a mão para baixo, se eu viro para o lado, se eu viro para cá... e eu não estou vendo os gestos que você está fazendo, então como é que eu não ter esse exercício de ver os gestos dificulta na hora que então eu vou lá, toco uma pessoa e depois vou reproduzir, como é que eu ainda estou primitiva em relação a isso, como é que eu fico torpe né? Porque é uma coisa que eu fiz muito menos na vida.

Se os gestos, as mímicas ou as "caras" utilizadas pelas pessoas no dia a dia não podem ser imitadas visualmente por pessoas cegas, a linguagem corporal, por meio do tato, possibilita o aprendizado. Espaços que rompem com as restrições sociais ao toque permitem entrar em contato com esse reservatório gestual, através de iniciativas que têm como proposta a pesquisa expressiva. As oficinas, como espaços de criação, permitem o desenvolvimento de técnicas singulares de observação, imitação e cópia na cegueira que são necessariamente inventivas (Sautchuk; Derbotoli, 2013). A técnica pode ser vista aqui não como um produto objetivável, mas como uma forma sempre nova de acoplamento com as mais diversas situações, ambientes, coisas, pessoas e instrumentos. Importante ressaltar que no caso relatado por Dora, os participantes eram pessoas cegas e não cegas, a interação entre as duas formas de estar no mundo possibilitando a troca e o aprendizado. Para os dois lados, ela diz:

Quando eu fui fazendo, ele ia consertando as coisas que eu fazia errado porque não tinha guardado direito, mas ele também consertava as próprias imprecisões dele mesmo, ele ia sacando assim, "ih isso aqui eu acho que eu não fiz legal não”... através de mim ele ia refinando a própria percepção dele. Então uma coisa legal que eu vi naquele exercício foi como que, através dessa experiência com a pessoa cega, o próprio ator pode refinar o seu próprio gesto. (...) Meu trabalho com atores é esse de eu poder ganhar de alguma forma, pelo menos em parte, esse recurso. Eu quero ganhar esse recurso. De comunicação. Ganhar esse controle de mim mesma. E quero ter esse feedback da minha expressão. Porque quando você não está se vendo, muitas vezes você não tem o ajuste fino da sua própria expressão. E eu tenho certeza que no trabalho de ganhar esse recurso expressivo eu também vou estar propiciando que o ator aumente os dele, porque na hora que 
ele tiver que me explicar com palavras o quê que é, ele vai aumentar a consciência dele mesmo sobre os recursos dele.

Grande parte das nossas ações corporais diárias são inerentes às necessidades humanas essenciais, como caminhar, sentar, comer, levantar, etc., mas a atitude corporal é um aprendizado que se expressa nas infinitas possibilidades de como realizar essas ações (Laban, 1978). A experiência entre visão e cegueira, compartilhada por Dora e pelo ator com quem fez o trabalho, possibilita um espaço para a pesquisa infinita de gestos e movimentos atravessados pela diferença. O equívoco e a repetição dos gestos promovem a abertura de um espaço para o ajuste, o refinamento, a conscientização, a transformação de si através do contato e da composição com o outro. Como sugere Silva,

o equívoco gestual se refere ao caráter sempre conjectural da experiência, inclusive o das nossas experiências íntimas e imaginativas. Habitar essa equivocação significa, portanto, abrir-se a uma especulação potencialmente infinita dos movimentos (Silva, 2016:27).

Cada gesto provocado nas oficinas funciona como um ato de engajamento e participação, convidando os participantes não tanto ao desempenho de uma atividade com um teor funcional ou prático pré-determinado, mas a um ato de experimentação e improviso. O que se promove no desempenhar dos gestos são aberturas para a invenção de modos de solucionar corporalmente provocações motoras / culturais que nunca se repetem perfeitamente (Sautchuk; Derbotoli, 2013). Pensada neste sentido, as técnicas e os gestos desenvolvidos estariam mais próximos da noção de habilidade, enquanto um processo de produção e transformação do mundo que emerge nas práticas corporais nas quais os sujeitos se engajam (Ingold, 2015).

A técnica muitas vezes é tratada como um conjunto de saberes prontos, disponíveis para reprodução por imitação. Entretanto, na esfera da dança, dominar bem uma técnica não significa dançar bem, a técnica é entendida como condição necessária, mas não suficiente (Katz, 2009). Depois da técnica, é preciso superá-la. A superação seria a conquista de um modo próprio de lidar com o conhecimento que advém da técnica. Para Greiner e Katz (2001), no corpo humano estão as evidências da inevitabilidade de ser contaminado e de contaminar. Corpo como uma porta de vaivém que promove e rompe contatos. Cada tipo de aprendizado traz uma rede particular de conexões ao corpo. Quando se aprende um movimento, aprende-se 
junto o que vem antes e o que vem depois dele. O corpo se habitua a conectá-los. Desenvolver técnicas de imitação do movimento e a consciência da expressão corporal, de que cada parte do corpo pode ser um signo, mesmo quando o sentido visual não é preponderante ou é inexistente, é uma das contribuições substanciais que as formas de expressão artística podem provocar no campo da cegueira.

\section{Considerações finais}

As experiências relatadas sugerem que o encontro entre a arte e a cegueira é capaz de ampliar os poderes do corpo que não enxerga, expandindo tanto a sua potência de agir quanto a sua sensibilidade expressiva. A bela análise e tipologia do gesto proposta por Silva (2016) nos ajudam a retomar a problemática gestual na relação entre visão e cegueira não como um mal-entendido ou desajuste na comunicação, mas como um chamado.

Pensar a problemática do gesto na cegueira como questão relativa às técnicas funcionais do corpo pode ter o efeito de contornar o problema da emergência das formas e dos motivos - daquilo que nos move. O movimento acaba sendo tratado a partir de sua eficácia, recorrendo, para tanto, a uma externalidade que, em sua vertente culturalista, é localizada em alguma transcendência - seja a tradição, seja a textualidade. As sucessivas reduções do gesto - à funcionalidade prática ou à função comunicativa - se tornam também instrumentos de exclusão e controle que acabam submetendo a existência singular de corpos que não enxergam à lógica dominante da visualidade.

O adjetivo "expressivo" para qualificar o gesto que busquei delinear aqui se refere tanto à vivacidade ou a energia (Silva, 2016), quanto a sua ligação com o universo dos afetos. Embora a civilização ocidental tenha efetuado a separação entre os sentimentos e os gestos ou movimentos musculares, transformando a expressão de um sentimento em uma exteriorização de uma interioridade, como sugere Elias (1990), o gesto que estou chamando de expressivo é aquele em que o movimento emerge de uma corporalidade que está em relação de continuidade - em sintonização - com o ambiente e com os outros. Concordo com Silva quando diz que os gestos que realizamos e os que observamos estão dentro das condições de possibilidade da nossa experiência corporal e acredito que um dos efeitos que a arte pode ter sobre nós é de, ao intervir para expandir nossa experiência corporal, ampliar as condições de possibilidade perceptivas e expressivas do gesto. Nessa qualidade, o gesto não é um elemento a mais que se soma ao corpo para ajustar a conduta - seja 
à cultura, à sociedade ou à linguagem - mas a própria emergência de um plano de conectividade ou associação (Silva, 2016).

Ao longo do artigo foram identificadas duas modalidades de imitação, duas maneiras distintas de copiar aquilo que os outros fazem nas práticas entre visão e cegueira. Uma com o intuito normativo de aproximar os gestos da cegueira à visualidade a fim de tornar pessoas cegas capazes de agir socialmente "como se" fossem normais (Winance, 2007). Outra com o propósito criativo de ampliar o repertório de movimentos, acessibilizando o conhecimento cultural corporificado nos gestos e propondo novas aberturas e conexões a partir das singularidades perceptivas presentes. Se os gestos que nos interpelam, e que somos capazes de observar, precisam estar dentro das condições de possibilidade da experiência corporal que acumulamos, o encontro entre arte e cegueira promove precisamente ocasiões que permitem, por meio da experimentação de posturas e movimentos, na relação com outros corpos, com materiais e o ambiente, dilatar as condições de possibilidade de existência dos corpos.

$\mathrm{O}$ artigo foi principalmente estruturado no sentido de explorar as ações desenvolvidas por uma sociedade visuocentricamente centrada para adaptar / incluir pessoas com deficiência visual - seja para elas, seja com elas -, ações que, como espero ter ficado claro, apresentam suas variações no grau de abertura e envolvimento com a diferença da cegueira. Em outro momento, o desejo é o de desenvolver uma reflexão simétrica que articule as contribuições do universo corporal e perceptivo da cegueira para as formas comunicativas humanas, a partir do que corpos cegos em interação são capazes. A proposta, então, será na direção de abrir os "horizontes imaginativos" (Crapanzano, 2005) da expressão visual para as potencialidades inventivas da experiência da cegueira, entendida como um conjunto de condições sensoriais e físicas que permitem a criação de um mundo (Reynolds, 2017).

Recebido: $14 / 02 / 2019$

Aprovado: 02/05/2019 
Olivia von der Weid é professora do Departamento de Antropologia da Universidade Federal Fluminense (UFF). Desenvolve pesquisas sobre corporalidades, percepções e sentidos, sobre as relações de interdependência, cuidado e autonomia na experiência da deficiência e investiga as práticas e as relações humano-animais na formação de cães-guia. ORCID:0000-0003-0433-6890. Contato: oliviaweid@, gmail.com

\section{Notas}

1. As oficinas fizeram parte da metodologia desenvolvida no doutorado, em que investiguei a percepção de mundo de pessoas cegas (von der Weid, 2014). Durante o mês de abril de 2011 participei da Oficina Inclusiva, um workshop de teatro de 48 horas que ocorreu na Caixa Cultural, ministrado por AnaLu Palma e Inny Accioly, que propunha trabalhar recursos corporais expressivos, como os gestos, as mímicas e o movimento, e ainda as possibilidades de comunicação e representação em cena de atores cegos e não cegos. Juntamente com Clara de Andrade, desenvolvi posteriormente a oficina "Criatividade, teatro e imaginAção", por um ano e três meses, como voluntárias, para frequentadores do Instituto Benjamim Constant, localizado no bairro da Urca na cidade do Rio de Janeiro. A ideia era desenvolver uma abordagem não apenas discursiva sobre a cegueira, mas onde os exercícios corporais e jogos teatrais pudessem servir de estímulo para aprofundar questões relativas aos usos do corpo como recurso expressivo por pessoas cegas e ao estigma advindo da deficiência visual.

2. Dora tinha cerca de 60 anos de idade no período em que se realizou o campo para esta pesquisa. Ela é considerada congênita em função de um tipo específico de retinose pigmentar. Embora considerada cega de nascença, teve uma porcentagem muito baixa de visão periférica. Nunca viu cores, mas conseguiu diferenciar claro e escuro e ter noção de perspectiva. Quando criança, sua família morava no bairro da Penha, localizado na Zona Norte da cidade do Rio de Janeiro e, em função da localização, ela precisou estudar dois anos como aluna interna do Instituto Benjamin Constant (IBC), dos 6 aos 8 anos. Depois completou os estudos em uma escola de ensino regular onde sua tia lecionava. Formou-se em psicologia pela UFRJ e hoje em dia atende como psicóloga, mas também tem uma empresa que presta serviços de acessibilidade na web. Na década de 1970, Dora ajudou a criar e fez parte do "Movimento de cegos em luta por sua emancipação social". Foi casada três vezes; o último casamento durou 13 anos. Não teve filhos e atualmente vive sozinha em um apartamento no bairro da Glória, na Zona Sul do Rio de Janeiro.

3. Publicada pela Organização Mundial de Saúde (OMS) em 2001, a CIF indica que a deficiência é resultado de uma interação dinâmica entre condições de saúde e fatores ambientais, sociais e pessoais. Ver Diniz, Medeiros e Squinca (2007) para uma reflexão crítica sobre a tradução dos termos disability e impairment na versão brasileira da CIF e as implicações políticas desta opção.

4. Conforme presente no artigo segundo do Decreto $N^{\circ} 5.626$ (dez/2005), que regulamenta a Lei 10.436 (abril/2002).

5. Pretendo aprofundar este ponto a respeito dos horizontes sonoros que se abrem a partir dos usos que pessoas cegas fazem da audição, já esboçado em Von Der Weid (2014), em outro momento. 
6. Além do trabalho de Moraes (2007), é imprescindível mencionar, no cenário carioca, as pesquisas de Kastrup e Vergara (2013), Gonçalves (2009), Pozzana (2013) e Andrade (2016), com as quais entrei em contato de forma mais ou menos aproximada ao longo destes anos de pesquisa. Vale salientar que tais menções são direcionadas pela minha própria experiência de trabalho de campo e não por um levantamento exaustivo de pesquisas sobre a temática da arte na interface com a deficiência visual. Sobre o assunto, ver ainda Moraes e Kastrup (2010), Oliveira (2002) e Cunha (2004).

\section{Referências bibliográficas}

ANDRADE, Aretha de. 2016. O outro lado do mundo: encontros entre surdocegueira e expressões artísticas. Tese (Doutorado em Programa de Pós-graduação em Artes Cênicas). Universidade Federal do Rio de Janeiro.

BIRDWHISTELL, Ray L. 1990. Kinesics and Context: essays on body motion communication. Philadelphia: University of Pennsylvania press.

BRUNO, Marilda Moraes G. 2009. Avaliação educacional de alunos com baixa visão e múltipla deficiência na educação infantil. Dourados, MS: Editora UFGD.

CRAPANZANO, Vincent. 2005. "Horizontes Imaginativos e o aquém e além”. Revista de Antropologia, p. 363-384.

CUNHA, Malíria Flávia. 2004. “A expressão corporal e o deficiente visual”. Revista Benjamin Constant, Rio de Janeiro, ano 10, n. 28.

DINIZ, Débora; MEDEIROS, Marcelo \& SQUINCA, Flávia. 2007. "Reflexões sobre a versão em português da Classificação Internacional de Funcionalidade, Incapacidade e Saúde da Organização Mundial da Saúde”. Cadernos de Saúde Pública, v. 23, n. 10, p. 2507-2510.

ELIAS, Norbert. 1994. O processo civilizador: uma história dos costumes. Rio de Janeiro: Zahar.

FOUCAULT, Michel. 2013. Vigiar e punir: nascimento da prisão. Petrópolis: Vozes.

FREHSE, Fraya. 2009. “Usos da rua”. In: FORTUNA, Carlos; LEITE, Rogério Proença (orgs.). Plural cidade: léxicos e culturas urbanas. Coimbra: CES.

GARLAND-THOMSON, Rosemarie. 1997. Extraordinary bodies: figuring physical disability in American culture and literature. New York: Columbia University Press.

GIL, José. 2001. Movimento total: o corpo e a dança. Lisboa: Relógio D’Água.

GOFFMAN, Erving. 1996. A representação do eu na vida cotidiana. Petrópolis: Vozes.

GOFFMAN, Erving. 2011. Ritual de Interação. Petrópolis: Vozes.

GONÇALVES, Ana Lúcia Palma. 2009. Atos no Escuro: uma Perspectiva Sensorial. Dissertação (Mestrado em Teatro). Programa de Pós-Graduação em Teatro do Centro de Letras e Artes da Universidade Federal do Estado do Rio de Janeiro, Rio de Janeiro.

HAMMER, Gili. 2013. “'This is the anthropologist, and she is sighted': Ethnographic Research with Blind Women”. Disability Studies Quarterly, v. 33, n. 2, p. 1-23.

HULL, John. 2001. "Recognizing another world”. The National Journal for People with Disability, Melbourne, v. 3, n. 2, p. 23-26.

INGOLD, Tim. 2015. Estar vivo. Petrópolis: Vozes. 
JACKSON, Michael. 1989. Paths toward a clearing: radical empiricism and ethnographic inquiry. Indianapolis: Indiana University Press.

KASTRUP, Virgínia \& VERGARA, Luiz G. 2013. "Zona de risco dos encontros multissensoriais: anotações éticas e estéticas sobre acessibilidade e mediações”. Trama Interdisciplinar, v. 4, n. 1, p. 53-68.

KATZ, Helena. 2009. "Método e Técnica: faces complementares do aprendizado da dança”. In: SALDANHA, S. (org.). Angel Vianna: sistema, método ou técnica. Rio de Janeiro: FUNARTE. p. 26-32.

KATZ, Helena \& GREINER, Christiane. 2001. “Corpo e Processos de comunicação”. Fronteiras estudos midiáticos, v. 3, n. 2, p. 65-74.

LABAN, Rudolf. 1978. Domínio do movimento. São Paulo: Summus.

LE BRETON, David. 2011. Antropologia do corpo e modernidade. Petrópolis: Vozes.

LE BRETON, David. 2009. As paixões ordinárias: antropologia das emoções. Petrópolis: Vozes.

MALINOWSKI, Bronislaw. 1986. "Introdução: o assunto, o método e o objetivo desta investigação". In: MALINOWSKI, B. Coleção antropologia: Malinowski. São Paulo: Ática.

MAUSS, Marcel. 2003. “As técnicas do corpo”. In: Sociologia e Antropologia. São Paulo: Cosac \& Naify.

MERLEAU-PONTY, Maurice. 1971. Fenomenologia da Percepção. Rio de Janeiro: Freitas Bastos.

MOL, A.; STRUHKAMP, R. \& SWIERSTRA, T. 2009. "Dealing with in/dependence: doctoring in physical rehabilitation practice”. Science, Technology \& Human Values, v. 34, n. 1, p. 55-76.

MORAES, Marcia. 2007. "Modos de intervir com jovens deficientes visuais”. Revista Semestral da Associação Brasileira de Psicologia Escolar e Educacional (ABRAPEE), v. 11, n. 2, p. 311-322.

MORAES, Marcia; CARDOSO-MANSO, C. \& LIMA-MONTEIRO, A. P. 2009. "Afetar e ser afetado: corpo e cognição entre deficientes visuais”. Universitas Psychologica, Bogotá, v. 8, n. 3, p. 785-792.

MORAES, Marcia \& KASTRUP, Virgínia. 2010. Exercícios de ver e não ver. Rio de Janeiro: NAU.

MOREIRA, Adriana Belmonte. 2008. "Terapia Ocupacional: história crítica e abordagens territoriais / comunitárias”. Vita et Sanitas, Trindade/GO, v. 2, n. 2, p. 79-91.

MOSER, Ingunn. 2000. “Against normalisation: subverting norms of ability and disability”. Science as Culture, v. 9, n. 2, p. 201-240.

OLIVEIRA, João Vicente G. 2002. Do essencial invisível: arte e beleza entre os cegos. Rio de Janeiro: Renavan.

POZZANA, Laura. 2013. Movimento sensível e vital: uma oficina articulando a cegueira com o mundo. Tese (doutorado em Psicologia). Instituto de Psicologia, Programa de Pós-Graduação em Psicologia, Universidade Federal do Rio de Janeiro.

RABELO, Miriam, C. M. 2011. "Estudar a religião a partir do corpo: algumas questões teórico-metodológicas”. Caderno CRH, Salvador, v. 24, n. 61, p. 15-28.

REYNOLDS, Joel M. 2017. "Merleau-Ponty,World-Creating Blindness, and the Phenomenology of Non-Normate Bodies”. Chiasmi International: Trilingual Studies Concerning Merleau-Ponty's Thought, n. 19, p. 419-434.

RODRIGUES, Maria Rita C. 2014. Mosaico no tempo: uma inter-ação entre corpo, cegueira e baixa visão. Rio de Janeiro: Instituto Benjamin Constant. 
ROLNIK, Suely. 1993. "Pensamento, corpo e devir: uma perspectiva ético/estético/ política no trabalho acadêmico”. Cadernos de Subjetividade, v. 1, n. 2, p. 241-251.

SAUTCHUK, Carlos Emanuel \& DEBORTOLI, José Alfredo O. 2013. "Técnica, corpo e arte: aproximações entre antropologia e motricidade”. Licere, Belo Horizonte, v. 16, n. 2, p. 1-19.

SILVA, Rodrigo C. Dias. 2016. Gestos Exemplares: sobre alguns modos de apreensão gestual da exemplaridade. Tese (Doutorado em Sociologia e Antropologia). Universidade Federal do Rio de Janeiro.

TARDE, Gabriel. 2000. As leis da imitação. Porto: Rés.

VON DER WEID, Olivia. 2014. Visual é só um dos suportes do sonho: práticas e conhecimentos de vidas com cegueira. Tese (Doutorado em antropologia cultural). Rio de Janeiro: PPGSA/ UFRJ.

VON DER WEID, Olivia. 2017. "Provincializar a visão: esboços para uma abordagem metodológica”. Teoria e Cultura, v. 11, p. 131-144.

VYGOTSKY, Lev. S. 1997. Fundamentos de defectologia. In: VYGOTSKY, L. S. Obras escogidas. Madrid: Visor.

WINANCE, Myriam. 2007. "Being normally different? Changes to normalization processes: from alignment to work on the norm”. Disability \& Society, v. 22, n. 6, p. 625-638.

WINKIN, Yves. 1998. A nova comunicação: da teoria ao trabalho de campo. Campinas: Papirus. 
A "janela da expressão": reflexões sobre corpo, movimento e gesto nas relações entre visão e cegueira

Resumo: $O$ artigo considera os meios não discursivos que medeiam a relação entre expressividade e comunicação entre pessoas cegas e não cegas. Quais as implicações advindas de uma interação que se baseia na dupla condição de ver e não ser visto / não ver e ser visto? Qual o papel dos movimentos corporais nesta experiência comunicativa? A restrição social ao toque entre as pessoas traz implicações para a apreensão, por pessoas cegas, de uma linguagem comunicativa presente nos gestos, seja como forma de conhecimento cultural seja como recurso expressivo nas relações de interação. Abordo as consequências desse hiato a partir das possibilidades criativas que se abrem para o resgate e a construção desta linguagem corporal por intermédio da arte, a partir da participação, como parte do trabalho de campo, em oficinas de teatro com pessoas cegas e não cegas.

Palavras-chave: gesto, cegueira, arte, corpo, movimento.
The "window of expression": reflections about body, movement and gesture in the relations between vision and blindness

Abstract: The article considers the non-discursive means that mediate the relationship between expression and communication between blind and non-blind people. What are the implications of an interaction that is based on the double condition of seeing and not being seen / not seen and being seen? What is the role of the corporeal movements in this communicative experience? The social restriction of touch between people has implications for the apprehension, by blind people, of a communicative body language alive in gestures, either as a form of cultural knowledge or as an expressive resource in interaction relations. I discuss the consequences of this hiatus on the basis of the creative possibilities that opens up for the rescue and construction of this body language through art, with the participation, as part of fieldwork, in theater workshops with blind and non-blind persons.

Keywords: gesture, blindness, art, body, movement. 